\title{
Regulation of glutathione-based antioxidant defenses in response to dehydration stress in the African Clawed frog, Xenopus laevis
}

\author{
Jessica Jayme Leigh Mattice
}

B.Sc. (Hons.), 2016

Carleton University

A Thesis Submitted to the Faculty of Graduate Studies and Research in partial fulfillment of the requirements for the degree of

\author{
Master of Science \\ Department of Biology \\ Carleton University \\ Ottawa, Ontario, Canada \\ (C) Copyright 2018 \\ Jessica J.L. Mattice
}


The undersigned hereby recommend to the Faculty of Graduate Studies and Research acceptance of this thesis

\section{Regulation of glutathione-based antioxidant defenses in response to dehydration} stress in the African Clawed frog, Xenopus laevis

submitted by

Jessica Jayme Leigh Mattice, B.Sc.

in partial fulfillment of the requirements for the degree of Master of Science

Chair, Department of Biology

Thesis Supervisor

Carleton University 


\begin{abstract}
The African clawed frog (Xenopus laevis) needs efficient antioxidant defenses to mitigate oxidative damage and endure dehydration stress under arid conditions in its natural environment. Two enzymes that aid glutathione-based antioxidant defenses, glutathione reductase (GR) and glucose-6-phosphate dehydrogenase (G6PDH), were purified from liver of control and dehydrated ( $\sim 35 \%$ total body water lost) frogs. Kinetic analysis revealed that GR was positively regulated in response to dehydration to regenerate GSH, particularly when physiological urea concentrations were high. G6PDH from dehydrated frogs showed lower affinity for glucose-6-phosphate than control but was strongly activated in the presence of high ATP. Both enzymes showed regulatory modification by reversible protein phosphorylation that affected substrate affinities. Dehydration also induced other PTMs including protein sumoylation, cys-nitrosylation, and acetylation that could affect kinetic properties and protein stability. This thesis provides novel insights into the regulation of glutathione-based enzymatic defenses against dehydration-induced oxidative stress.
\end{abstract}




\section{ACKNOWLEDGEMENTS}

I would like to take this opportunity to thank my thesis supervisor, Dr. Kenneth B. Storey, for welcoming me into the Storey lab family and for taking the time to answer so many more questions than I even thought to ask. Yes, I still have all of your drawings from our talks, and no, they do not make any sense once they leave your office! Jan, it's fair to say that a significant portion of the Storey lab success is attributable to your dedication and enthusiasm. Along with every other member of the Storey lab, I thank you for your time, encouragement, and editorial review of our manuscripts.

I'd like to also genuinely thank every past and present member of the Storey lab, who have either provided assistance when things go awry in my research project or laughed at my failures in the most loving way possible. Obviously, I must thank Mike Smolinski for being such an amazing mentor and encouraging me throughout the years. Stuart, you are an enzyme god and we are not worthy. Myriam, thanks for being the definition of a true friend! I will certainly miss our DMCs and coffee breaks at Tim's! Zephanie, you are such a ray of sunshine and always find a way to brighten everyone's day - keep it up, you deserve so much happiness! Alex, you have always been my favourite person to troll and I will honestly miss seeing you (and little Dro-Dro) every day of the week. Jannelle, thanks for always being there to help me up whenever I fall down (both figuratively and literally)! I would also like to thank Sanoji, Rasha, and Kama for all of our hilarious, meaningful, and (sometimes) scientific office chats. It has been a lovely time with some lovely people.

To the "Pitch Please" softball family: We may have never won the Broken Bat Trophy... but we had a lot of fun, right?? Thanks to all of the members who made the past four summers even more enjoyable!

And finally, I wouldn't be nearly as accomplished as I am today without the continuous love and support of my Mom and Dad throughout my academic career. Thank you for taking the leap of faith (@Dad) and supporting my new path towards healthcare! Amanda and Christopher thank you for inspiring me to be the best version of myself, listening to my research-related rants, and agreeing to spend some of your weekends as my lab buddy :-; I am so proud of who you two are becoming and I am so excited to see where this medical career takes us! \#AlwaysARaven

I am so very excited to start this new chapter in my life, and although I am moving on, I will never forget the invaluable lessons and unmeasurable love that have made me the person that I am today and the person that I will be tomorrow. 


\section{TABLE OF CONTENTS}

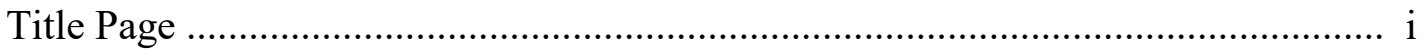

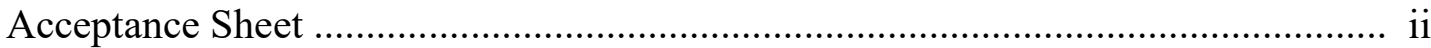

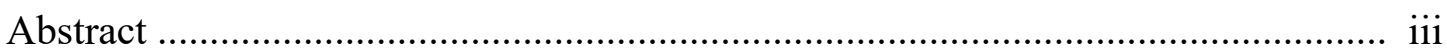

Acknowledgements ........................................................................................ iv

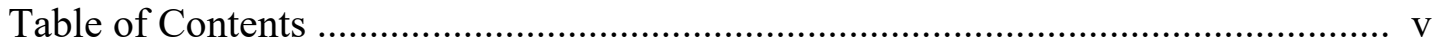

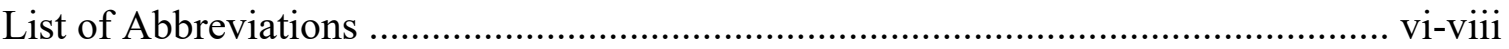

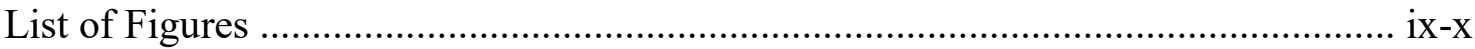

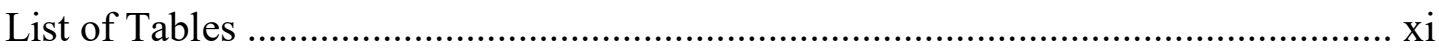

Chapter 1: General Introduction ................................................................... 1

Chapter 2: Differential regulation of liver GR in response to dehydration stress in the African clawed frog, Xenopus laevis ........................................ 20

Chapter 3: Characterization of G6PDH regulation in the liver of the dehydrating

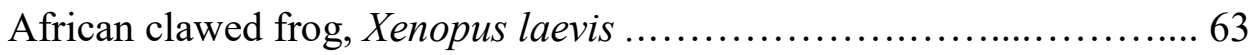

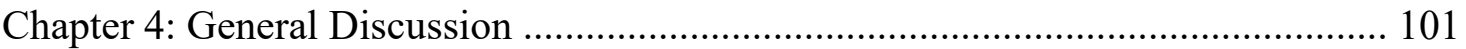

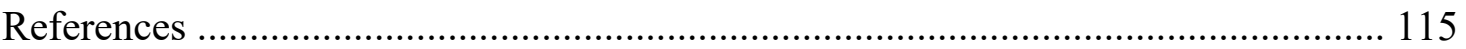

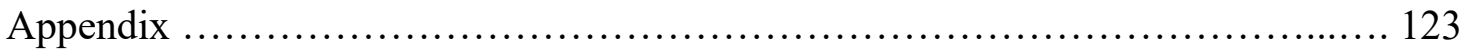




\section{LIST OF ABBREVIATIONS}

6-PG

Acetyl-CoA

ADP, ATP

AMPK

AOE

BSA

CAMK

CRTC2

DEAE $^{+}$

DIH

DHAP

DTT

E4P

EDTA

EGTA

ETC

F-1,6-bis-P

F6P

FoxO1

G3P

G6P

G6PDH 6-phosphogluconate

acetyl-coenzyme A

adenosine di- or triphosphate

AMP-activated protein kinase

antioxidant enzyme

bovine serum albumin

calcium-calmodulin protein kinase

CREB regulated transcription coactivators 2

diethylaminoethyl cellulose

dehydration-induced hypoxia

dihydroxyacetone phosphate

dithiothreitol

erythrose 4-phosphate

ethylenediaminetetraacetic acid

ethylene glycol tetraacetic acid

electron transport chain

Fructose 1,6-bisphosphate

fructose-6-phosphate

forkhead box $\mathrm{O} 1$

glyceraldehyde 3-phosphate

glucose-6-phosphate

glucose-6-phosphate dehydrogenase 


\begin{tabular}{|c|c|}
\hline GPx & glutathione peroxidase \\
\hline GR & glutathione reductase \\
\hline GSH & reduced glutathione \\
\hline GSSG & oxidized glutathione \\
\hline GST & glutathione-s-transferase \\
\hline HDAC & histone deacetylase \\
\hline HED & hydroxyethyl disulfide \\
\hline HIF-1 & hypoxia-inducible factor 1 \\
\hline HRP & horseradish peroxidase \\
\hline $\mathbf{I}_{50}$ & half maximal inhibitory concentration \\
\hline $\mathbf{K}_{\mathbf{a}}$ & half maximal activation concentration \\
\hline kDa & kilodalton \\
\hline $\mathbf{K}_{\mathbf{m}}$ & Michaelis-Menten constant \\
\hline LDH & lactate dehydrogenase \\
\hline mRNA & messenger ribonucleic acid \\
\hline $\mathbf{N A D}(\mathbf{P})^{+}$ & oxidized form of nicotinamide adenine dinucleotide (phosphate) \\
\hline NAD(P)H & reduced form of nicotinamide adenine dinucleotide (phosphate) \\
\hline NADP $^{+}$-IDH & $\mathrm{NADP}^{+}$isocitrate dehydrogenase \\
\hline PDK1 & pyruvate dehydrogenase kinase 1 \\
\hline PEG & polyethylene glycol \\
\hline PEP & phosphoenolpyruvate \\
\hline PFK & phosphofructokinase \\
\hline PKA & protein kinase $\mathrm{A}$ \\
\hline
\end{tabular}




$\begin{array}{ll}\text { PMSF } & \text { phenylmethylsulfonyl fluoride } \\ \text { PP1 } & \text { protein phosphatase 1 } \\ \text { PP2A } & \text { protein phosphatase 2A } \\ \text { PP2C } & \text { protein phosphatase 2C } \\ \text { PPP } & \text { pentose phosphate pathway } \\ \text { PTP } & \text { protein tyrosine phosphatase } \\ \text { PVDF } & \text { polyvinylidene difluoride } \\ \text { PTM } & \text { Posttranslational modification } \\ \text { R5P } & \text { ribose 5-phosphate } \\ \text { ROS } & \text { reactive oxygen species } \\ \text { S7P } & \text { sedoheptulose 7-phosphate } \\ \text { SDS } & \text { sodium dodecyl sulfate } \\ \text { SDS-PAGE } & \text { sodium dodecyl sulfate polyacrylamide gel electrophoresis } \\ \text { TBST } & \text { tris buffered saline with tween } \\ \text { TCA cycle } & \text { tricarboxylic acid cycle } \\ \text { TRIS } & \text { tris(hydroxymethyl)aminomethane } \\ \text { Total PK } & \text { total protein kinase } \\ \text { V } \text { max } & \text { maximal velocity } \\ \text { X5P } & \text { xalulose-5-phosphate } \\ \text { XO } & \text { xDH }\end{array}$




\section{LIST OF FIGURES}

Page

Figure 1.1 An overview of the antioxidant pathways and free radical 11 producing reactions.

Figure 1.2 The intricate connection between glycolysis and the pentose phosphate pathway

Figure 2.1 Representative Cibacron Blue elution profile for GR activity from liver of hydrated $X$. laevis. Representative DEAE Sephadex elution profile for GR activity from liver of hydrated and dehydrated $X$. laevis.

Figure 2.2 Silver stained 10\% SDS-PAGE gel representing the three-step 53 purification of GR from liver of control X. laevis.

Figure 2.3 Confirmation of GR protein band identity using a polyclonal 54 anti-GR antibody.

Figure 2.4 Relative post-translational modifications of semi-pure liver GR from control and dehydrated X. laevis: phosphoserine, phosphothreonine, and phosphotyrosine.

Figure 2.5 Summary of the western blots performed to ascertain the differences in post-translational modifications of semi-pure GR from control and dehydrated $X$. laevis liver.

Figure 2.6 Effects of in vitro incubations to stimulate the activities of endogenous protein phosphatases on the $\mathrm{K}_{\mathrm{m}}$ of GR for GSSG in the presence of $55 \mathrm{mM}$ urea in liver extracts of control and dehydrated $X$. laevis.

Figure 2.7 Relative protein expression levels of GR in liver extracts of control and dehydrated $X$. laevis.

Figure 2.8 Assessment of GR stability obtained by incubating purified

activity over the course of two hours $(0,0.5 \mathrm{hr}, 1 \mathrm{hr}, 2 \mathrm{hr})$. 
Figure 3.1 Representative Cibacron Blue elution profile for G6PDH

activity from liver of control $X$. laevis. Representative

Sephadex G-50 elution profile for G6PDH activity from liver

of control $X$. laevis. Representative hydroxyapatite elution

profile for G6PDH activity from liver of control $X$. laevis.

Figure 3.2 Silver stained 10\% SDS-PAGE gel representing the four-step

purification of G6PDH from liver of control X. laevis.

Figure 3.3 Confirmation of G6PDH protein band identity using a

polyclonal anti-G6PDH antibody.

Figure 3.4 Effect of 1\% polyethylene glycol (PEG) or $55 \mathrm{mM}$ urea on the 94

relative $\mathrm{K}_{\mathrm{m}} \mathrm{NADP}^{+}(\mathrm{mM})$ for liver G6PDH from control and

dehydrated frogs.

Figure 3.5 Relative post-translational modifications of semi-pure liver

G6PDH from control and dehydrated $X$. laevis:

phosphoserine, phosphothreonine, and phosphotyrosine.

Figure 3.6 Summary of the western blots performed to ascertain the

differences in post-translational modifications of semi-pure

G6PDH from control and dehydrated $X$. laevis liver.

Figure 3.7 Effects of in vitro incubations to stimulate the activities of

endogenous protein kinases on the relative $\mathrm{K}_{\mathrm{m}} \mathrm{NADP}^{+}$in the presence of $55 \mathrm{mM}$ urea for G6PDH purified from control and dehydrated frogs.

Figure 3.8 Relative protein expression levels of G6PDH in liver extracts of control and dehydrated $X$. laevis.

Figure 4.1 A mechanistic model for the HEDs assay which could be used to detect glutaredoxin activity and purify the enzyme (Begas et al., 2015). 


\section{LIST OF TABLES}

Page

Table 2.1 Representative purification and yield of GR from liver of control African clawed frogs.

Table 2.2 Kinetic parameters of functionally purified X. laevis liver GR taken from control and 34\% dehydrated African clawed frogs.

Table 2.3 Half maximal inhibitory concentration of functionally purified $X$. laevis liver GR taken from control and 34\% dehydrated African clawed frogs for physiological salts and urea.

Table 3.1 Representative purification and yield of G6PDH from liver of control African clawed frogs.

Table 3.2 Kinetic parameters of functionally purified $X$. laevis G6PDH taken from control and 35\% dehydrated African clawed frogs.

Table 3.3 Inhibition concentrations of functionally purified $X$. laevis G6PDH taken from control and 35\% dehydrated African clawed frogs. 


\section{Chapter 1}

General Introduction 


\subsection{Surviving arid environmental conditions}

The availability of water, as a major resource for most living organisms, presents itself as a crucial environmental factor contributing to the limited geographical range and adaptive behavior of amphibians. A highly water-permeable epidermis typically limits amphibious species to inhabiting moist environments that allow for the continuous hydration of their skin. Various species that are native to more arid environments display a wide tolerance for extreme body water content depletion imposed by dehydration stress (Kobelt and Linsenmair, 1995). To survive whole-body desiccation, amphibians are required to balance the water provided to the internal system to that lost transcutaneously (Shoemaker and Nagy, 1977). Periods of environmental drought, elevated temperatures, or even low food abundance in the surrounding ecosystem are common prompts that trigger the behavioral response of aestivation in amphibians and other organisms. Aestivation refers to a state of summer dormancy characterized by reduced activity, fasting, and, in some species, metabolic rate depression (Guppy and Withers, 1999). In order to survive this extended period of inactivity, aestivators ensure a low usage of energy to preserve tissue function until arousal, a retention of body water to delay the progression of dehydration, a rationalized fuel storage and usage to prolong viability during the dormant state, and a conversion of nitrogenous end products to more stable and less toxic constructs in order to minimize metabolic damage (Storey and Storey, 2012).

\subsubsection{Strategies to delay rapid dehydration}

The survival of amphibians during extensive periods of hot arid conditions that place the animals under dehydration stress is typically granted by two strategies: (1) 
entering a state of summer dormancy (aestivation); and, (2) using physiological strategies to delay the progression of dehydration. This latter strategy can include (a) the formation of a waterproof barrier over the epidermis to minimize transcutaneous water loss, (b) the establishment of a large water reservoir in the bladder prior to dormancy, and (c) the accumulation of urea as an osmolyte to provide colligative resistance to cell water loss (Cartledge et al., 2007). Due to their relatively water-permeable epidermis, many aestivators form cocoons upon initial exposure to drought as a physical method to minimize transcutaneous water loss. These cocoons can be generated from many constituents such as mucous secretions from the epidermal skin glands in the semiaquatic African lungfish genus Protopterus (Carvalho et al., 2010), or via a series of skin molts in burrowing frogs like the reed frog (Hyperolius viridiflavus) to create a thick body covering of dead skin (Jorgensen, 1997; Geise and Linsenmair, 1986). These physical barriers provide a significant reduction in evaporative water loss, but, once formed, the animal becomes a closed system and must rely on internal carbohydrate and lipid reserves as a source of energy fuel (Cartledge et al., 2007). At this point, survival relies on water reserves generated prior to dormancy or cocoon-formation and further chemical-based limitations to dehydration.

A large bladder with respect to body size represents another physiological adaptation to arid environments for amphibians. This feature provides a substantial internal water reserve which benefits the aestivating amphibian by replenishing tissue water lost due to transcutaneous evaporation. As the amphibian's epidermis begins to dry, the hormone arginine vasotocin is released into circulation (Jorgensen, 1997; Shoemaker and Nagy, 1977). This hormone induces water reabsorption from the bladder and helps to 
maintain tissue hydration, blood volume and hold plasma ionic strength and osmolality within viable limits during summer dormancy. This characteristic is most notably observed in amphibians residing in extremely arid environments such as desert cocoonforming frogs that enter aestivation with bladder water making up $\sim 50 \%$ of total body mass or the terrestrial toad, Bufo cognatus, which is native to arid regions of North America with bladders representing $45 \%$ total body mass (Jorgensen, 1997; Rubail, 1962). However, bladder size is significantly less important for aquatic species where bladder volume may only hold a mere $2-8 \%$ total body mass or only $1 \%$ total body mass in the semi-aquatic African clawed frog, Xenopus laevis (Cartledge et al., 2007; Jorgensen, 1997).

Burrowing into muddy terrain or entering a hyperosmotic medium reduces contact between the amphibian's epidermis and environmental water triggering the upregulation of arginine vasotocin. When localized to the urinary bladder, this neurohypophysial hormone allows a high plasma osmolality to be maintained by increasing the water permeability of the bladder membrane (Jorgensen, 1997; Shoemaker and Nagy, 1977; Bentley, 1969). Maintaining a high plasma osmolality keeps the frog's tissues hyperosmotic to the environment and reduces water efflux from the system. If water deprivation persists, this internal water reserve will be depleted, and the frog will no longer be able to sustain plasma osmolality. During these prolonged periods of dehydration, the amphibian can increase urea biosynthesis and use this compound to generate an appreciable osmotic gradient for limiting water lost to the environment. For terrestrial amphibians that are commonly ureotelic, nitrogenous waste is readily converted and saved as urea to increase the osmotic potential of body fluids during 
aestivation. The spadefoot toad, Scaphiopus couchii, is a suitable example of an aestivator that can generate an appreciable osmotic gradient through the accumulation over time of $\sim 300 \mathrm{mM}$ urea (Pinder et al., 1992). By contrast, aquatic amphibians are ammonotelic and excrete nitrogenous end-products in the form of ammonia transcutaneously. This process requires water to dilute out this toxic compound for excretion. During low water stress or aestivation, these aquatic or semi-aquatic amphibians switch to become ureotelic; urea being not only much less toxic as a nitrogenous waste product, but also a product that can be accumulated in high concentrations to generate an appreciable osmotic gradient (McBean and Goldstein, 1970). For instance, $X$. laevis is a semi-aquatic amphibian that can accumulate at least 55 $\mathrm{mM}$ urea, limiting transcutaneous water loss upon aestivation (Malik and Storey, 2009b). Remaining hyperosmotic to the external environment is critical for limiting body water loss under dehydration stress.

\subsubsection{Metabolic rate depression}

Metabolic rate depression refers to an animal's ability to lower its energetic needs below its basal metabolic rate and is commonly measured as a reduction in oxygen consumption and/or carbon dioxide production upon stress (Guppy and Withers, 1999). Hypometabolism is an essential survival strategy for a variety of animals faced with environmental stress. With lower energetic requirements during dormancy, the hypometabolic animal can survive for longer on the limited fuel reserves previously acquired than a metabolically-active animal (Storey and Storey, 1990). Metabolic rate depression also facilitates an animal's response to hypoxia, caused by dehydration stress as will be discussed in section 1.2.1., by reducing the rate of oxygen consumption and the 
dependency of tissues on oxygen delivery during stress (Storey and Storey, 1990). This strategy is seen in the African lungfish genus Protopterus, particularly P. amphibious, a species that can survive in this dormant state for as long as 6 years using adaptations including the formation of a water-impermeable cocoon and a $95 \%$ suppression of its basal metabolic rate (Carvalho et al., 2010). Similarly, spadefoot toads can survive 9-10 months of dormancy owing to an $80 \%$ suppression of its basal metabolic rate that allows fuel reserves to be conserved and depleted slowly over a prolonged time period (Cowan and Storey, 2002). Hypometabolism supports animal survival in adverse environmental conditions by allowing prolonged periods of dormancy without rapidly exhausting stored fuel supplies.

\subsection{Xenopus laevis, a model organism for dehydration tolerance}

The African clawed frog (X. laevis) is a largely aquatic amphibian native to several countries in southern Africa and inhabits ponds that experience seasonal desiccation. This frog has developed strategies to facilitate survival in freshwater and terrestrial habitats. During the hot summer months, shallow pond water can completely evaporate exposing the frog to the arid climate and imposing dehydration stress. During these periods, $X$. laevis have one of two choices. One option is overland migration to a more permanent basin of water; however, this migration exposes the frogs to predation by native avian species and exhaustive metabolic requirements (Loveridge, 1976). Alternately, X. laevis can burrow into the muddy terrain of the drying pond and enter a state of aestivation in order to circumvent the damage inflicted by their arid environments (Balinsky et al., 1961). As with the aforementioned aestivating amphibians, X. laevis is required to adapt to the environmental consequence of water deprivation in order to delay 
the progression of tissue dehydration and avoid attaining the critical point of desiccation invoking death (Lobos and Jaksic, 2005).

Strategies used by the African clawed frog to delay rapid whole-body dehydration are largely through the means of chemical constructs. Typically, aestivating amphibians will have a large bladder for the sole purpose of sustaining a substantial water reserve that they can use to maintain tissue hydration during the period of dormancy. However, $X$. laevis possess a small bladder representing only $\sim 1 \%$ of their body mass which is insufficient for balancing transcutaneous water loss (Jorgensen, 1997). Likewise, while many aestivating animals form a water-impermeable cocoon to limit water loss, this feature is absent in the African clawed frog. Initial adaptation to water deprivation involves increasing the internal osmolality of the frog to delay the rapid progression of whole-body dehydration. Studies have shown that $X$. laevis can readily adapt to external hyperosmotic solutions of $300 \mathrm{mM}$ or $500 \mathrm{mM} \mathrm{NaCl}$ by increasing their internal osmolality to $304 \mathrm{mM}$ or $545 \mathrm{mM}$, respectively (Balinsky, 1981). In this specific example, the increased osmolality is likely caused by the combined effect of an influx of sodium and chloride across the frog's epidermal membrane and water reabsorption by the frog's urinary bladder (Boutilier et al., 1992). This ionic flux across the epidermal membrane is a recognized adaptation for $X$. laevis in saline environments of up to 600 $\mathrm{mM} \mathrm{NaCl}$ (Boutilier et al., 1992). However, in a burrowed frog in a drying terrestrial environment, an increase in internal osmolality is only achievable by either (a) allowing evaporative water loss into the environment (an undesirable outcome that would dangerously dehydrate the frog) or (b) enhanced production of organic osmolytes (e.g. urea) to help retard water loss form the body. Indeed, a switch to ureotelism as an 
adaptation to a hyperosmotic environment was illustrated by Lee et al. (1982) when $X$. laevis was acclimated to a high-salinity environment. X. laevis was shown to increase the expression of urea cycle enzymes including carbamoyl-phosphate synthetase (6-fold) and arginase (3-fold) (Janssens, 1972; Lee et al., 1982). A similar enzymatic response to dehydration likely occurs in X. laevis under dry environmental conditions since these frogs quickly accumulated $\sim 55 \mathrm{mM}$ urea in plasma as they dried to $28 \%$ of total body water lost (Malik and Storey, 2009b). This would generate a substantial osmotic gradient to reduce water loss into the environment.

\subsubsection{The physiological effect of dehydration stress}

The progress of whole-animal dehydration is highly controlled in X. laevis during aestivation. Up to about $18 \%$ whole-body dehydration, the frog can maintain systemic circulation to visceral organs but appears to favour redirection of oxygen and nutrient supply to the brain over circulation to skeletal muscle and the gastrointestinal tract (Hillman and Sommerfeldt, 1981). As dehydration persists, the transcutaneous loss of water leads to hypovolemia and increased hematocrit levels which reduces oxygen delivery within the frog resulting in dehydration-induced hypoxia (DIH) and ischemia (Hillman, 1978). Reduced oxygen delivery to energy-demanding cells starves these metabolically-active tissues. In response, the frog's system increases its heart rate in order to enhance the cardiac output and increase oxygen transport to these deprived tissues. If the frog is incapable of maintaining sufficient plasma volume and rapidly dehydrates past a critical point of desiccation, the animal could succumb to irreparable tissue damage or progress to dehydrational death. At this critical point, the accumulation of salts within the cardiac muscle during dehydration stress prevent this vital organ from 
generating sufficient tension to maintain circulation (Hillman, 1978). Altogether, dehydrational death is equally attributable to the cardiac muscle strain induced by hypovolemia which could cause cardiac arrest and the inability of the animal to meet metabolic demands in arid environmental conditions.

\subsubsection{Reactive oxygen species and antioxidant defense}

Any animal that relies on aerobic metabolism is naturally subjected to the toxic effects created by the generation of harmful oxygen radicals, or reactive oxygen species (ROS). Whereas tetravalent reduction of oxygen to produce water by the mitochondrial electron transport chain (ETC) is by far the main fate of oxygen, univalent reduction of oxygen also occurs and generates ROS intermediates. However, this single electron reduction of oxygen is rapidly detoxified via enzymatic and non-enzymatic antioxidants. The primary source of ROS in aerobes is complex I (NADH-ubiquinone oxidoreductase) of the ETC that generates superoxide $\left(\mathrm{O}_{2}{ }^{-}\right)$whereas complex III (ubiquinol-cytochrome c oxidoreductase) can also generate hydrogen peroxide $\left(\mathrm{H}_{2} \mathrm{O}_{2}\right)$. Although $\mathrm{O}_{2}{ }^{-}$and $\mathrm{H}_{2} \mathrm{O}_{2}$ are rather harmful oxygen species, their conversion to hydroxyl radicals $(\cdot \mathrm{OH})$ in the presence of transition metals (iron, copper) in the Fenton reaction is even more damaging to cells (Fig. 1.1 depicts the net reaction of this catalytic cycle, known as the HaberWeiss reaction) (Basaga, 1990).

Damage induced by ROS include (1) lipid peroxidation, (2) protein denaturation, and (3) DNA damage (França et al., 2007, Hermes-Lima and Zenteno-Savin, 2002). Polyunsaturated fatty acids can be attacked by reactive oxygen radicals to form lipid hydroperoxides. In the cell membrane, these structures will alter functionality and fluidity of the phospholipid bilayer affecting membrane transport and communication between 
the intracellular compartment and interstitial space (Storey, 1996). Another implication for cellular damage is ROS-induced conformational changes to proteins that can render them incapable of performing their structural or catalytic role in the cell. This is primarily done through amino acid modifications and sulfhydryl oxidation (Storey, 1996). ROS can also induce DNA strand breaks and base modifications (Storey, 1996). In order to minimize the deleterious effects of ROS in vivo, it is important for the organism to have a strong enzymatic and non-enzymatic antioxidant defense system.

To minimize ROS damage during dehydration stress, enzymatic and nonenzymatic antioxidant defenses can destroy or detoxify ROS species (Fig. 1.1). The primary antioxidant enzymes that neutralize $\mathrm{O}_{2}{ }^{-}$and $\mathrm{H}_{2} \mathrm{O}_{2}$ to limit the amount of damaging hydroxyl radicals generated through the Haber-Weiss reaction include superoxide dismutase, catalase, and glutathione peroxidase (GPx). An important player in the ROS response is reduced glutathione (GSH) which serves as the substrate for three antioxidant enzymes: the glutathione peroxidases (GPx) that neutralize various types of peroxides, the glutathione S-transferase family (GST) that are core enzymes in the detoxification of xenobiotics, and glutaredoxin enzymes that have a myriad of cellular functions including assisting in protein refolding and repairing oxidatively damaged proteins (Meyer et al., 2009; Grant, 2001). GSH used by these enzymes is converted to GSSG and then must be recycled back to GSH by the enzyme glutathione reductase (GR). Due to the crucial function of GSH for sustaining the antioxidant system, the cellular ratio between oxidized and reduced glutathione (GSSG and GSH) is a key buffering system for an efficient ROS response. GR is crucial for maintaining this antioxidant buffer system and utilizes NADPH as the source of reducing power to 
catalyze the reaction. One of the main enzymes that produce NADPH is glucose-6phosphate dehydrogenase (G6PDH), the first enzyme of the pentose phosphate pathway.

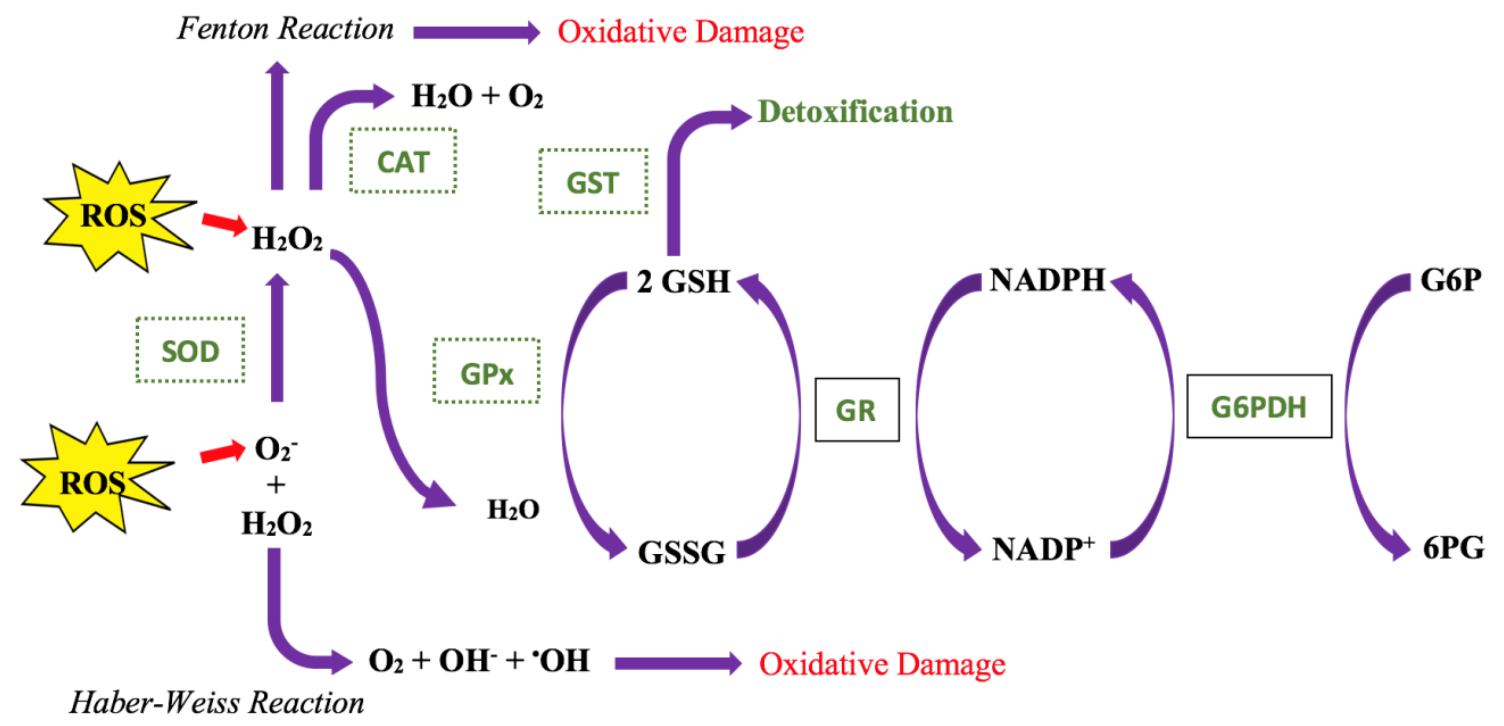

Figure 1.1. An overview of the antioxidant pathways and free radical producing reactions. Adapted from N. Dawson Ph.D. thesis (2014).

Previous studies have shown that both mRNA and protein expression of the antioxidant enzymes superoxide dismutase, catalase, and GST increase in the liver of $X$. laevis upon dehydration (Malik and Storey, 2009a; Malik and Storey, 2011). Consequently, an elevated activity level for GR may be required to sustain the GSH levels required to supplement the heightened antioxidant defense first investigated by Malik and Storey (2009a, 2011).

\subsection{2.ii Sources of NADPH}

The NADPH pool is essential for many biosynthetic pathways in cells as well as for sustaining antioxidant defenses. Although some cytosolic reactions produce NADPH, including the malic enzyme in the pyruvate cycling pathway, $\mathrm{NADP}^{+}$-isocitrate 
dehydrogenase (NADP ${ }^{+}$-IDH), and two enzymes of the pentose phosphate pathway (PPP), the majority of NADPH is supplied from mitochondrial sources (Wang et al., 2014; Weigl and Sies, 1977). Mitochondrial sources of NADPH originate from the transhydrogenation of NADH in the mitochondria generated during aerobic metabolism in the ETC. However, when ATP production shifts from oxidative phosphorylation via the ETC to anaerobic glycolysis, the supply of NADPH from NADH trans-hydrogenation would be limited and this would be one factor that could help to suppress anabolic processes under hypoxic/anoxic conditions (Storey and Storey, 2004). With a compromised ETC induced by the hypoxic consequences of dehydration stress in X. laevis, the frog would then rely more heavily on non-mitochondrial reactions for its NADPH requirements. A substantial amount of NADPH is generated from the first two catalytic steps of the PPP including the rate-limiting enzyme G6PDH and 6-phosphogluconate dehydrogenase (Tian et al., 1999). The first enzyme of the pathway, G6PDH, is tightly regulated by the cellular ratio of NADPH:NADP ${ }^{+}$(Wang et al., 2014). In unstressed cell cultures, a high steady-state ratio of NADPH:NADP ${ }^{+}$is found to inhibit G6PDH activity. However, induction of exogenous oxidative stress that would trigger an ROS response and lower cellular levels of NADPH rapidly revitalizes G6PDH activity (Wang et al., 2014). Antioxidant capacity is directly correlated to G6PDH activity and inhibition of this PPP enzyme results in increased ROS-mediated cell death (Tian et al., 1999). Similarly, when G6PDH is overexpressed in cell cultures there is an increase in antioxidant capacity and viability in response to oxidative stress (Ursini et al., 1997). The NADPH product of G6PDH activity contributes to sustaining oxidative stress defense in vivo in a process outlined in Fig. 1.1 and 1.2. 


\subsubsection{Metabolic rate during whole-body dehydration}

In order to prolong survival in a dehydrated state, X. laevis would be expected to conserve internal fuel stores through a suppression of its metabolic rate. However, routine measurements of oxygen consumption did not change during dehydration in X. laevis (Hillman, 1978). The lack of metabolic rate depression in the aestivating frog was supported by the observation of an increased heart rate, increased arterio-venous blood oxygen content difference, and plasma acidification upon dehydration. Ischemic conditions induced by elevated hematocrit levels and hypovolemia during whole-animal dehydration causes the frog's resting heart rate to increase in order to supply oxygen to the energy-demanding tissues. A study by Hillman (1978) found inactive X. laevis to have a greater arterio-venous blood oxygen content difference than control frogs. That is, a greater percentage of arterial oxygen was being delivered to tissues in the aestivating frog than control. This relative decrease in oxygen content of venous blood in aestivating $X$. laevis is likely attributable to lactate-induced plasma acidification caused by enhanced lactate dehydrogenase (LDH) activity in dehydrated frogs at physiological concentrations of urea (Katzenback et al., 2014). At a low pH, hemoglobin has a higher release rate of oxygen and this could allow greater oxygen unloading in peripheral tissues when wholebody water content is reduced (Jokumsen and Weber, 1980). Altogether, X. laevis can

maintain a basal metabolic rate under hypoxic conditions through mechanisms that include enhanced anaerobic metabolism, increased heart rate, and lactate-induced plasma acidification. 


\subsection{3.i Anaerobic metabolism and pentose-phosphate pathway}

As previously mentioned, whole-body dehydration results in hypovolemia and poor oxygen delivery which can lead to hypoxic and ischemic conditions. Hypoxia compromises the ETC, limiting energy production through oxidative phosphorylation. This process causes an accumulation of electrons, limiting NADH oxidation, and consequently causing an accumulation of intermediates within the TCA cycle (Chinopoulos, 2013). Recent literature has identified the hypoxia-inducible factor (HIF1) as a promoter of anaerobic ATP production via glycolysis through the trans-activation of multiple genes including that encoding pyruvate dehydrogenase kinase 1 (Kim et al., 2006). In the hibernating ground squirrel (Spermophilus lateralis), this kinase phosphorylates and inhibits the E1 enzyme of the pyruvate dehydrogenase complex thereby reducing or halting the conversion of pyruvate to acetyl-CoA, the substrate of the TCA cycle (Brooks and Storey, 1992). Dysregulation of the TCA cycle reduces ATP production within the organism, implementing an increased reliance on anaerobic metabolism by glycolysis for ATP synthesis. In order to regenerate the $\mathrm{NAD}^{+}$needed to run the glyceraldehyde-3-phosphate dehydrogenase reaction of glycolysis, LDH converts the NADH generated by this reaction back to $\mathrm{NAD}^{+}$. This role for $\mathrm{LDH}$ and the accumulation of lactate has been recorded in multiple dehydration-tolerant amphibians including the freeze-tolerant frogs Rana sylvatica and Pseudacris crucifer, and the aestivating X. laevis (Churchill and Storey 1994, 1995; Katzenback et al., 2010). An intermediate of anaerobic glycolysis, glucose-6-phosphate (G6P), can be redirected to the PPP shunt to produce the NADPH equivalents needed for various biosynthetic pathways as well as the antioxidant defense pathway. The regulation of $\mathrm{G} 6 \mathrm{PDH}$, the rate-limiting 
enzyme of the PPP, has been studied in several animal models exposed to environmental stress. In response to stress, reversible protein phosphorylation is primarily responsible for a measured increase in substrate affinity of G6PDH found in dormant or hypoxic animals including the aestivating milk snail (Otala lactea), anoxia-tolerant crayfish (Orconectes virilism), anoxia-tolerant mollusk (Littorina littorea), and freeze-tolerant wood frog (R. sylvatica) (Ramnanan and Storey, 2005; Lant and Storey, 2011; Lama et al., 2013; Dieni and Storey, 2010). This result may also occur in the dehydrating African clawed frog. 

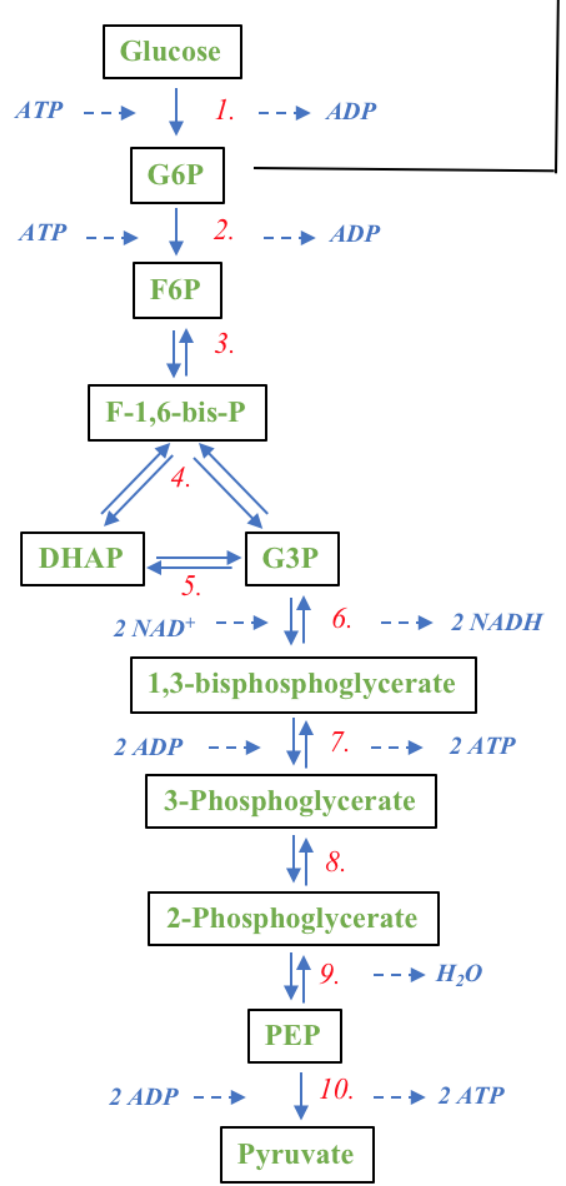

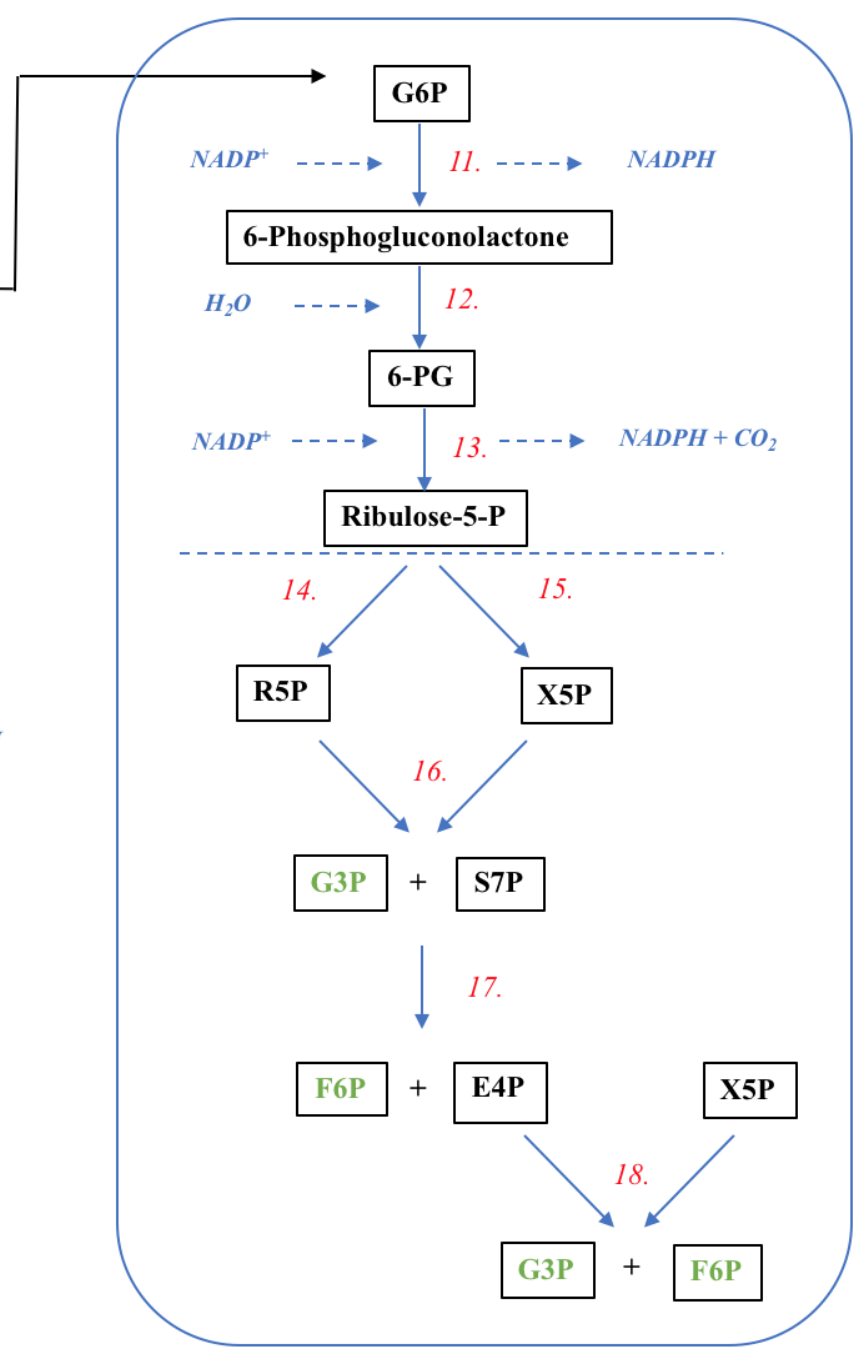

Figure 1.2. The intricate connection between glycolysis and the pentose phosphate pathway. The glycolytic pathway involves hexokinase (1), phosphoglucose isomerase (2), phosphofructokinase (3), aldolase (4), triphosphate isomerase (5), glucose-3-phosphate dehydrogenase (6), phosphoglycerate kinase (7), phosphoglycerate mutase (8), enolase (9), pyruvate kinase (10). The pentose phosphate pathway involves glucose6-phosphate dehydrogenase (11), gluconolactonase (12), 6phosphogluconate dehydrogenase (13), ribulose-5-phosphate isomerase (14), ribulose-5-phosphate 3-epimerase (15), transketolase (16), transaldolase (17), and transketolase (18). Refer to list of abbreviations on page vi-viii for substrate identification. 


\subsection{Protein post-translational modifications}

Post-translational modification (PTM) via reversible protein phosphorylation is one of the most versatile and cost-efficient mechanisms of enzyme regulation. In the cell, protein phosphorylation is regulated by a myriad of endogenous protein kinases and protein phosphatases, each with a specificity for a particular amino acid residue (tyrosine, serine, or threonine) and each kinase or phosphatase species typically regulating only a selected group of enzymes/proteins that are identified by a common amino acid signature sequence around the phosphorylated residue. This specificity provides tight control over enzyme activation. Due to their low energy cost, PTMs are particularly important for animals entering a hypometabolic state where energy conservation is critical for viability during seasonal dormancy. Phosphorylation-control is seen as a regulatory feature for multiple pathways in animals using hypometabolism including in the aestivating milk snail (O. lactea), the hibernating golden-mantled ground squirrel (Spermophilus lateralis), and the anoxia-tolerant marine mollusks (Storey and Storey, 2004). Each of these model organisms exercise the strategy of metabolic rate depression when faced with adverse environmental conditions and need a low-cost mechanism of regulation. X. laevis may also regulate molecular pathways by stimulating endogenous protein kinases and/or phosphatases. In fact, phosphorylation has already been seen as a regulatory feature for hexokinase in the liver of the African clawed frog (Childers and Storey, 2016) and may also be a regulatory feature for enzymes related to antioxidant defense in this thesis.

\subsection{Objectives and hypothesis}

The African clawed-frog is a largely aquatic amphibian under normal conditions but can deal with seasonal dehydration by burrowing into the muddy bottom of drying ponds 
and entering a state of summer dormancy. During this time, the frog becomes ureotelic and delays the progression of dehydration via the accumulation of urea in its tissues. However, whole-body dehydration exerts a physiological consequence of hypovolemia and reduced oxygen delivery triggering dehydration-induced hypoxia and ischemic conditions. During aestivation, the frog can be subjected to two sources of ROS from (a) an ETC compromised by dehydration-induced hypoxia, and (b) an increase in XO protein levels induced by ischemia. This thesis investigates whether $X$. laevis has a glutathione system (GSH:GSSG ratio) that is PTM-regulated in response to dehydration. The differential regulation of GR is investigated due to its critical role in reducing GSSG to GSH and maintaining this buffered glutathione system. The differential regulation of $\mathrm{G6PDH}$ is also investigated as it is the most important enzyme that can generate the essential NADPH needed to by GR to reconvert GSSG to GSH.

\subsubsection{Glutathione reductase}

The GSH/GSSG ratio is critically important to ensure an effective response in the presence of ROS. This ratio is maintained primarily through the action of cytosolic GR, with the following enzymatic reaction:

$$
\mathrm{GSSG}+2 \mathrm{NADPH} \rightarrow 2 \mathrm{GSH}+2 \mathrm{NADP}^{+}
$$

The kinetic and regulatory properties of GR from the liver tissue of control and dehydrated $X$. laevis are investigated in Chapter 2 of this thesis.

\section{Chapter 2 Hypothesis}

GR is modified to increase the ability of $X$. laevis liver to recycle GSSG back to GSH that is a needed substrate for selected enzymes that detoxify reactive oxygen species. 


\section{Chapter 2 Prediction}

The maximum velocity and/or substrate affinity of GR will increase during dehydration in the African clawed frog, X. laevis, to permit the GSH:GSSG ratio to be maintained by rapidly recycling GSH levels.

\subsubsection{Glucose-6-phosphate dehydrogenase}

The first committed step of the pentose phosphate pathway involves the oxidation of G6P by G6PDH as follows:

Glucose-6-phosphate + NADP $^{+} \rightarrow$ 6-Phosphogluconolactone + NADPH

The study of G6PDH is crucial to understand the global regulation of antioxidant defense in $X$. laevis liver upon dehydration as this enzyme is a major contributor to the NADPH reducing equivalents required for the glutathione system described in section 1.2.2. The kinetic and regulatory properties of G6PDH from liver of control and dehydrated X. laevis are investigated in Chapter 3 of this thesis.

\section{Chapter 3 Hypothesis}

G6PDH is modified in order to increase the ability of $X$. laevis liver to replenish the NADPH reserves needed by the antioxidant defense system for a strong enzymatic response to ROS during aestivation.

\section{Chapter 3 Prediction}

The maximum velocity and/or substrate affinity of G6PDH will increase during dehydration in the African clawed frog, $X$. laevis, to sustain the antioxidant defense system. 


\section{Chapter 2}

Differential regulation of liver GR in response to dehydration stress in the African clawed frog, Xenopus laevis 


\subsection{Introduction}

The African clawed frog is a semi-aquatic amphibian that can be found in either permanent or ephemeral ponds in arid environments of its native southern Africa. If pools dry out in the summer heat, the frogs are exposed to dehydration stress. Behavioural adaptions to this seasonal occurrence include migration to a more permanent basin or burrowing into the muddy terrain of the drying pond and entering a state of summer dormancy known as aestivation (Balinsky et al., 1961). During prolonged dehydration stress, Xenopus laevis can use a metabolic adaptation to retard water efflux from the body by converting from ammonotelism to ureotelism and accumulating high urea levels in body fluids as a colligative defense against water loss (Cartledge et al., 2007). With this chemical means of osmoprotection, X. laevis can survive the loss of up to about $30-40 \%$ loss in total body water. Past this critical point of desiccation, hypovolemia causes added strain on the heart and impairs blood circulation due to insufficient cardiac output (Hillman, 1978). The severely dehydrated frog will have insufficient oxygen delivery to vital organs and will be unable to meet metabolic demands, resulting in dehydrational death (Hillman, 1978).

Water balance between amphibians and their environments is only one critical parameter that is highly regulated and pertinent to survival in a dehydrating frog (Shoemaker and Nagy, 1977). Another crucial component that requires significant regulation is the antioxidant defense system due to an increased generation of ROS upon dehydration in X. laevis. Dehydration-induced hypoxia (DIH) is a consequence of wholebody dehydration due to increased hematocrit levels and hypovolemia which limits adequate oxygen delivery to vital organs and peripheral tissues (Hillman, 1978). Since 
circulation is preferentially redirected to the heart and brain during dehydration stress, this hypoxic condition would be notable in other vital organs including the liver (Hillman and Sommerfeldt, 1981). DIH causes the frog to rely increasingly on anaerobic metabolism for ATP production by dysregulating the TCA cycle and compromising the ETC, in part as a result of HIF-1-mediated trans-activation of pyruvate dehydrogenase kinase-1 (Kim et al., 2006). With an increased arterio-venous oxygen content difference upon dehydration (Hillman, 1978), a compromised ETC could continue to be a major generator of ROS in the aestivating frog. To minimize ROS damage during dormancy and prior to arousal, cells must maintain a highly regulated antioxidant defense system.

The primary defense against oxidative stress includes antioxidant enzymes (AOE) that detoxify cellular ROS in order to limit damage inflicted to lipids, proteins, and DNA (França et al., 2007; Hermes-Lima and Zenteno-Savin, 2002). There are four main categories of ROS: peroxides, which includes $\mathrm{H}_{2} \mathrm{O}_{2}$ and lipid peroxides; superoxide, $\mathrm{O}_{2}{ }_{2}$; hydroxyl radicals, $\bullet \mathrm{OH}$; and, singlet oxygen, ${ }^{1} \mathrm{O}_{2}$ (Hayyan et al., 2016). If $\mathrm{H}_{2} \mathrm{O}_{2}$ and $\mathrm{O}_{2}{ }^{-}$ undergo the Haber-Weiss reaction, they will generate highly reactive hydroxyl radicals which represents a very damaging class of ROS. In order to limit the amount of damaging hydroxyl radicals generated, $\mathrm{O}_{2}^{-}$and $\mathrm{H}_{2} \mathrm{O}_{2}$ are detoxified by the primary antioxidant enzymes (AOE) through the conversion of $\mathrm{O}_{2}{ }^{-}$to $\mathrm{H}_{2} \mathrm{O}_{2}$ by superoxide dismutase and the conversion of $\mathrm{H}_{2} \mathrm{O}_{2}$ to water by either catalase or glutathione peroxidase (GPx) enzymes. The latter enzyme relies on the availability of GSH in order to neutralize $\mathrm{H}_{2} \mathrm{O}_{2}$. Secondary AOEs include glutathione- $S$-transferase which detoxifies xenobiotics and glutathione reductase (GR) which assists in the enzymatic response to ROS and xenobiotics by replenishing cellular GSH levels. GSH serves as a reducing agent for GPx 
during the neutralization of $\mathrm{H}_{2} \mathrm{O}_{2}$, GST during the detoxification of foreign chemical substances, and during the regeneration of glutaredoxin following the reduction of disulfides in ROS-damaged proteins (Meyer et al., 2009; Grant, 2001).

Glutathione-based enzymes use the tripeptide GSH as a reducing agent in order to neutralize ROS, detoxify xenobiotics, or repair damaged proteins with the consequent formation of GSSG (Meyer et al., 2009; Grant, 2001). GSH is a simple tripeptide consisting of glutamate, cysteine, and glycine that is predominantly found in the cytoplasm, but also exists in many organelles in the cell including the mitochondria, peroxisomes, nuclear matrix, and the endoplasmic reticulum (Forman et al., 2008). If there are insufficient levels of the tripeptide, cells are susceptible to oxidative shock which could lead to apoptosis (Galluzzi et al., 2007; Circu and Aw, 2008). In order to preserve an efficient glutathione system by maintaining a high GSH:GSSG ratio, GR is responsible for recycling GSSG back to its reduced form. Previous studies have shown that both mRNA and protein expression of the antioxidant enzymes superoxide dismutase, catalase, and GST increase in the liver of $X$. laevis upon dehydration (Malik and Storey, 2009a; Malik and Storey, 2011). Although GPx has yet to be studied in this dehydrated frog, the increase in GST expression implies an increased oxidation of GSH. In order to sustain the GSH levels required to supplement heightened antioxidant defense first investigated by Malik and Storey (2009a, 2011), GR is expected to be differentially regulated in the liver of $X$. laevis in response to dehydration stress.

Glutathione reductase (GR; E.C. 1.8.1.7), is an antioxidant enzyme involved in maintaining the glutathione system for a secondary ROS response through the reduction 
of glutathione disulfide (GSSG) into two glutathione molecules (GSH). This enzyme catalyzes the following reaction:

$$
\mathrm{GSSG}+\mathrm{NADPH}+\mathrm{H}^{+} \rightarrow 2 \mathrm{GSH}+\mathrm{NADP}^{+}
$$

In $X$. laevis, this enzyme is a homodimer transcribed from the $g s r$ gene as reported in the UniProtKB database (Q58E89_XENLA). According to Expasy analysis of its mRNA sequence (NP_001089322.2; obtained from the NCBI database), each subunit of GR has a calculated molecular weight of $\sim 51.7 \mathrm{kDa}$. The reaction mechanism has been investigated for human GR and includes a reductive half reaction followed by an oxidative half reaction (Berkholz et al., 2008). In the reductive half reaction, NADPH reduces the FAD prosthetic group of the active site which subsequently reduces the Cys58-Cys63 disulfide bond and releases NADP ${ }^{+}$. The enzyme is now active and initiates a nucleophilic attack on the first cysteine residue of GSSG, releasing $\mathrm{GS}^{-}$which is then reduced to GSH by His467. A nucleophilic attack between Cys58 and Cys63 will reform the disulfide bond and release $\mathrm{GS}^{-}$to be protonated within the mitochondrial compartment (Berkholz et al., 2008). Two key tyrosine residues are located at the active site of GR and facilitate the binding of NADPH and GSSG during catalysis (KrauthSiegel et al., 1988).

Another model organism that must endure elevated ROS generated under ischemic conditions during dormancy is the freeze-tolerant wood frog, Rana sylvatica. GR in the muscle of $R$. sylvatica showed an increased affinity for GSSG when exposed to physiological glucose concentrations found in a frozen frog (Dawson and Storey, 2017). This result demonstrates an environmental stimulation of the enzyme, enhancing substrate affinity during freezing. Therefore, GR activity may be vital to maintain the 
GSH:GSSG ratio and limit ROS-mediated tissue damage during dormancy in the freezetolerant wood frog (Dawson and Storey, 2017). A similar result could occur in the African clawed frog which is known to accumulate urea as a mechanism of delaying transcutaneous water loss. That is, an environmental stimulation of GR via physiological

urea may lead to changes that enhance the substrate affinity of the enzyme in the liver of X. laevis.

The present study investigates the changes in substrate affinity, maximum velocity and protein expression of GR in the liver of $X$. laevis in response to whole-animal dehydration stress. It further investigates whether exposure to urea levels similar to those in a dehydrated frog affects GR enzymatic properties (e.g. substrate affinity) as observed in the muscle of $R$. sylvatica (Dawson and Storey, 2017). The mechanism(s) by which the enzyme alters its properties under dehydration stress are also investigated by analyzing differences in post-translational modifications, with a focus on phosphorylation-specific changes.

\subsection{Materials and Methods}

\subsubsection{Animal care and Chemicals}

Male $X$. laevis frogs, obtained from the University of Alberta, were allowed to acclimate to $22^{\circ} \mathrm{C}$ for 10 days in dechlorinated water tanks during which time, the amphibians were provided fresh dechlorinated water and Xenopus pellets every 2-3 days. A subset of frogs was sampled from this acclimated state and served as the control biological test group. Feeding was stopped several days before the start of experimental trials. Frogs belonging to the experimental dehydration group were placed in containers deprived of water. The percentage dehydration was determined by measuring the mass of 
each frog every few hours over the course of a couple of days until the experimental group achieved more than a $30 \%$ loss of body weight due to dehydration. The change in mass was used to calculate the percentage of total body water lost via the following equation, where $\mathrm{W}_{\mathrm{i}}$ is the initial mass of an individual, $\mathrm{W}_{\mathrm{d}}$ is the mass during experimental dehydration, and $\mathrm{BWC}_{\mathrm{i}}$ is the initial body water content of frogs before dehydration:

$$
\% \text { water loss }=\frac{W_{i}-W_{d}}{W_{i} \times B W C_{i}} \times 100
$$

The frogs belonging to the high dehydration sample group had an average starting weight of $64.6 \pm 3.6 \mathrm{~g}$ and experienced a $34 \pm 0.8 \%$ mean body water loss $(\mathrm{n}=10)$. All frogs were euthanized by pithing and tissues were quickly dissected out and flash-frozen in liquid nitrogen prior to long-term storage at $-80^{\circ} \mathrm{C}$. Animal care, holding and experimental procedures were approved by the Carleton University Animal Care Committee (protocol \#106936) in accordance with the guidelines of the Canadian Council on Animal Care.

The chemicals used in the experiments were purchased from BioShop (Burlington, ON) and Sigma Chemical Company (St. Louis MO). All buffers and reagents were prepared in double distilled water obtained using a Milli-Q (Millipore Corp.) water purifier.

\subsubsection{Preparation of liver tissue lysates for protein purification}

Liver tissue from control and $34 \%$ dehydrated frogs were removed from a $-80^{\circ} \mathrm{C}$ freezer and crushed under liquid nitrogen in preparation for homogenization. The powdered tissue was homogenized 1:10 w:v in ice-cold homogenate buffer A (20 mM Tris-HCl, $15 \mathrm{mM} \beta$-mercaptoethanol, $1 \mathrm{mM}$ EDTA, $1 \mathrm{mM}$ EGTA, $15 \mathrm{mM} \beta$ glycerophosphate, and 15\% v:v glycerol, $\mathrm{pH}$ 8.7) with a few crystals of 
phenylmethylsulfonyl fluoride (PMSF) added immediately before homogenization. Samples were homogenized on ice using a Janke \& Kunkel IKA-Werk Ultra Turrax homogenizer and then centrifuged using a pre-chilled Eppendorf 5810R centrifuge set to $4^{\circ} \mathrm{C}$. Centrifugation was 30 minutes at 10,000 RPM. The supernatant was collected, and the pellet of cellular debris was discarded.

\subsubsection{GR enzyme assay and kinetic parameter determination}

The activity of GR was determined using a Multiskan Spectrum microplate reader (Thermo Scientific) by measuring the decrease in sample absorbance at $340 \mathrm{~nm}$. This absorbance reading corresponds with the oxidation of NADPH to form $\mathrm{NADP}^{+}$, a conversion that is catalysed by GR activity. The catalytic activity of GR was detected in a $20 \mathrm{mM}$ potassium phosphate assay buffer at $\mathrm{pH}$ 7.5. Standard assay conditions for the catalytic reaction included $0.4 \mathrm{mM} \mathrm{NADPH}$ and $3 \mathrm{mM}$ oxidized glutathione. Assays were run at room temperature $\left(21^{\circ} \mathrm{C}\right)$, typically with 40 data points collected in intervals of 21 seconds. All kinetic parameters were analyzed using an enzyme kinetic analysis program, Kinetics v.3.5.1 (Brooks, 1992). Data collected derived from $n=3-4$ semi-independent determinations of a functionally purified sample of GR from both control and dehydrated $X$. laevis liver. The affinity $\left(\mathrm{K}_{\mathrm{m}}\right)$ of GR for the substrates glutathione and NADPH were measured under aforementioned standard assay conditions with and without exposure to the physiological levels of urea $(55 \mathrm{mM})$ found in a high dehydrated frog (Malik and Storey, 2009b). The half maximal inhibitor concentration $\left(\mathrm{I}_{50}\right)$ for various salts and urea was determined under the aforementioned standard GR assay conditions in assays containing increasing inhibitor concentrations. The $\mathrm{I}_{50}$ was determined with a 0-4 M range of $\mathrm{NaCl}$, a $0-1.4 \mathrm{M}$ range of $\mathrm{KCl}$, and 0-5 $\mathrm{M}$ range of urea. The effect of adenosine 
triphosphate (ATP) and adenosine diphosphate (ADP) on the activity of GR was similarly assessed. The maximal activity $\left(\mathrm{V}_{\max }\right)$ of GR was determined under saturating substrate concentrations with a fully purified GR sample following the complete purification scheme.

\subsubsection{Purification of GR from control and dehydrated liver lysates}

Purification of GR from the liver X. laevis involved polyethylene glycol (PEG) precipitation followed by the application of two functionally distinct chromatography columns. A stock 50\% PEG solution (average MW=8000 g/mol) prepared in buffer A was added to the supernatant obtained following centrifugation until an overall $20 \%$ PEG solution was attained. The protein-PEG solution was thoroughly mixed on a rotator for 30 minutes. Following this, the enzyme/PEG mixture was centrifuged at 10000 RPM for 30 minutes. Initial tests at different PEG concentrations determined that GR was in the precipitated pellet solution at 20\% PEG. The supernatant was discarded, and the pellet was re-suspended in $2 \mathrm{~mL}$ of buffer A. The protein resuspension was applied to a $3 \times 1$ cm Cibacron Blue 3GA (Sigma Chemical Co) chromatography column equilibrated in buffer A. The dye-ligand affinity column was washed with $40 \mathrm{~mL}$ of buffer A to remove unbound proteins from the column, leaving GR bound to the Cibacron Blue resin. A 20 $\mathrm{mL}$ wash containing $10 \mathrm{mM} \mathrm{NAD}^{+}$in buffer A was then used to elute contaminating $\mathrm{NAD}^{+}$-binding proteins from the column prior to eluting the target $\mathrm{NADP}^{+}$-binding enzymes of the protein mixture, including GR. The column was re-equilibrated again using a subsequent $40 \mathrm{~mL}$ wash with buffer A. For the control purification scheme, the bound GR protein was then eluted with a gradient of 0-1 $\mathrm{M} \mathrm{KCl}$ dissolved in buffer A followed by a $1 \mathrm{M} \mathrm{KCl}$ bump with $900 \mu \mathrm{L}$ fractions collected. The purification scheme 
for dehydrated GR involved a $0-600 \mathrm{mM} \mathrm{KCl}$ gradient with a subsequent $600 \mathrm{mM} \mathrm{KCl}$ bump. GR enzymatic activity of each fraction was determined through the biochemical assay outlined in section 2.2.3. and peak fractions with significant activity were pooled for further column chromatography applications. The pooled sample was diluted threefold with buffer A and applied to a $5 \mathrm{x} 1 \mathrm{~cm}$ diethylaminoethanol-Sephadex (DEAE Sephadex ${ }^{\mathrm{TM}}$ A-25, GE Healthcare) that was equilibrated in buffer A. This anionexchange column was washed with $40 \mathrm{~mL}$ of buffer A to remove unbound proteins from the column. The bound GR was eluted with a $0-1 \mathrm{M} \mathrm{KCl}$ gradient in buffer A followed by a $1 \mathrm{M} \mathrm{KCl}$ bump and collected in $900 \mu \mathrm{L}$ fractions. The fractions were assayed for GR activity and peak fractions were pooled. The pooled sample was then applied to an Amicon Ultra-4 centrifugal filter unit with a 10,000 kDa nominal molecular weight limit (NMWL) and centrifuged for 10 minutes at $7500 \mathrm{RPM}$ in order to concentrate the enzyme prior to kinetic analysis.

\subsubsection{Protein concentration determination}

Protein concentrations were determined with the Coomassie Blue G-250 method using BioRad Protein Assay Dye reagent and bovine serum albumin as the standard. Absorbance at $595 \mathrm{~nm}$ was measured using a BioTek PowerWave HT spectrophotometer.

\subsubsection{Visual assessment of GR purification scheme}

To ensure that $X$. laevis liver GR was purified to homogeneity, samples from different steps of the purification scheme were analyzed via sodium dodecyl sulfatepolyacrylamide gel electrophoresis (SDS-PAGE). Each of the pooled protein samples obtained through column chromatography was applied to a new syringe containing $5 \mathrm{~mL}$ of Sephadex G-25 (Sigma-Aldrich) resin, previously equilibrated in buffer A. Each 
syringe containing $500 \mathrm{uL}$ of the protein sample was centrifuged at $2500 \mathrm{RPM}$ in a VWR Clinical 50 bench-top centrifuge for 1 minute to separate the enzyme (in the eluate) from the high salt concentrations in the different fractions and return all enzyme samples into buffer A. The crude homogenate and desalted pooled samples (from Cibacron blue and DEAE fractionation) were then mixed 1:1 and 4:1, respectively, with 2X SDS loading buffer $(100 \mathrm{mM}$ Tris buffer, $\mathrm{pH}$ 6.8, 4\% w:v SDS, $20 \%$ v:v glycerol, $0.2 \%$ w:v bromophenol blue) supplemented with $10 \%$ v:v $\beta$-mercaptoethanol. Samples were boiled for 5 minutes and then stored at $-20^{\circ} \mathrm{C}$. Enzyme samples from control and dehydrated frogs were run on separate $10 \%$ polyacrylamide gels with a GeneDirex $10.5-175 \mathrm{kDa}$ protein ladder and a purified GR sample from bovine liver prepared in the same manner (Sigma-Aldrich, cat. \#G1786). Protein samples were run on gels for 60 minutes at $180 \mathrm{~V}$ in running buffer (25 mM Tris-base, $250 \mathrm{mM}$ glycine and 0.1\% w:v SDS). Gels were subsequently stained using a silver nitrate staining procedure (Gromova and Celis, 2006) and visualized on the ChemiGenius Bioimaging System (Syngene, Frederick, MD). Using Expasy, a bioinformatic resource portal that calculates protein molecular weight based on amino acid sequence, the expected subunit molecular weight of $X$. laevis GR (obtained from the NCBI database (NP_001089322.2)) was $\sim 51.7 \mathrm{kDa}$. This calculated molecular weight corresponds well with the previous studies of vertebrate amphibians including $\sim 55.1 \mathrm{kDa}$ in Trachemys scripta elegans and $\sim 50 \mathrm{kDa}$ in $R$. sylvatica (Willmore and Storey, 2007; Dawson and Storey, 2017).

\subsubsection{Western Blots for Post-Translational Modifications}

The relative levels of post-translational modifications (PTMs) to liver GR from control vs. dehydrated X. laevis were assessed using Western blotting with semi- 
independent determinations of the enzyme. Semi-purified control and dehydrated samples obtained from the Cibacron blue column step of the purification scheme were mixed 1:1 v:v with SDS loading buffer (100 mM Tris buffer, $\mathrm{pH} 6.8,4 \%$ w:v SDS, $20 \% \mathrm{v}: \mathrm{v}$ glycerol, $0.2 \% \mathrm{w}: \mathrm{v}$ bromophenol blue, $10 \% \mathrm{v}: \mathrm{v} \beta$-mercaptoethanol) and boiled for 10 minutes. The semi-pure preparation of GR was confirmed to have sufficient protein band separation on an $8 \%$ polyacrylamide gel to allow accurate PTM analysis. The samples were loaded onto an $8 \%$ gel and run for 55 minutes at $180 \mathrm{~V}$. Proteins on the gel were then transferred at $4^{\circ} \mathrm{C}$ and $160 \mathrm{~mA}$ for 110 minutes to a polyvinylidene fluoride (PVDF) membrane using a Bio-Rad Mini Trans-Blot Cell apparatus immersed in transfer buffer (25 mM Tris-base ( $\mathrm{pH} 8.8), 192 \mathrm{mM}$ glycine, and 20\% v:v methanol). Following the transfer, membranes were blocked with $0.5 \% \mathrm{w}: \mathrm{v}$ skim milk powder dissolved in TBST (20 mM Tris-base, $140 \mathrm{mM} \mathrm{NaCl}, 0.05 \% \mathrm{v}: \mathrm{v}$ Tween-20, $\mathrm{pH}$ 7.6) for 10 minutes to prevent non-specific antibody binding to the membrane. The membranes were washed with TBST three times for 5 minutes to remove excess milk. It is important to note that the membranes used for phosphorylation-based antibody detection (antibodies \#1-3 listed below) were not blocked prior to primary antibody incubation. Incubation of the membranes with primary antibodies was performed overnight in a refrigerator at $4{ }^{\circ} \mathrm{C}$. All of the primary antibodies were diluted 1:1000 v:v in TBST and are listed as follows:

1. Mouse polyclonal anti-phosphotyrosine (Invitrogen, cat. \# 13-6600)

2. Rabbit polyclonal anti-phosphoserine (Invitrogen, cat. \# 61-8100)

3. Rabbit polyclonal anti-phosphothreonine (Invitrogen, cat. \# 71-14)

4. Rabbit polyclonal anti-methyl lysine (Invitrogen, cat. \#14-679) 
5. Rabbit polyclonal pan anti-acetyl lysine (Santa Cruz Biotechnology, cat. \# SC8663)

6. Mouse polyclonal anti-mono and dimethyl arginine (Covalab, cat. \#mab0002-0)

7. Rabbit polyclonal anti-malonyllysine (PTM biolabs, cat. \#PTM-901)

8. Rabbit polyclonal anti-nitrocysteine (abcam \# ab50185)

9. Rabbit polyclonal anti-succinyllysine (PTM biolabs, cat. \#PTM-401)

10. Rabbit polyclonal pan anti-glutaryllysine (PTM biolabs, cat. \#PTM-1151)

11. Mouse polyclonal anti-N-acetylglucosamine (Santa Cruz, cat. \#sc-59624)

12. Rabbit polyclonal anti-ubiquitin (Santa Cruz, cat. \#sc-8017)

13. Rabbit polyclonal anti-sumo 1 (gift from Dr. J.M. Hallenbeck, NINDS, NIH, Bethesda, MD)

14. Rabbit polyclonal anti-sumo 2/3 (gift from Dr. J.M. Hallenbeck, NINDS, NIH, Bethesda, MD)

Unbound primary antibody was removed with three 5-minute washes with TBST and the membrane was incubated with either horseradish peroxidase (HRP) conjugated antirabbit or anti-mouse secondary antibody (BioShop, diluted 1:6000 v:v in TBST containing $0.05 \%$ milk) for 30 minutes at room temperature. Unbound secondary antibody was removed with three 5-minute washes with TBST. Immunoreactive bands were visualized using an enhanced chemiluminescence (ECL) protocol and visualized on the ChemiGenius Bioimaging System (Syngene, Frederick, MD). The ECL protocol involved briefly incubating the membrane with the HRP substrate mixture containing equal volumes of luminol solution $(2.5 \mathrm{mM}$ luminol, $0.4 \mathrm{mM}$ p-coumaric acid, $100 \mathrm{mM}$ 
Tris $\mathrm{pH} 8.8)$ and hydrogen peroxide $\left(0.0186 \% \mathrm{H}_{2} \mathrm{O}_{2}, 100 \mathrm{mM}\right.$ Tris $\left.\mathrm{pH} 8.8\right)$ followed by a 10-minute exposure. Subsequently, the membranes were stained with Coomassie blue ( $0.25 \%$ w:v Coomassie brilliant blue, $7.5 \%$ v:v acetic acid, $50 \%$ methanol). To correct for any variation in sample loading, the raw intensity values were standardized to the amount of protein in the corresponding GR bands after staining the membrane with Coomassie brilliant blue stain $(0.25 \% \mathrm{w} / \mathrm{v}$ Coomassie Brilliant Blue $\mathrm{R}$ in $50 \% \mathrm{v} / \mathrm{v}$ methanol, 7.5\% v/v acetic acid). Quantification of the luminescent protein band intensities was conducted using GeneTools software. PTM levels of GR from dehydrated frog was analyzed relative to the corresponding PTM level in control frogs.

\subsubsection{Protein Expression levels via Western Blotting}

Total protein levels of GR were assessed in control and dehydrated X. laevis liver crude homogenates essentially as described in section 2.2.7. with minor modifications, including the use of independent determinations for the enzyme. Equal amounts of protein from control and dehydrated samples were applied to a $12 \%$ polyacrylamide gel and run at $180 \mathrm{~V}$ for 120 minutes. Proteins were then transferred to a PVDF membrane via electroblotting for 100 minutes at $160 \mathrm{~mA}$. Following transfer, the membrane was blocked for 30 minutes with 5\% w:v milk in $1 \mathrm{x}$ TBST and then washed three times at 5 minutes with 1x TBST. The primary antibody for this analysis, rabbit polyclonal antiglutathione reductase (Genetex, cat. \#GTX114199), was prepared as a 1:1000 dilution in TBST. Quantification of protein expression levels differ from the methodology described in section 2.2.7. in that the immunoblot band density in each lane was standardized against the summed intensity of a group of Coomassie-stained protein bands in the same 
lane rather than the corresponding protein band. Protein expression of dehydrated GR was analyzed relative to corresponding expression level from control frogs.

\subsubsection{In vitro incubation to stimulate endogenous protein phosphatases}

In order to correlate protein phosphorylation state to changes in kinetic activity, endogenous protein kinases and phosphatases were stimulated in both control and dehydrated X. laevis liver homogenates and the altered kinetic parameter was reassessed. The crude homogenates, previously prepared in STOP buffer (Buffer A), were filtered through a Sephadex G-25 spun column equilibrated in OPEN buffer ( $20 \mathrm{mM}$ Tris pH 7.6, $10 \% \mathrm{v}: \mathrm{v}$ glycerol, $15 \mathrm{mM} \beta$-mercaptoethanol). Aliquots of the filtered homogenate were mixed 3:1 v:v with a concentrated stock solution of specific inhibitors and stimulators of protein kinases and phosphatases prepared in OPEN buffer, as follows:

Control "STOP" conditions: $1 \mathrm{mM}$ EGTA, $1 \mathrm{mM}$ EDTA, and $15 \mathrm{mM} \beta$ glycerophosphate to inhibit all protein phosphatase and kinase activities.

Stimulation of endogenous protein phosphatase activities: OPEN buffer containing the following:

1) $5 \mathrm{mM} \mathrm{CaCl}_{2}$ and $5 \mathrm{mM} \mathrm{MgCl} 2$ to stimulate total protein phosphatases (Total PPase);

2) $2 \mathrm{mM}$ EDTA and $2 \mathrm{mM}$ EGTA to stimulate PP1 and PP2A;

3) $1 \mu \mathrm{M}$ okadaic acid, $5 \mathrm{mM} \mathrm{CaCl}_{2}$, and $2 \mathrm{mM}$ EDTA to stimulate PP2B;

4) $1 \mu \mathrm{M}$ okadaic acid, $5 \mathrm{mM} \mathrm{MgCl}$, and $2 \mathrm{mM}$ EGTA to stimulate PP2C;

5) 30mM sodium fluoride to stimulate tyrosine phosphatases (PTPs); 
6) $2.5 \mathrm{nM}$ okadaic acid, $2 \mathrm{mM}$ EDTA, and $2 \mathrm{mM}$ EGTA to stimulate protein phosphatase $1(\mathrm{PP} 1)$;

7) $1 \mu \mathrm{M}$ okadaic acid, $5 \mathrm{mM} \mathrm{CaCl}_{2}$, and $5 \mathrm{mM} \mathrm{MgCl}_{2}$ to stimulate total PPase but inhibit PP1/PP2A (PP-PP1 PP2A);

8) $1 \mathrm{U}$ calf intestinal alkaline phosphatase (AP), $5 \mathrm{mM} \mathrm{MgCl}_{2}$, and 5 $\mathrm{mM} \mathrm{CaCl} 2$ for full dephosphorylation (Comm PP)

Following an overnight incubation at $4^{\circ} \mathrm{C}$, low molecular weight metabolites and ions were removed via centrifugation for 1 minute at $12500 \mathrm{x}$ g through small spun columns of Sephadex G-25 equilibrated in STOP buffer.

\subsubsection{Stability of GR}

To assess the structural stability of the enzyme's active site, the $V_{\max }$ of GR purified from control and dehydrated frog liver was measured following incubation in various concentrations of urea over a period of two hours at room temperature $\left(22^{\circ} \mathrm{C}\right)$. Maximal velocity was measured at saturating substrate concentrations. The purified enzyme was incubated with varying amounts of urea $(0 \mathrm{M}, 55 \mathrm{mM}, 200 \mathrm{mM}, 600 \mathrm{mM}, 1$ $\mathrm{M}, 2 \mathrm{M}, 4 \mathrm{M}$ ) in $1.5 \mathrm{~mL}$ Eppendorf tubes and contents were mixed every 30 minutes using a vortex device. The $\mathrm{V}_{\max }$ of GR was measured following immediate inoculation (time $=0$-hour), after 30 minutes, 1-hour, and 2-hours exposure to the osmolyte.

\subsubsection{Statistical Analyses}

Data presented in this thesis were analyzed for statistically using the Student's ttest with a $p$-value of $<0.05$ accepted as significant. Each data set consisted of a minimum of four independent replicates for an enzyme or tissue sample extracted from a minimum 
of three different $X$. laevis liver extracts. Graphical images were generated using RBioplot (Zhang and Storey, 2016).

\subsection{Results}

\subsubsection{Purification of GR from the liver of control and dehydrated frogs}

The purification of GR from liver was achieved through the application of PEG precipitation followed by two distinct chromatography columns. The purification scheme for control GR is shown in Table 2.1 and the same procedure for dehydrated GR gave comparable results. This purification began by incubating the crude homogenate with the hydrophilic compound PEG and consequently causing proteins that require a high degree of solvation to precipitate out of solution during centrifugation. This first step retained the majority of GR activity (98.0\% yield) while significantly reducing the amount of total protein in the resulting pellet resuspension to just $53.5 \%$ of the starting value (Table 2.1.). The second step involved dye-ligand affinity chromatography using a Cibacron Blue column with a highly effective pre-elution wash containing $10 \mathrm{mM} \mathrm{NAD}^{+}$prior to eluting GR with a 0-1 M KCl gradient (Fig. 2.1A). GR from liver of both control and dehydrated X. laevis eluted from this column at $\sim 150 \mathrm{mM} \mathrm{KCl}$ (Fig. 2.1A). This step lead to a 71.5fold purification, a specific activity $86.5 \mathrm{mU} / \mathrm{mg}$, and the retention of $70.8 \%$ total GR activity. The final purification step was an anion-exchange chromatography with a simple $\mathrm{KCl}$ gradient; control GR eluted from the column at $\sim 350 \mathrm{mM} \mathrm{KCl}$ whereas $\mathrm{GR}$ from dehydrated frogs eluted at $\sim 150 \mathrm{mM} \mathrm{KCl}$ (Fig. 2.1B). Overall, the scheme gave a final fold purification of 221.7, a specific activity of $268.3 \mathrm{mU} / \mathrm{mg}$, and a yield of $22.8 \%$ total GR activity in control liver tissue (Table 2.1). In the dehydrated liver tissue, the 
purification scheme gave a final fold purification of 115.0, a specific activity of 276.6 $\mathrm{mU} / \mathrm{mg}$, and a yield of $9.5 \%$ total GR activity.

\subsubsection{Quality assessment of GR purification}

In order to assess the purity of GR obtained from the purification scheme, a sample of each pooled elution was applied to a $10 \%$ polyacrylamide gel, electrophoresed, and stained using the silver nitrate protocol. The gel image shown in Fig. 2.2 for control GR demonstrates a continuous reduction in the number of protein bands through the progression of the purification procedure. The expected subunit molecular weight of $X$. laevis GR as calculated via Expasy $(\sim 51.7 \mathrm{kDa})$ corresponds quite well with the single bands found at $\sim 55 \mathrm{kDa}$ in lanes loaded with purified GR (boxed in red). The lack of other bands in these lanes at $\sim 50-60 \mathrm{kDa}$ (Fig. 2.2) confirmed that GR was purified to near homogeneity. The identity of this protein band as GR was validated through Western blot techniques using a polyclonal anti-GR antibody (Fig. 2.3).

\subsubsection{Kinetic characterization of $G R$}

A number of kinetic parameters were analysed to identify a change in activity of the antioxidant enzyme upon dehydration stress in X. laevis liver (Table 2.2; Table 2.3). With exception to the $\mathrm{V}_{\max }$ calculation, a functionally purified sample of GR obtained following the Cibacron Blue chromatography column elution was used for kinetic analysis of the target enzyme. Under normal assay conditions with saturating NADPH, there was no significant change in $\mathrm{K}_{\mathrm{m}}$ of GR for GSSG between control and dehydrated liver extracts $(0.65 \pm 0.02 \mathrm{mM}$ and $0.64 \pm 0.02 \mathrm{mM}$, respectively). When exposed to $55 \mathrm{mM}$ urea, a concentration that is physiologically relevant to dehydrated $X$. laevis, the $\mathrm{K}_{\mathrm{m}}$ of GR for GSSG is significantly reduced in the stress condition from $0.64 \pm 0.02 \mathrm{mM}$ 
to $0.13 \pm 0.01 \mathrm{mM}$ GSSG. In the control condition, $55 \mathrm{mM}$ urea had an insignificant effect on the $\mathrm{K}_{\mathrm{m}}$ for GSSG with values altering from $0.65 \pm 0.02 \mathrm{mM}$ to $0.54 \pm 0.09 \mathrm{mM}$ GSSG. In the presence of saturating GSSG, the $\mathrm{K}_{\mathrm{m}}$ of GR for NADPH was significantly increased upon dehydration with values of $0.045 \pm 0.003 \mathrm{mM}$ NADPH in control and $0.076 \pm 0.006 \mathrm{mM}$ NADPH in dehydrated frog liver. (Table 2.2) Exposure to $55 \mathrm{mM}$ urea resulted in a significant increase in $\mathrm{K}_{\mathrm{m}}$ for NADPH in the dehydrated tissue from $0.076 \pm$ $0.006 \mathrm{mM}$ NADPH to $0.23 \pm 0.02 \mathrm{mM} \mathrm{NADPH}$ and an insignificant change in the control tissue from $0.045 \pm 0.003 \mathrm{mM}$ NADPH to $0.13 \pm 0.04 \mathrm{mM}$ NADPH (Table 2.2). A similar concentration of $\mathrm{NaCl}$ was required to deplete GR activity by $50 \%$ in control $(0.74 \pm 0.03 \mathrm{M})$ and dehydrated $(0.58 \pm 0.06 \mathrm{M})$ liver tissue (Table 2.3). Similarly, the concentration of $\mathrm{KCl}$ required to deplete GR activity by $50 \%$ in control and dehydrated liver tissue was comparable, being $0.69 \pm 0.07 \mathrm{M}$ and $0.725 \pm 0.006 \mathrm{M}$, respectively (Table 2.3). However, a greater concentration of urea was needed to deplete GR activity by $50 \%$ in dehydrated liver tissue $(3.26 \pm 0.03 \mathrm{M})$ than control $(2.82 \pm 0.07 \mathrm{M})$. Kinetic analysis found concentrations up to $20 \mathrm{mM}$ ATP and ADP had no effect on GR activity in both control and dehydrated tissues. The calculated $V_{\max }$ of GR purified in control liver tissue $(1.86 \pm 0.01 \mathrm{mU} / \mathrm{mg})$ was significantly greater than the $\mathrm{V}_{\max }$ of $\mathrm{GR}$ in dehydrated liver tissue $(0.26 \pm 0.03 \mathrm{mU} / \mathrm{mg})$ (Table 2.2).

\subsubsection{Post-translational modifications of $G R$}

Western blotting allowed assessment of variations in post-translational modifications (PTMs) between control and dehydrated liver GR to be detected and quantified (Fig. 2.4; Fig. 2.5). A significant difference between GR from control versus dehydrated frogs was seen only for phosphothreonine content that showed a significant 
decrease of $12.3 \%$ for dehydrated GR as compared with the control (Fig. 2.4). This study also investigated several other potential PTM variations as shown in Fig. 2.5. Immunoblotting revealed a significant change in lysine-methylation (0.86-fold), cysteinenitrosylation (0.82-fold), ubiquitination ( 0.77 -fold), and sumoylation-1 (1.24-fold) for dehydrated GR as compared with the control (Fig. 2.5).

\subsubsection{In vitro incubation to stimulate endogenous protein phosphatases}

Changes in GR phosphorylation in response to dehydration (Fig. 2.4) indicated that the enzyme was modified by dephosphorylation. To determine if the change in GR substrate affinity (observed in section 2.3.3) between control and dehydrated frogs was attributable to reversible phosphorylation of the protein, crude liver extracts were incubated with activators of specific endogenous protein phosphatases, and then the $\mathrm{K}_{\mathrm{m}}$ GSSG in the presence of $55 \mathrm{mM}$ urea was revisited (Fig. 2.6). In vitro incubations (described in section 2.2.9) set up a series of conditions that allowed individual phosphatase types to be active as well as conditions that both fully inhibited (STOP condition) or fully facilitated (TOTAL PPases) all endogenous protein phosphatases. The $\mathrm{K}_{\mathrm{m}}$ for GSSG in the presence of $55 \mathrm{mM}$ urea was chosen as the kinetic parameter to assess given its large change between control and dehydrated states (Table 2.2). The results obtained provide insight regarding the correlation between the phosphorylation state of GR and its substrate affinity. Stimulation of protein tyrosine phosphatases (PTPs), protein phosphatase 1 (PP1), PP1+PP2A, and commercial alkaline phosphatases (Comm PP) produced negligible changes in the $\mathrm{K}_{\mathrm{m}}$ for GSSG in neither control nor dehydrated extracts (Fig. 2.6). However, compared with the fully inhibited STOP situation, the relative $\mathrm{K}_{\mathrm{m}}$ GSSG (in the presence of $55 \mathrm{mM}$ urea) of control GR decreased 
significantly in incubations that promoted TOTAL PPases, PP2A, PP2B or PP2C. In comparison to the $\mathrm{K}_{\mathrm{m}} \mathrm{GSSG}$ of the stop condition $\left(\mathrm{K}_{\mathrm{m}}=0.99 \mathrm{mM} \mathrm{GSSG}\right)$, the $\mathrm{K}_{\mathrm{m}} \mathrm{GSSG}$ of GR in extracts of control liver was reduced after incubation to $0.23 \mathrm{mM}$ after stimulation of total PPases, and to $0.30 \mathrm{mM}, 0.09 \mathrm{mM}$, or $0.32 \mathrm{mM}$ after incubation to stimulate PP2A, PP2B, or PP2C, respectively (Fig. 2.6). By contrast, in extracts of dehydrated liver, the substrate affinity of GR was only affected by the stimulation of PP2A, showing a significant increase in the $\mathrm{K}_{\mathrm{m}}$ compared with the STOP situation (0.48 mM GSSG vs 0.26 mM GSSG).

\subsubsection{Protein Expression level of GR}

Immunoblotting allowed for an assessment of total protein expression levels of GR in liver of control and dehydrated $X$. laevis. Figure 2.7 shows that there was no significant change in GR expression levels in response to dehydration.

\subsubsection{Stability of GR upon dehydration stress}

The structural stability of GR was analysed by incubating the enzyme in various concentrations of urea and measuring $\mathrm{V}_{\max }$ at saturating substrate concentrations over a period of two hours for GR from liver of control (Fig. 2.8a) and dehydrated frogs (Fig. $2.8 \mathrm{~b})$. The data collected was standardized to an experimental control defined as the $\mathrm{V}_{\max }$ of GR measured from an extract containing no urea. When exposed to low urea concentrations (55-200 mM), GR purified from control liver displayed no significant change in $V_{\max }$ from the experimental control over the full period of 2 hours (Fig. 2.8a). With exception to the 30-minute timepoint, a urea concentration of at least $600 \mathrm{mM}$ generated a significant reduction in the $V_{\max }$ of GR in comparison to the experimental control (Fig. 2.8a). A 30-minute incubation with 1-2 $\mathrm{M}$ urea reduced the $\mathrm{V}_{\max }$ of GR by 
$50 \%$, while $4 \mathrm{M}$ urea reduced the $\mathrm{V}_{\max }$ by $90 \%$. After a 1-hour incubation with at least $600 \mathrm{mM}$ urea, the $\mathrm{V}_{\max }$ was reduced by $80-90 \%$ of the experimental control. A comparable analysis of GR purified from dehydrated liver again showed that moderate levels of urea $(0.055-1 \mathrm{M})$, had no significant effect on maximal activity from the experimental control over the course of an hour (Fig. 2.8b). After a 2-hour incubation, 0.6-2 $\mathrm{M}$ urea inflicted a $20-40 \%$ reduction in $\mathrm{V}_{\max }$ in comparison to the no-urea control while $4 \mathrm{M}$ urea inflicted a $90 \%$ reduction (Fig. $2.8 \mathrm{~b}$ ). The $\mathrm{V}_{\max }$ of dehydrated GR was significantly altered by high urea concentrations over the first hour incubation with a 30$40 \%$ reduction at $2 \mathrm{M}$ urea and a $60-80 \%$ reduction at $4 \mathrm{M}$ urea.

\subsection{Discussion}

The physiological consequence of whole-body dehydration in $X$. laevis includes hypovolemia and reduced oxygen delivery triggering DIH and ischemic conditions. Such physiological conditions of oxidative stress create significant sources of ROS, primarily being the compromised ETC induced by HIF-1 stimulation (Kim et al., 2009). To limit oxidative tissue damage inflicted during dormancy by ROS, $X$. laevis would require differentially regulated antioxidant defense responses. GSH provides the reducing power for neutralizing ROS via GPx, detoxifying xenobiotics via GSTs, and repairing oxidatively damaged proteins via regeneration of glutaredoxin (Meyer et al., 2009; Grant, 2001). Some investigation into glutathione-based AOEs in $X$. laevis found an upregulation of the glutathione-S-transferase (GST) proteins GSTP1 and GSTM1 in response to dehydration (Malik and Storey, 2009a). Similarly, GST and GPx activity increased in the muscle and hepatopancreas, respectively, in response to anoxia in $O$. lactea (Hermes-Lima and Storey, 1995). Further insight into the differential AOE 
regulation in X. laevis derives from the hypothesis suggesting that dehydration tolerance is an evolutionary predecessor to freeze tolerance in anurans, meaning that mechanisms implemented to adapt to dehydration stress are likely to also be seen in freeze-tolerant frogs. Despite years of investigation, the search for a common ancestor linking the freeze-tolerant $R$. sylvatica to the dehydration-tolerant $X$. laevis remains inconclusive. However, the fact that freezing imposes dehydration stress through water amalgamation to the abdomen as extracellular ice (Storey, 1990) may suggest that these amphibians share a similar dehydration-mediated regulation of their AOE defenses. Therefore, the increase in GPx and GST activity found in $R$. sylvatica liver tissue in response to freezing, initially reported by Joanisse and Storey (1996), may be attributable to mitigating the damaging effects of cellular dehydration. According to this speculation, a similar AOE response may also be observed in the dehydrated X. laevis. This increased glutathione-based AOE response in other dormant amphibians, validates the importance of maintaining elevated levels of GSH-equivalents during dehydration stress in X. laevis.

GR serves a pivotal role in recycling GSSG produced by glutathione-based AOEs and is crucial for maintaining elevated levels of GSH for an effective antioxidant response to mitigate ROS-mediated cellular damage generated during dehydration stress. In this study, GR was purified 221.7-fold from control frog liver tissue with a final specific activity of $268.3 \mathrm{mU} / \mathrm{mg}$ and was similarly purified 115.0 -fold from dehydrated frog liver tissue with a final specific activity of $276.6 \mathrm{mU} / \mathrm{mg}$. The enzyme was purified to near homogeneity and the single protein band existing at $\sim 55 \mathrm{kDa}$ was identified via Western blot techniques to be GR (Fig. 2.2; Fig. 2.3). This chapter shows that liver GR from control and dehydrated $X$. laevis displays markedly different kinetic properties and 
responses to urea. Furthermore, it is demonstrated that reversible phosphorylation is a likely mechanism responsible for the observed changes in the kinetic properties of GR.

\subsubsection{Kinetic changes of $G R$ during dehydration}

Kinetic analysis of GR provided useful insight into its physiological regulation in the liver of $X$. laevis (Table 2.2). Under standard conditions, there was no significant change in substrate affinity for GSSG in response to dehydration, with the Michaelis Menton constant remaining at $\sim 0.65 \pm 0.02 \mathrm{mM} \mathrm{GSSG}$ for both control and dehydrated GR. However, exposure to physiological urea levels dramatically increased the substrate affinity of dehydrated GR for GSSG with $\mathrm{K}_{\mathrm{m}}$ values falling from $0.64 \pm 0.02 \mathrm{mM}$ to 0.13 $\pm 0.01 \mathrm{mM}$ GSSG. As previously mentioned, $X$. laevis accumulates urea in order to generate an appreciable osmotic gradient to delay transcutaneous water loss and retard whole-body dehydration (Malik and Storey, 2009b). The results suggest that the frog may be benefitting from a preexisting hyperuremic response to augment the function of GR and promote the recycling of GSSG to GSH for antioxidant defense. A similar result was observed for $R$. sylvatica muscle GR, with $\mathrm{K}_{\mathrm{m}}$ GSSG remaining constant between control and frozen conditions but decreasing significantly when exposed to the high glucose levels (used as a cryoprotectant) of the frozen wood frog (Dawson and Storey, 2017). With hyperglycemia as a freeze-tolerance mechanism in $R$. sylvatica and hyperuremia as a dehydration-tolerance mechanism in $X$. laevis, it is clear that similar mechanism for GR regulation is being used in both cases.

Investigation of total GR activity provided a surprising result. Dehydrated GR had a $V_{\max }$ that was only $14 \%$ of the control value (Table 2.2 ). Together with the $\mathrm{K}_{\mathrm{m}} \mathrm{GSSG}$ in the presence of physiological urea described above, this suggests that dehydrated GR has 
a high affinity for GSSG but a lower total activity than the control enzyme. In this case, the kinetic parameter that dictates whether there is a positive or negative regulation of GR in response to dehydration stress is dependent on the concentration of the substrate, GSSG. Although GSSG levels have not been measured in X. laevis, it is known that the amount of cellular GSH is always many-fold greater than the amount of GSSG. For instance, the GSH:GSSG ratio was measured to be $80: 1$ in the anoxic T. s. elegans, 111:1 in the frozen R. sylvatica, and 312:1 in the anoxic R. pipiens (Willmore and Storey, 1997; Joanisse and Storey, 1996). Therefore, although maximum velocity was significantly diminished in response to dehydration, the low cellular abundance of GSSG would suggest that maximum GR activity is not attained in vivo in the dehydrated liver tissue. That is, the substrate affinity for oxidized glutathione is more important than the enzyme's total activity when determining the functional regulation of GR in response to environmental stress. This finding reinforces that GR is regulated to respond effectively to low substrate concentrations as a means of creating the required downstream product of GSH and maintaining the high GSH:GSSG ratio for effective glutathione-based antioxidant defense in response to dehydration stress.

Under standard conditions, control GR had a significantly higher affinity for the cofactor NADPH than dehydrated GR $\left(\mathrm{K}_{\mathrm{m}}=0.045 \pm 0.003 \mathrm{mM}\right.$ vs $0.076 \pm 0.006 \mathrm{mM}$ NADPH, respectively) (Table 2.2). However, whereas exposure to physiological urea levels was found to enhance the substrate affinity for GSSG of dehydrated GR, it was found to reduce NADPH substrate affinity $\left(\mathrm{K}_{\mathrm{m}}=0.076 \pm 0.006 \mathrm{mM}\right.$ to $0.23 \pm 0.02 \mathrm{mM}$ NADPH) (Table 2.2). Likewise, physiological urea was also found to reduce NADPH substrate affinity for control GR $\left(\mathrm{K}_{\mathrm{m}}=0.045 \pm 0.003 \mathrm{mM}\right.$ to $\left.0.13 \pm 0.04 \mathrm{mM} \mathrm{NADPH}\right)$ 
(Table 2.2). Since physiological levels of this cofactor are quite low, e.g. $\sim 0.082 \mathrm{mM}$ NADPH as measured in Caudiverbera caudiverbera (Preller et al., 1999), these changes in $\mathrm{K}_{\mathrm{m}} \mathrm{NADPH}$ could have significant impact on G6PDH regulation in response to dehydration.

The effect of ATP and ADP were independently investigated as a potential allosteric effector for GR (Table 2.2). In this study, neither ATP nor ADP were found to modify GR activity in $X$. laevis liver.

The half maximal inhibitor $\left(\mathrm{I}_{50}\right)$ concentration for various salts and urea of GR purified from control and dehydrated frog liver was investigated to determine the relative integrity of the enzyme's active site. That is, an enzyme showing a high $\mathrm{I}_{50}$ value for a denaturing solute such as $\mathrm{NaCl}, \mathrm{KCl}$ or urea clearly has an active site that is less susceptible to effects of denaturant and can maintain its structural integrity in the face of high inhibitor concentrations. In this study, GR from control and dehydrated frogs had similar $\mathrm{I}_{50}$ values for $\mathrm{NaCl}$ and $\mathrm{KCl}$ (Table 2.3). However, dehydrated GR retained kinetic activity at a higher concentration of urea than control GR ( $\mathrm{I}_{50}$ urea being $3.26 \pm$ $0.03 \mathrm{M}$ vs $2.82 \pm 0.07 \mathrm{M}$, respectively). This concentration of urea is not physiologically relevant to the dehydrating African clawed frog and is not likely to have negative implications on the frog's antioxidant capacity. In fact, this value is far greater than the concentration of urea naturally accumulated by X. laevis $(\sim 55 \mathrm{mM})$ or S. couchii $(\sim 350$ $\mathrm{mM}$ ). Since $\sim 3.26 \mathrm{M}$ is not physiologically attainable, the ability of dehydrated GR to withstand a more elevated concentration of urea in comparison to control GR is likely attributable to PTM-related changes that serve to increase the enzyme's substrate affinity or relative stability in response to dehydration stress. While measuring the initial velocity 
of GR following brief exposure to denaturing inhibitors provides useful insight into immediate effects of the inhibitor on enzyme kinetics, it does not investigate the enhanced structural stability of GR in response to dehydration.

\subsubsection{Reversible protein phosphorylation of $G R$}

The kinetic differences observed in this study indicated that there may be distinct structural differences between the control and aestivated forms of GR. During enzyme purification, the DEAE elution profile illustrated a shift in peak activity suggesting that dehydrated GR has a less negative surface charge and therefore does not interact as strongly with the anion-exchange column, requiring a lower salt concentration for the enzyme to be eluted (Fig. 2.1). Changes in surface charge distribution can be the result of enzyme regulation by some form of post-translational modification, commonly through reversible protein phosphorylation. The three amino acids that are susceptible to protein phosphorylation include serine, threonine, and tyrosine. Through western blot analysis, the only significant phosphorylation change detected in dehydrated vs control GR was a $12.3 \%$ decrease in phospho-threonine content in response to dehydration (Fig. 2.4). This observation correlates well with the DEAE elution profile for the enzyme. In theory, the incubation of the dehydrated crude extract with stimulators of total protein kinases or incubation of the control crude extract with stimulators of total protein phosphatases would cause both forms of GR to elute from the DEAE chromatography column at the same salt concentration due to similar interactions with the positively charged column resin.

Kinetic parameters including substrate affinity, maximum velocity, and enzyme stability are often correlated with a change in phosphorylation state. A comparison 
between the relative phospho-threonine levels and GSSG substrate affinity in the presence of $55 \mathrm{mM}$ urea revealed that control GR had a higher threonine-phosphorylation state and a higher $\mathrm{K}_{\mathrm{m}}$ GSSG than dehydrated GR (Fig. 2.4; Table 2.2.). Incubation of control crude extracts with stimulators of several forms of protein phosphatases resulted in a significant increase in GSSG substrate affinity from the no-phosphatase control, as shown by a decrease in the $\mathrm{K}_{\mathrm{m}}$ value. The $\mathrm{K}_{\mathrm{m}}$ decreased from $0.99 \mathrm{mM}$ GSSG to 0.23 $\mathrm{mM}, 0.30 \mathrm{mM}$, to $0.09 \mathrm{mM}$, and to $0.32 \mathrm{mM}$ following the stimulation of total protein phosphatases, PP2A, PP2B, and PP2C, respectively (Fig. 2.6). The results show a strong correlation between GR phosphorylation state and its substrate affinity: as protein phosphorylation was reduced, there was an increase in affinity for GSSG (in the presence of $55 \mathrm{mM}$ urea). Further dephosphorylation of dehydrated GR through incubation of crude extract with stimulators of various protein phosphatases resulted in no significant change in GSSG substrate affinity, with the exception of an effect by PP2A. Further dephosphorylation at residues recognized by PP2A resulted in a decrease in GSSG affinity for dehydrated GR suggesting that specific sites targeted by PP2A must be differentially phosphorylated for optimal substrate affinity. Although it is possible to analyze the primary structure of GR and identify potential threonine-phosphorylation sites, it is not currently possible to identify which of these threonine residues are dephosphorylated by PP2A, PP2B, or PP2C which could give us a better understanding of the reversible phosphorylation regulation of GR in response to dehydration stress. This complication is due to the promiscuity of the protein phosphatases. 


\subsubsection{Other post-translational modifications of $G R$}

Phosphorylation is not the only PTM that provides regulatory control over enzyme kinetics and/or protein stability. Other PTMs were similarly investigated for GR and western blot analysis measured a significant decrease in lysine-methylation, cysteinenitrosylation and ubiquitination to 86,82 and $77 \%$ of the control value, respectively, whereas sumoylation- 1 content increased by 1.24 -fold in response to dehydration stress (Figure 2.5). Methylation is very common in histones for regulation of gene expression. However, for non-histone proteins, methylation may serve as a promoter or repressor for additional phosphorylation and is commonly referred to as methylation-phosphorylation crosstalk (Biggar and Li, 2015). Since both the phosphorylation state and methylation state of $X$. laevis GR decreased during dehydration, cross-talk may be involved in coordinating this PTM-mediated enzymatic regulation. It has been previously shown that nitrosylation of cysteine residues located at the GR active site can have a significant regulatory role on kinetic activity (Bauer et al., 2001). The cysteine residues at the active site of GR serve an important function as nucleophiles that initiate the reduction of GSSG to GSH (Berkholz et al., 2008). Hence, decreased cys-nitrosylation at the active site may enhance substrate affinity for GSSG in the presence of $55 \mathrm{mM}$ urea upon dehydration. However, it is unclear at this time whether the decrease in global cys-nitrosylation is the cause of the kinetic outcome. In recent years, the cellular function of protein ubiquitination has extended beyond its original role in targeting proteins for degradation by the proteasome and has been identified as a PTM involved in a myriad of cell functions including regulating protein stability, internalization, enzyme activity, and protein-protein interactions (Radivojac et al., 2010; Schnell and Hicke, 2003). The wide 
array of cellular targets/functions affected by ubiquitination modification makes it rather difficult to establish the exact role of GR de-ubiquitination in response to dehydration without further experimentation. Similarly, the general function of sumoylation includes enhanced protein stability and subcellular localization (Klenk et al., 2005; Yang et al., 2012). Both sumo- 1 and sumo- $2 / 3$ protein conjugates are known to increase in tissues of hibernating 13-lined ground squirrels (Ictidomys tridecemlineatus) during torpor (Lee et al., 2007). When mice exposed to hypoxic stimulation via reducing atmospheric oxygen from $20.9 \%$ to $10 \%$, the cell lysates have shown enhanced expression of sumo-1 mRNA and protein levels (much like HIF-1) (Shao et al., 2004). Sumo-1 protein modification has been found to enhance nuclear protein stability, reducing susceptibility to ubiquitinmediated protein degradation (Desterro et al., 1998). It is interesting, then, that relative ubiquitination versus sumoylation of GR changed in opposite directions in response to dehydration and increased sumo-1 conjugation of dehydrated GR may act to increase protein stability in response to DIH in X. laevis or contribute to counteracting any negative effects of rising urea on GR (Fig. 2.8). Inferences made concerning the function of non-phosphorylation PTMs require further investigation to provide credibility.

\subsubsection{GR protein expression}

To investigate whether post-translational modifications and hyperuremia are the only mechanisms regulating GR kinetics and stability in response to dehydration stress, this study also investigated protein expression levels of GR (Fig. 2.7). Overall, there was no detectable change in GR protein levels suggesting a lack of transcriptional or translational regulation. 


\subsubsection{Assessing GR structural stability with urea incubations}

Initial investigations regarding protein stability in the presence of urea was simply looking at the instantaneous effect of the osmolyte on GR activity (Table 2.3). Following western blot analysis, a couple of PTMs that varied between experimental conditions were found in literature to be implicated in enhancing protein stability. According to section 2.4.3., dehydrated GR may have enhanced stability due to the increase in sumo-1 conjugation and decrease in ubiquitination which together suggests increased protein resilience to degradation. In Figure 2.8, each form of GR was incubated with varying concentrations of urea over the period of 2 hours. Both the control and dehydrated GR retained similar maximal activity to the no-urea control at low levels of urea (55-200 $\mathrm{mM}$ ). However, whereas a 30 -minute exposure to $600 \mathrm{mM}$ urea caused a $30 \%$ decrease in the $\mathrm{V}_{\max }$ of control GR, a 1-hour incubation resulted in an $80 \%$ loss in kinetic activity (Fig. 2.8a). GR purified from dehydrated frog liver retained the majority (60\%) of its maximal activity throughout its 2-hour exposure to $2 \mathrm{M}$ urea (Fig. 2.8b). Although these urea levels are not attained during $X$. laevis dehydration, this analysis provides insight indicating an enhanced stability of GR from dehydrated frog liver in comparison to control.

\subsubsection{Conclusion}

This study of the regulation of GR in the dehydration-tolerant frog, X. laevis, provides useful insights into the maintenance of an elevated GSH:GSSG ratio required by the dehydrating frog to fuel glutathione-based AOEs. GR purified from dehydrated frogs displayed a greater affinity for GSSG in the presence of physiological urea and a lower threonine-phosphorylation state. This correlation between a low phosphorylation state 
and high substrate affinity was validated through crude extract incubation with stimulators of endogenous protein phosphatases. Therefore, the results suggest that reversible phosphorylation is used as a regulatory mechanism of GR during times of environmental stress and functions by increasing substrate affinity. Dehydrated GR was found to have enhanced stability as shown by the relatively low reduction in $\mathrm{V}_{\max }$ of $40 \%$ following 2-hour exposure to $2 \mathrm{M}$ urea in comparison to the $90 \%$ reduction seen for control GR. This enhanced stability may be caused by increased sumo-1 protein conjugation or reduced ubiquitination (or both) but requires further investigation. Increased GR affinity for GSSG would ensure a continuous reduction of the substrate to reform GSH, facilitating the neutralization of ROS by GPx, detoxification of xenobiotics by GSTs, and repair of oxidatively damaged proteins by reducing glutaredoxin. 
Table 2.1. Representative purification and yield of GR from liver of control African clawed frogs. The optimized purification scheme includes: (a) 20\% PEG precipitation, (b) dye-ligand affinity chromatography on a Cibacron Blue column pre-cleared with a $10 \mathrm{mM} \mathrm{NAD}^{+}$bump and with elution using a 0-1M $\mathrm{KCl}$ gradient, (c) ion exchange chromatography on a DEAE Sephadex column with elution using a $0-1 \mathrm{M} \mathrm{KCl}$ gradient.

\begin{tabular}{ccccccc}
\hline Step & $\begin{array}{c}\text { Total } \\
\text { Protein } \\
(\mathrm{mg})\end{array}$ & \%Yield & $\begin{array}{c}\text { Total } \\
\text { Activity } \\
(\mathrm{mU})\end{array}$ & \%Yield & $\begin{array}{c}\text { Specific } \\
\text { Activity } \\
(\mathrm{mU} / \mathrm{mg})\end{array}$ & $\begin{array}{c}\text { Fold } \\
\text { purification }\end{array}$ \\
\hline Crude extract & 61.2 & --- & 74.0 & --- & 1.209 & --- \\
$20 \%$ PEG & 32.6 & 53.3 & 72.5 & 98.0 & 2.214 & 1.8 \\
Cibacron Blue & 0.819 & 1.3 & 52.4 & 70.8 & 64.0 & 52.9 \\
DEAE Sephadex & 0.063 & 0.1 & 16.9 & 22.8 & 268.3 & 221.7 \\
\hline
\end{tabular}


A.

B.

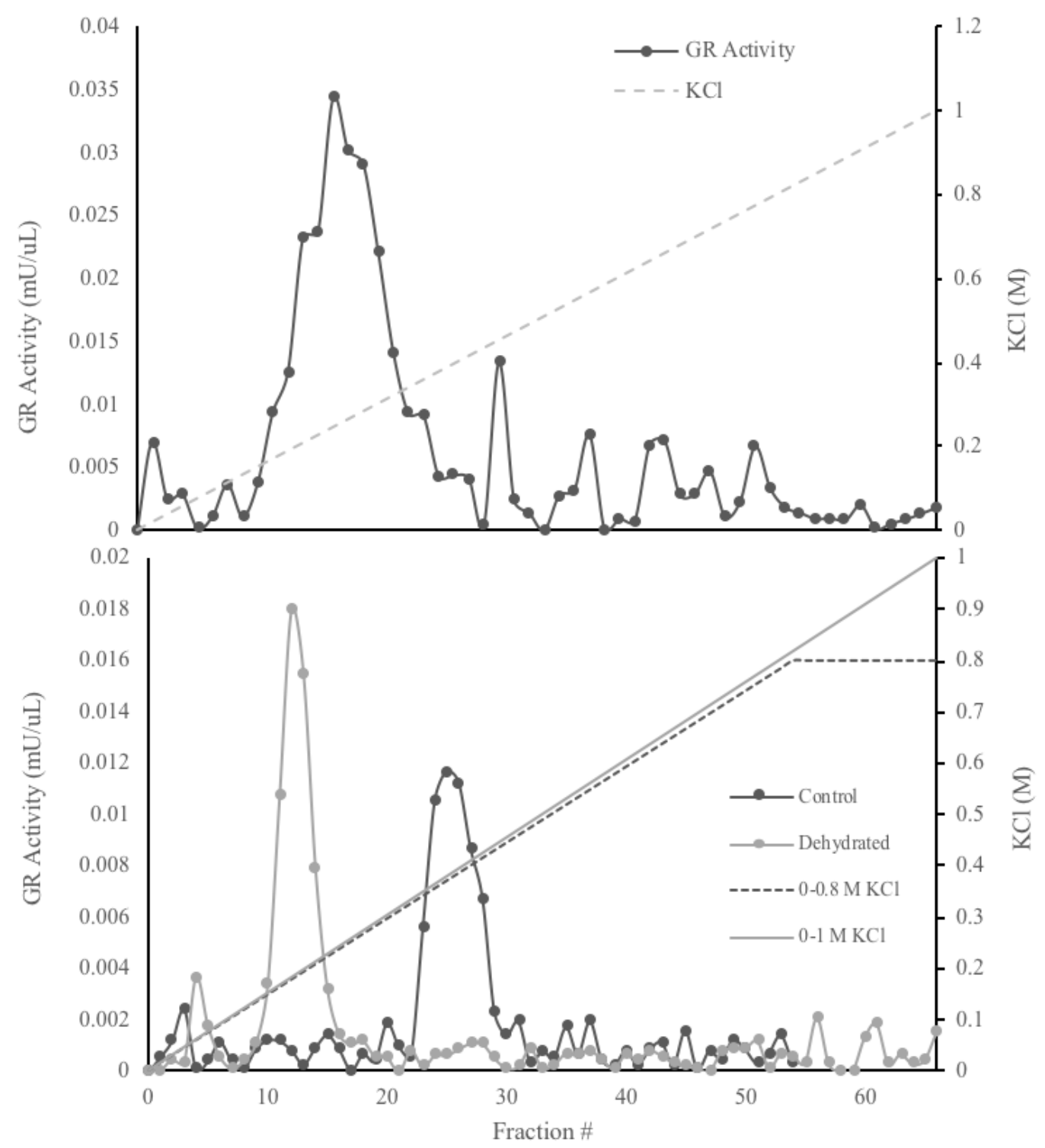

Figure 2.1. (A) Representative Cibacron Blue elution profile for GR activity from liver of hydrated $X$. laevis. (B) Representative DEAE Sephadex elution profile for GR activity from liver of hydrated and dehydrated $X$. laevis. 


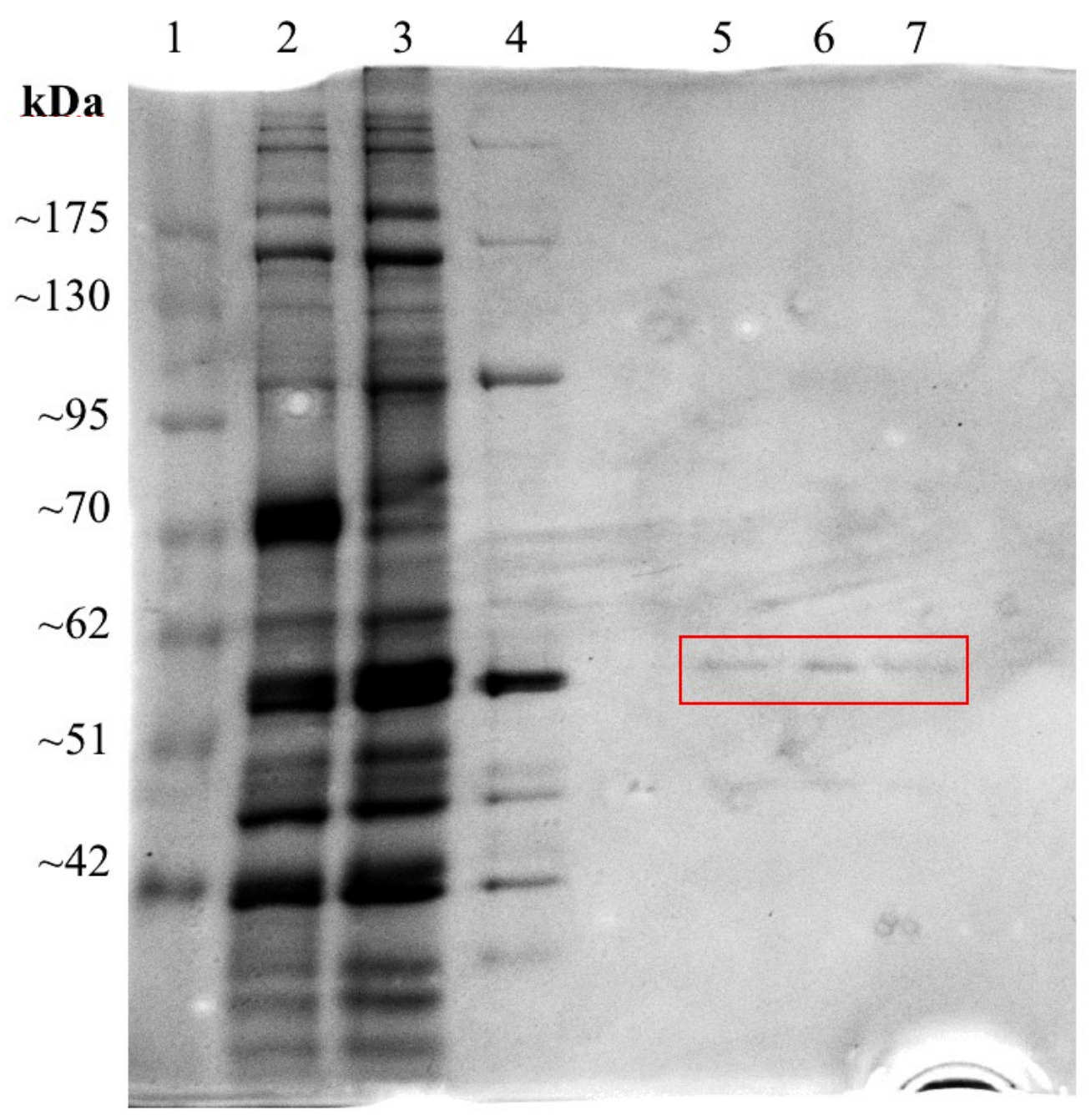

Figure 2.2. Silver stained 10\% SDS-PAGE gel representing the three-step purification of GR from liver of control X. laevis. Gel image shows GeneDirex protein ladder (10.5-175kDa, lane 1), crude extract (lane 2), resuspension from $20 \%$ PEG precipitation (lane 3), pooled fraction from Cibacron Blue column (lane 4), and three technical replicates of the pooled fraction from the final DEAE column (lane 5-7). 


\section{$\begin{array}{llllllllllllll}1 & 2 & 3 & 4 & 5 & 6 & 7 & 8 & 9 & 10 & 11 & 12 & 13 & 14\end{array}$}

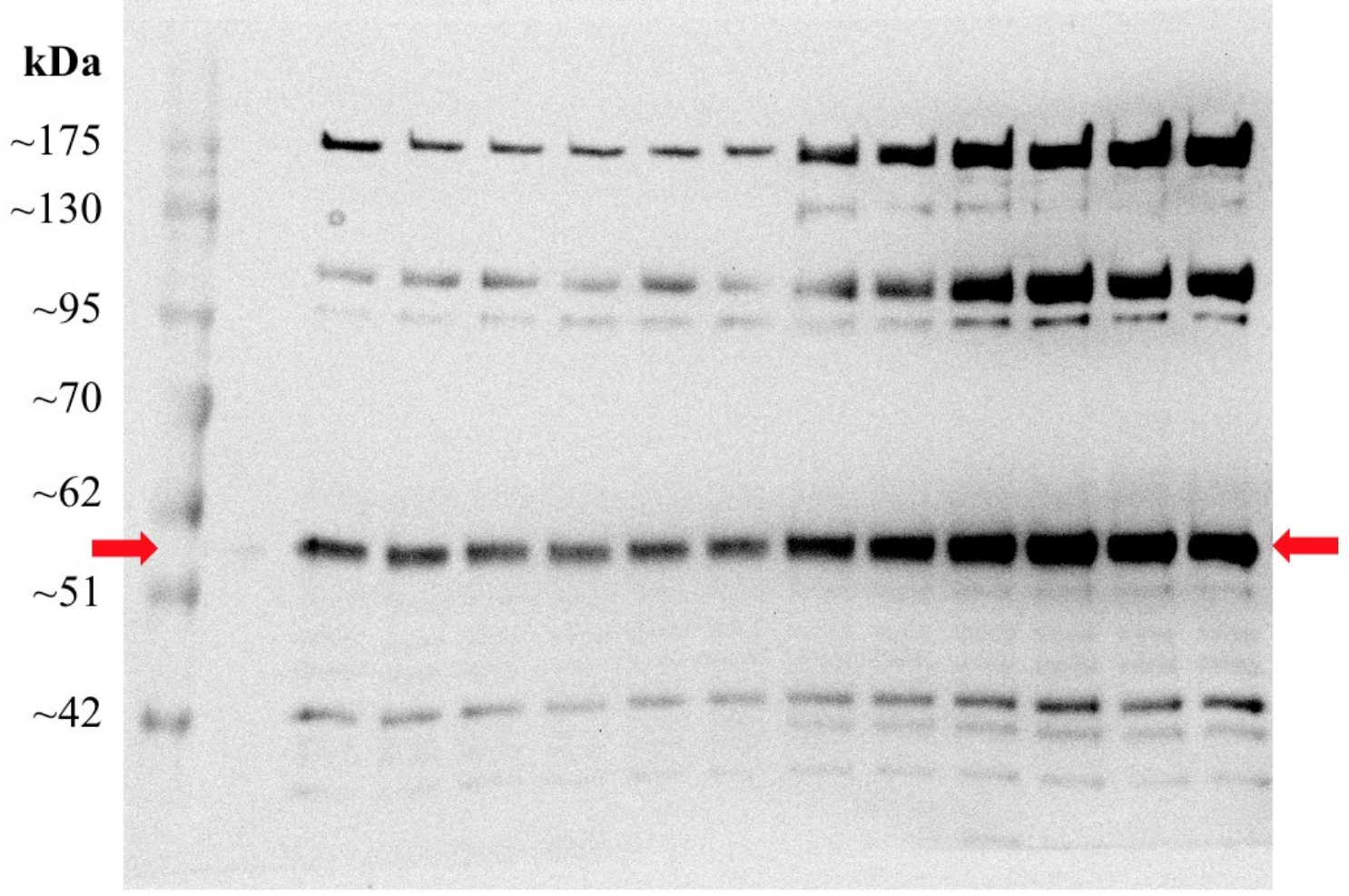

Figure 2.3. Confirmation of GR protein band identity using a polyclonal anti-GR antibody. The target protein was identified using a sample obtained from simply performing the Cibacron Blue column elution with the initial $20 \%$ PEG precipitation (instead of 20\%). The membrane includes a GeneDirex protein ladder (10.5-175kDa, lane 1), commercial standard GR (SigmaAldrich cat. \#G3664, lane 2), six technical replicates of the control liver elution from Cibacron Blue (lanes 3-8), and six technical replicates of the dehydrated liver elution from Cibacron Blue (lanes 9-14). The target protein subunit band is expected to be $\sim 51.7 \mathrm{kDa}$ according to the Expasy bioinformatic resource portal. Molecular weight was calculated using the protein sequence of $X$. laevis GR acquired from the NCBI database (NP_001089322.2). 
Table 2.2. Kinetic parameters of functionally purified $X$. laevis liver GR taken from control and 34\% dehydrated African clawed frogs. $\mathrm{K}_{\mathrm{m}}$ values were determined using saturating conditions of co-substrate(s). Data are presented as means \pm SEM, $n=3\left({ }^{a}\right)$ or $n=4\left({ }^{b}\right)$ determinations. All assays were performed at $\mathrm{pH} 7.5,22^{\circ} \mathrm{C}$. Statistical significance of the data is denoted by an asterisks $(*)$ and determined from Student's t-test, two-tailed, $p<0.05$.

\begin{tabular}{lccr}
\hline \multicolumn{1}{c}{ Kinetic Parameter } & Control $(\mathrm{mM})$ & Dehydrated $(\mathrm{mM})$ \\
\hline $\mathrm{K}_{\mathrm{m}}$ GSSG $(n=3)$ & $0.65 \pm 0.02^{\mathrm{a}}$ & $0.64 \pm 0.02^{\mathrm{a}}$ \\
$\mathrm{K}_{\mathrm{m}}$ GSSG + 55mM urea & $0.54 \pm 0.09^{\mathrm{a}}$ & $0.13 \pm 0.01^{\mathrm{b}}$ & $* * *$ \\
$\mathrm{~K}_{\mathrm{m}}$ NADPH & $0.045 \pm 0.003^{\mathrm{a}}$ & $0.076 \pm 0.006^{\mathrm{b}}$ & $*$ \\
$\mathrm{~K}_{\mathrm{m}}$ NADPH $+55 \mathrm{mM}$ urea & $0.13 \pm 0.04^{\mathrm{b}}$ & $0.23 \pm 0.02^{\mathrm{b}}$ & $* *$ \\
Calculated $_{\max }(\mathrm{mU} / \mathrm{mg})$ & $1.86 \pm 0.01^{\mathrm{b}}$ & $0.26 \pm 0.03^{\mathrm{b}}$ & $*$ \\
$\mathrm{~K}_{\mathrm{a}}$ ATP & No effect $\leq 20 \mathrm{mM}^{\mathrm{b}}$ & No effect $\leq 20 \mathrm{mM}^{\mathrm{a}}$ & \\
$\mathrm{K}_{\mathrm{a}}$ ADP & No effect $\leq 20 \mathrm{mM}^{\mathrm{b}}$ & No effect $\leq 20 \mathrm{mM}^{\mathrm{b}}$ & \\
\hline
\end{tabular}

* - indicates a significant difference from the corresponding control tissue ** - indicates a significant difference from the corresponding value without urea. *** - indicates a significant difference from the corresponding control tissue and from corresponding value without urea. 
Table 2.3. Half maximal inhibitory concentration of functionally purified $X$. laevis liver GR taken from control and 34\% dehydrated African clawed frogs for physiological salts and urea. Data are presented as means SEM, $n=4$ determinations unless otherwise indicated. All assays were performed at $\mathrm{pH}$ $7.5,22^{\circ}$ C. Statistical significance of the data is denoted by an asterisks (*) and determined from Student's t-test, two-tailed, $p<0.05$.

\begin{tabular}{ccc}
\hline Kinetic Parameter & Control (M) & Dehydrated (M) \\
\hline $\mathrm{I}_{50} \mathrm{NaCl}$ & $0.74 \pm 0.03 \quad(n=3)$ & $0.58 \pm 0.06$ \\
$\mathrm{I}_{50} \mathrm{KCl}$ & $0.69 \pm 0.07 \quad(n=3)$ & $0.725 \pm 0.006$ \\
$\mathrm{I}_{50}$ Urea & $2.82 \pm 0.07$ & $3.26 \pm 0.03^{*}$ \\
\hline
\end{tabular}




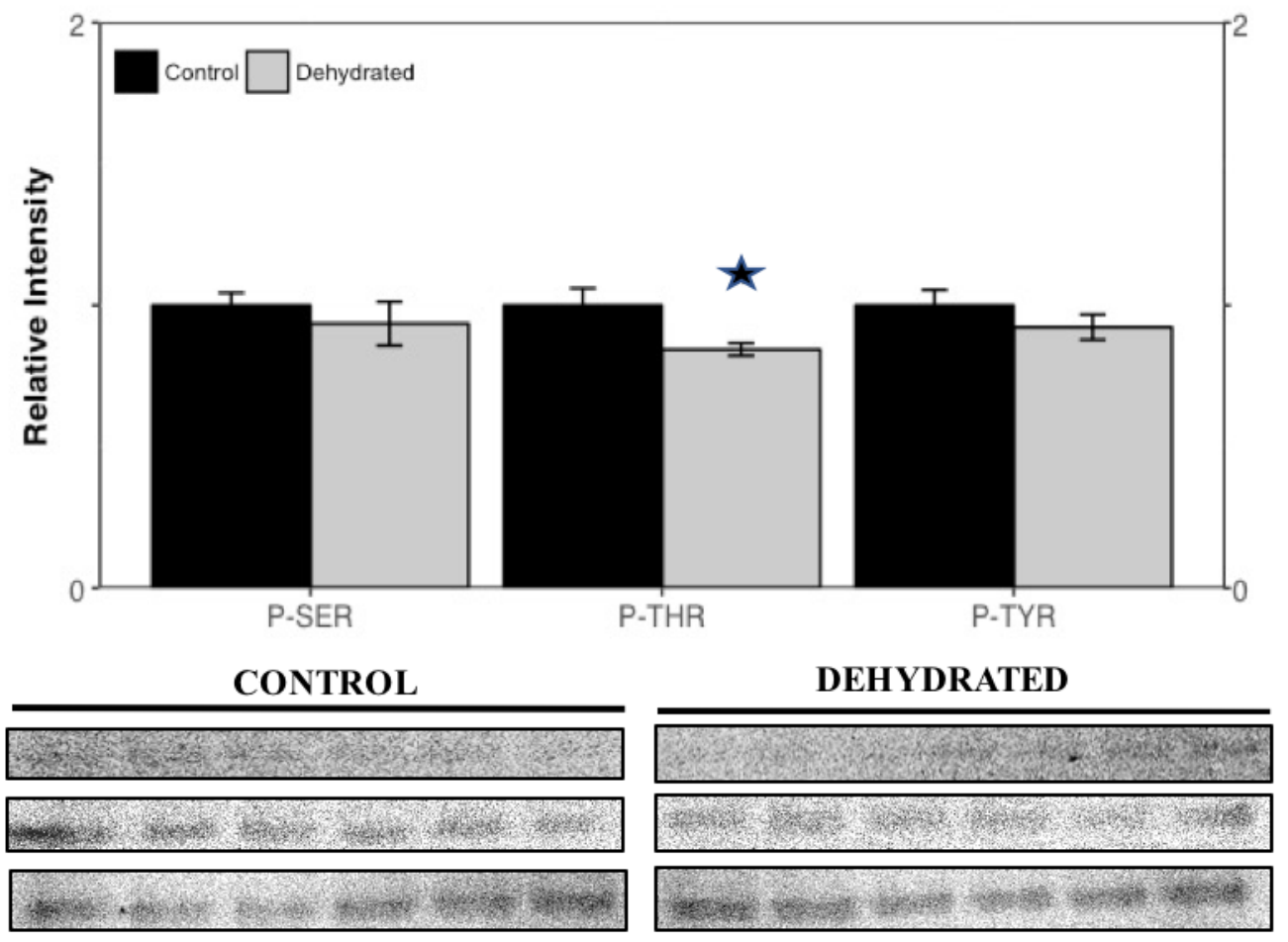

Figure 2.4. Relative post-translational modifications of semi-pure liver GR from control and dehydrated $X$. laevis: phosphoserine, phosphothreonine, and phosphotyrosine. Statistical significance of the data from the corresponding control PTM levels is denoted by $(\star)$ and determined from the Student's t-test, two-tailed, $p<0.05$. 

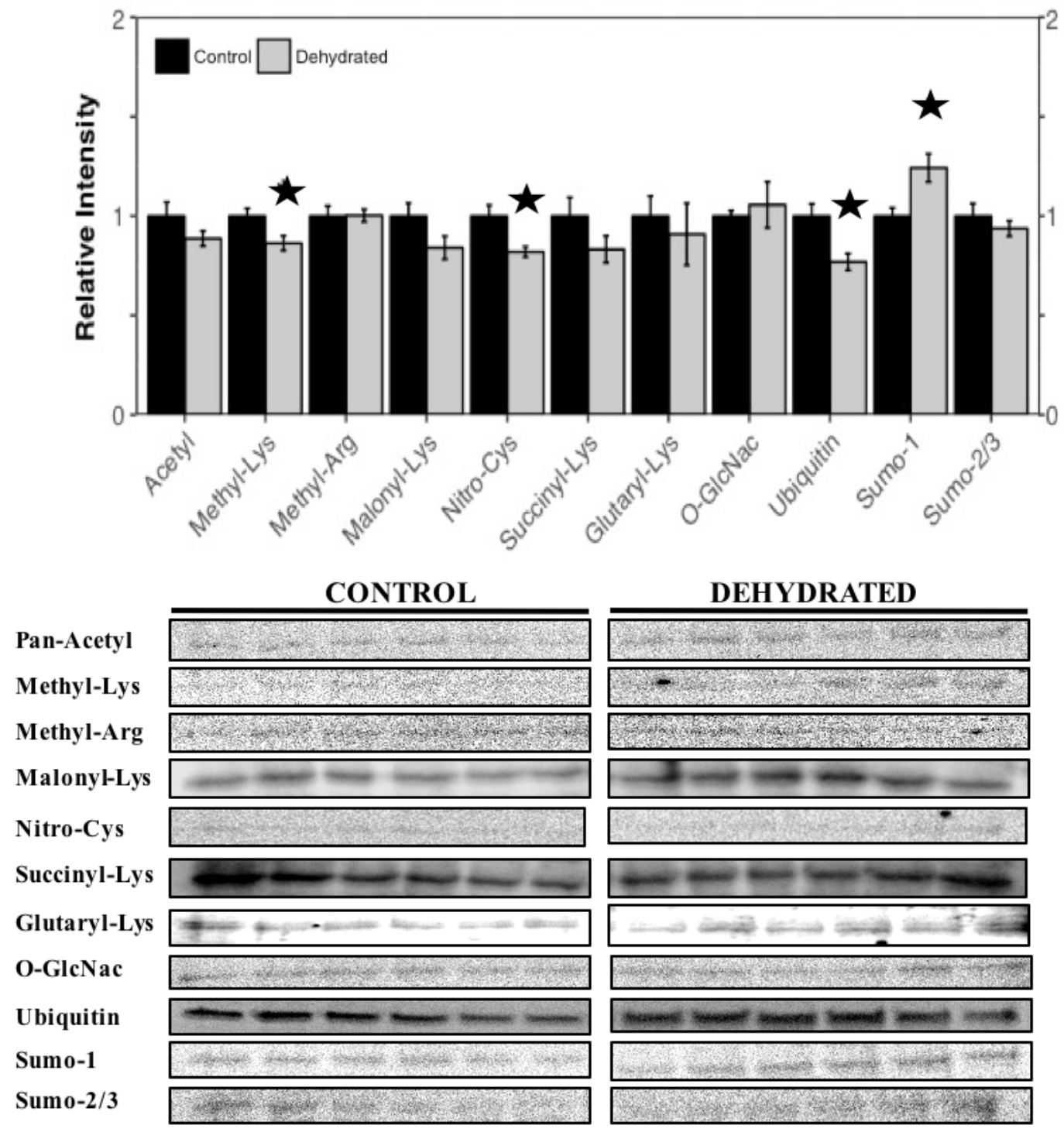

Figure 2.5. Summary of the western blots performed to ascertain the differences in post-translational modifications of semi-pure GR from control and dehydrated $X$. laevis liver. Data presented in the figure are normalized relative band intensities, mean $\pm \mathrm{SEM}, \mathrm{n}=5$ independent determinations. Statistical significance of the data from the corresponding control PTM levels is denoted by $(\star)$ ) and determined from the Student's t-test, twotailed, $p<0.05$. 


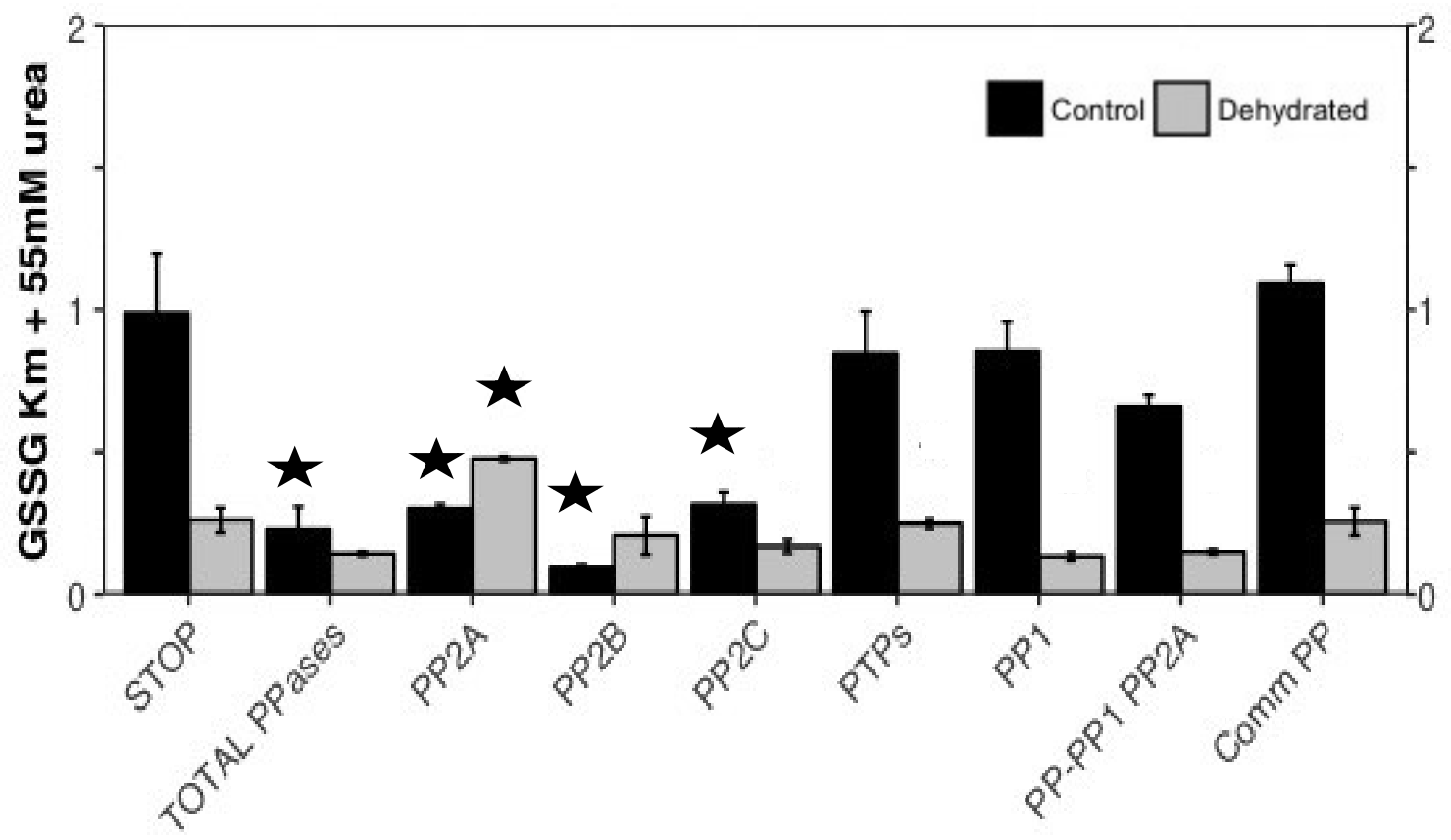

Figure 2.6. Effects of in vitro incubations to stimulate the activities of endogenous protein phosphatases on the $\mathrm{K}_{\mathrm{m}}$ of GR for GSSG in the presence of $55 \mathrm{mM}$ urea in liver extracts of control and dehydrated X. laevis. Data are means \pm SEM, with $\mathrm{n}=3-4$ separate determinations on enzyme isolated from different individuals. Conditions are defined in the Materials and Methods. Statistical significance of the data from the corresponding control PTM levels is denoted by $(\star)$ and determined from the Student's t-test, twotailed, $p<0.05$. 


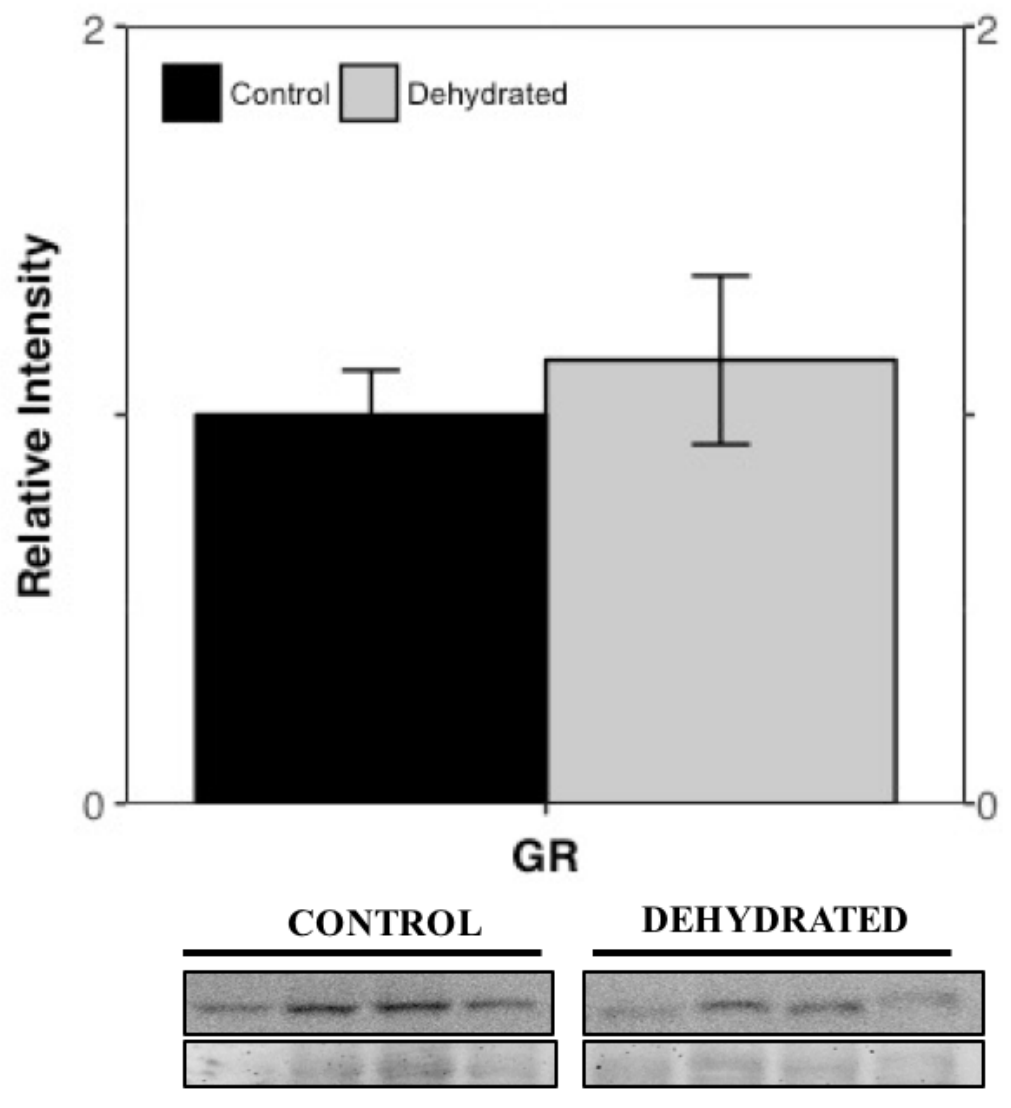

Figure 2.7. Relative protein expression levels of GR in liver extracts of control and dehydrated $X$. laevis. Data are mean \pm SEM, $\mathrm{n}=4$ determinations on separate preparations of enzyme. A two-tailed Student's T-test found the protein expression levels of GR to be statistically insignificant between control and dehydrated frog liver samples $(p>0.05)$. 
A.

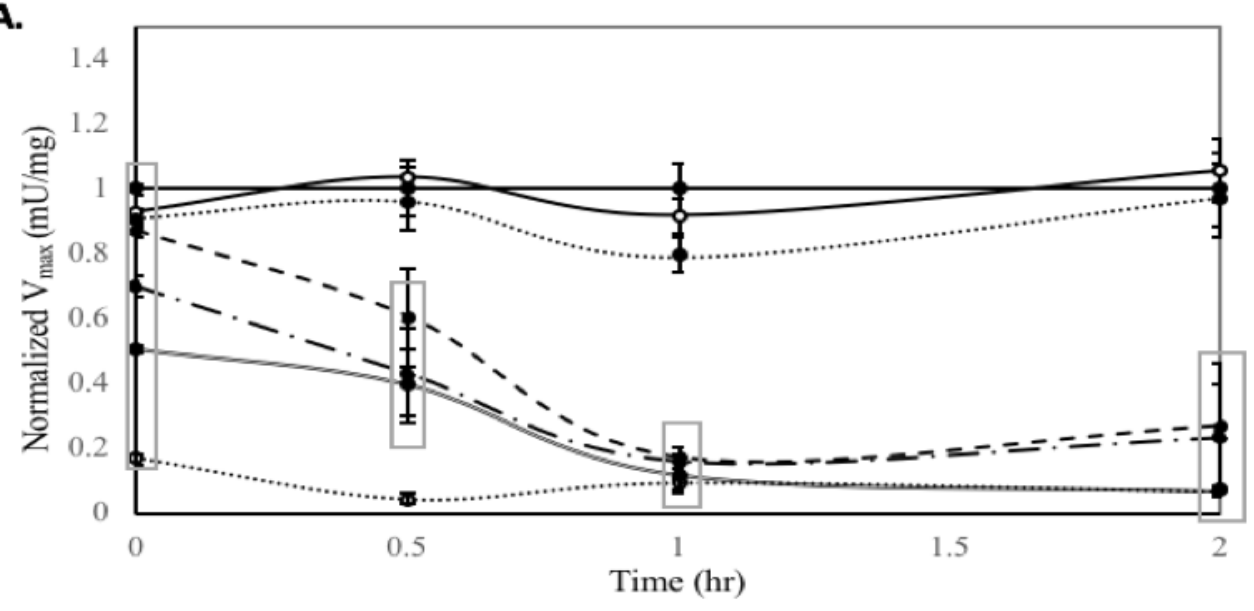

B.

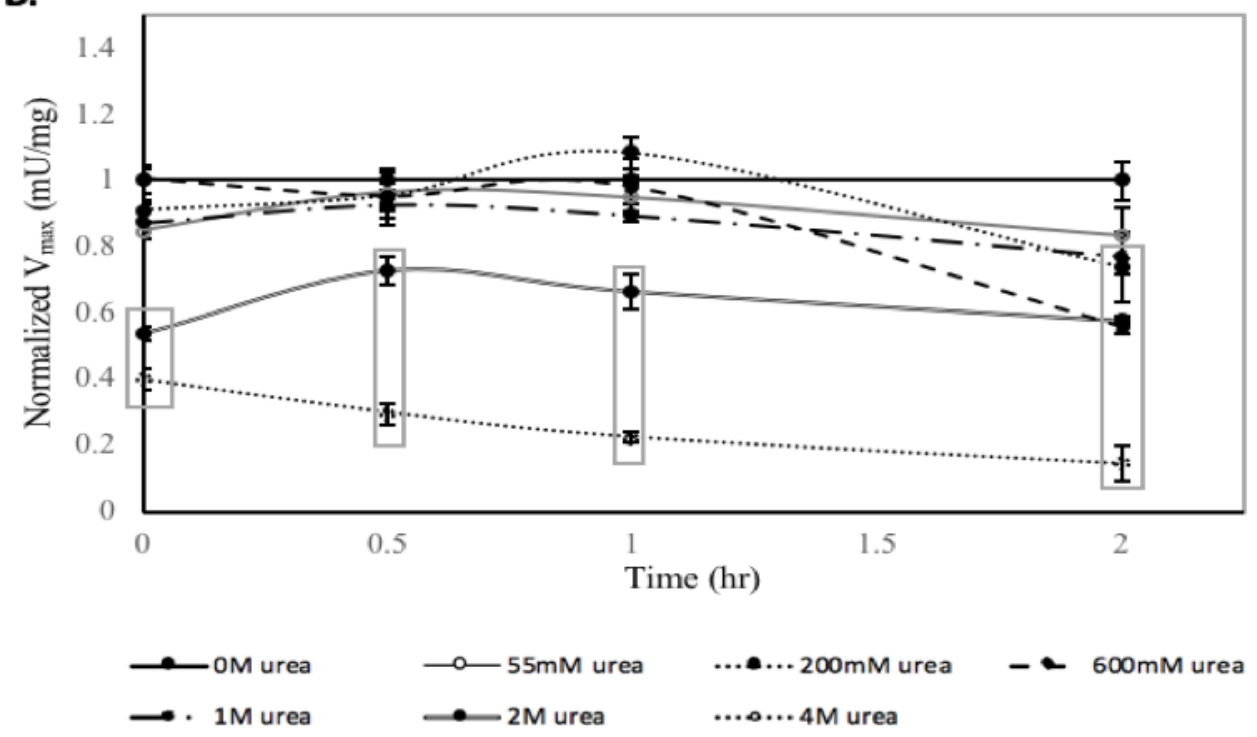

Figure 2.8. Assessment of GR stability obtained by incubating purified GR with various concentrations of urea and measuring $\mathrm{V}_{\max }$ activity over the course of two hours $(0,0.5 \mathrm{hr}, 1 \mathrm{hr}, 2 \mathrm{hr})$. Determinations were performed with $0.046 \mathrm{mg} / \mathrm{mL}$ purified GR from control liver tissue (A) and $0.056 \mathrm{mg} / \mathrm{mL}$ purified GR from dehydrated liver tissue $(\mathbf{B})(n=3-4)$. In each graph, data was normalized to the $0 \mathrm{M}$ urea time-point $\mathrm{V}_{\max }$ data. Statistical significance of the data from the $0 \mathrm{M}$ urea $\mathrm{V}_{\max }$ at the time-point in question is denoted by $(\square)$ and determined from the Student's t-test, twotailed, $p<0.05$. 


\section{Chapter 3}

Characterization of G6PDH regulation in the liver of the dehydrating African clawed frog, Xenopus laevis 


\subsection{Introduction}

During prolonged environmental water deprivation, the dehydrated frog experiences the physiological consequences of hypovolemia and reduced oxygen delivery which triggers dehydration-induced hypoxia (DIH) and ischemic conditions. Among other effects, HIF-1 can cause the accumulation of TCA cycle intermediates through the trans-activation of PDK1, ultimately compromising the ETC (Kim et al., 2006). The dysregulation of the TCA cycle reduces the frog's ability to produce ATP via oxidative phosphorylation and enhances its reliance on anaerobic glycolysis. Hence, glycolysis would play a greater role in ATP production and LDH will become more important as the enzyme responsible for regenerating NADH. This statement is supported by data from a study of liver LDH from $X$. laevis where LDH showed enhanced substrate affinity for pyruvate when urea levels were high during dehydration but was poised to regenerate pyruvate when urea levels were low in arousal (Katzenback et al., 2010). A compromised ETC causes complex I and III to form ROS $\left(\mathrm{O}_{2}^{-}\right.$and $\left.\mathrm{H}_{2} \mathrm{O}_{2}\right)$ in the mitochondria resulting from one-electron reduction of molecular oxygen (Basaga, 1990). In order to respond to increased ROS generation and limit ROS-induced damage, the frog requires an efficient antioxidant response which relies on the combined efforts of superoxide dismutase and catalase as well as glutathione-based antioxidant reactions mediated by GPx, GSTs, and GR.

In Chapter 2, GR was shown to be differentially regulated in response to dehydration stress and showed an increased substrate affinity for GSSG that would aid enzyme function in reducing GSSG back to GSH in the presence of urea. However, to maintain or re-establish a high GSH:GSSG ratio for efficient glutathione-based 
antioxidant defense, GR relies on a continuous availability of NADPH reducing power. In theory, $\mathrm{NADP}^{+}$-isocitrate dehydrogenase could represent an adequate source of NADPH for antioxidant defense; however, it has been shown to have decreased substrate affinity for isocitrate in the liver of dehydrated X. laevis (C.L. Childers and K.B. Storey, unpublished). Another main source of NADPH reducing power in cells is established by a shunt branching from the glycolytic pathway. An intermediate of anaerobic glycolysis, glucose-6-phosphate (G6P), can be redirected into the pentose phosphate pathway (PPP) to produce the NADPH equivalents needed by GR to support glutathione-based antioxidant enzymes.

Glucose-6-phosphate dehydrogenase (G6PDH; E.C. 1.1.1.49) is the first of the two enzymes of the PPP that generates the NADPH reducing equivalents needed for a variety of biosynthetic pathways and for sustaining the glutathione-based antioxidant enzymes through GR-mediated recycling of GSSG to GSH. This enzyme catalyzes the following reaction:

D-glucose-6-phosphate $+\mathrm{NADP}^{+} \rightarrow$ 6-phospho-D-glucono-1,5-lactone $+\mathrm{NADPH}$

In $X$. laevis, the enzyme is a homodimer transcribed from the $g 6 p d$ gene as reported in the UniProtKB database (Q6PCH4_XENLA) (Kiani et al., 2007). According to an Expasy analysis of its mRNA sequence (NP_001080019.1; obtained from the NCBI database), each subunit of G6PDH has a calculated molecular weight of $\sim 59.7 \mathrm{kDa}$. A number of studies have investigated the regulation of G6PDH in cell cultures exposed to oxidative stress. As previously stated in this thesis, HIF-1 can dysregulate the TCA cycle and compromise the ETC by activating PDK1 to shut down PDH in response to ROS (Kim et al., 2006). However, this transcription factor is also known to upregulate g6pd 
gene expression resulting in an increased cellular G6PDH protein level (Gao et al., 2004). Cell-culture studies found G6PDH activity to be inhibited at a high steady-state cellular ratio of NADPH:NADP ${ }^{+}$with activity being rapidly restored following exposure to exogenous oxidation. This exogenous oxidation would generate an antioxidant response from the cell which would subsequently reduce cellular NADPH levels, lowering the NADPH:NADP ${ }^{+}$ratio and allowing G6PDH activity to resume (Wang et al., 2004). In HEK293T cells, acetylation of Lys403 inhibits G6PDH activity by interrupting dimer formation and preventing proper protein folding (Wang et al., 2004). Deacetylation of this residue is mediated by sirt2 in human cell lines and $X$. laevis. Recent investigation into the expression and activity of sirtuin homologs 1-7 in the liver of $X$. laevis found sirt 2 mRNA to be unchanged but global sirt activity was increased in response to dehydration (Luu, B.E., personal communication).

Another model organism that must endure ROS generated under ischemic and oxygen-limited conditions during dormancy is the aestivating milk snail, O. lactea. The milk snail undergoes a similar oxidative stress as the African clawed frog with ROS generated from a compromised ETC and from increased levels of XO (Hermes-Lima and Storey, 1995; Hermes-Lima et al., 1998). G6PDH in the hepatopancreas of O. lactea showed an increased total enzyme activity and greater affinity for G6P under dehydration conditions (Ramnanan and Storey, 2005). Immunoblotting techniques suggested a phosphorylation-mediated regulation of G6PDH during dehydration which was confirmed through incubation analysis with stimulators of endogenous protein kinases or phosphatases (Ramnanan and Storey, 2005). Reversible protein phosphorylation is a common regulatory feature for G6PDH in animals responding to environmental stress. 
Whether the phosphorylation state of G6PDH is increasing or decreasing in response to stress, the enzyme displays enhanced affinity for its substrate as seen in the aestivating milk snail (O. lactea), anoxia-tolerant crayfish (Orconectes virilis), anoxia-tolerant marine periwinkle snail (Littorina littorea), and freeze-tolerant wood frog (R. sylvatica) (Ramnanan and Storey, 2005; Lant and Storey, 2011; Lama et al., 2013; Dieni and Storey, 2010). Results obtained in these model organisms suggest that G6PDH may enhance relative carbon flow through the PPP to produce sufficient NADPH for use in antioxidant defense. A similar method of enzyme regulation might occur in the African clawed frog. That is, G6PDH may be regulated via protein phosphorylation.

The present study investigates the properties, regulation and protein expression of G6PDH in the liver of $X$. laevis comparing the enzyme from control and dehydrated physiological conditions. Since the frog accumulates urea to generate an appreciable osmotic gradient for delaying transcutaneous water efflux, this study also assesses the effect of physiological urea levels on G6PDH properties. Furthermore, the role of posttranslational modification via phosphorylation is investigated as a means to make distinct alterations to G6PDH properties under dehydrating conditions, potentially revealing a conserved mechanism for G6PDH control between frog liver and snail (O. lactea) hepatopancreas. Other post-translational modifications were also investigated.

\subsection{Materials and Methods}

\subsubsection{Animal Care and Chemicals}

The animal care, holding, and experimentation protocols were performed as described in section 2.2.1. of Chapter 2. Smaller male adult X. laevis frogs (34-37g) were used and the mean total body water loss of the dehydrated group as $35 \pm 2.9 \%(\mathrm{n}=10)$. 


\subsubsection{Preparation of liver tissue lysates for protein purification}

Liver samples from control and 35\% dehydrated frogs were removed from a $80^{\circ} \mathrm{C}$ freezer and crushed under liquid nitrogen in preparation for homogenization. The powdered tissue was homogenized 1:10 w:v in ice-cold homogenate buffer A (20 mM Tris-HCl, $10 \mathrm{mM} \beta$-mercaptoethanol, $1 \mathrm{mM}$ EDTA, $1 \mathrm{mM}$ EGTA, $15 \mathrm{mM} \beta$ glycerophosphate, and 15\% v:v glycerol, $\mathrm{pH}$ 7.6) with a few crystals of PMSF added just prior to homogenization. Samples were homogenized on ice using a Janke \& Kunkel IKA-Werk Ultra Turrax homogenizer and centrifuged using a pre-chilled Eppendorf 5810R tabletop centrifuge set to $4^{\circ} \mathrm{C}$. Centrifugation was 30 minutes at $10,000 \mathrm{RPM}$. The supernatant was collected, and the pellet was discarded.

\subsubsection{G6PDH enzyme assay and kinetic parameter determination}

The activity of G6PDH was determined using a Multiskan Spectrum microplate reader (Thermo Scientific) by measuring the increase in light absorption at $340 \mathrm{~nm}$. This absorbance reading corresponds with the reduction of $\mathrm{NADP}^{+}$to form NADPH. Assays were performed in $20 \mathrm{mM}$ potassium phosphate assay buffer $(\mathrm{pH}$ 7.5). The optimal assay conditions for the forward reaction included $1.5 \mathrm{mM} \mathrm{NADP}^{+}$and $2 \mathrm{mM} \mathrm{G6P}$. Assays were run at room temperature $\left(21^{\circ} \mathrm{C}\right)$ with 40 data points collected in intervals of 21 seconds. All kinetic parameters were analyzed using an enzyme kinetic analysis program, Kinetics v.3.5.1 (Brooks, 1992). Data collected derived from $n=3-4$ semi-independent determinations of a functionally purified sample of G6PDH from both control and dehydrated X. laevis liver. The affinity $\left(\mathrm{K}_{\mathrm{m}}\right)$ of $\mathrm{G} 6 \mathrm{PDH}$ for the substrates glucose-6phosphate and $\mathrm{NADP}^{+}$was measured in both the absence and presence of physiological urea concentration $(55 \mathrm{mM})$ found in dehydrated frog. Half maximal inhibitor 
concentrations $\left(I_{50}\right)$ were also determined for various salts and urea. The $I_{50}$ was identified along a $0-4.5 \mathrm{M}$ range for $\mathrm{NaCl}$, a $0-2.25 \mathrm{M}$ range for $\mathrm{KCl}$, and a $0-7.5 \mathrm{M}$ range of urea. The effect of adenosine triphosphate (ATP), prepared as a stock solution of $20 \mathrm{mM}$ $\mathrm{ATP} \cdot \mathrm{Mg}$, and adenosine diphosphate (ADP) on the kinetic activity of G6PDH was similarly assessed.

To investigate the effect of polyethylene glycol (PEG), a hydrophilic compound that can be used to mimic molecular crowding of a dehydrating cell, on G6PDH substrate affinity, the $\mathrm{K}_{\mathrm{m}}$ of G6PDH for $\mathrm{NADP}^{+}$was reassessed with an in-well concentration of $1 \%$ PEG. The effect of $55 \mathrm{mM}$ urea or $1 \%$ PEG on substrate affinity was analysed relative to the $\mathrm{K}_{\mathrm{m}}$ of G6PDH for $\mathrm{NADP}^{+}$obtained from the optimized assay conditions indicated previously.

\subsubsection{Purification of G6PDH from liver of control and dehydrated frogs}

Purification of G6PDH from the liver of $X$. laevis involved polyethylene glycol (PEG) precipitation followed by the application of two functionally distinct chromatography columns. A stock 50\% PEG solution (average $\mathrm{MW}=8000 \mathrm{~g} / \mathrm{mol}$ ) prepared in buffer A was added to the supernatant obtained following centrifugation until an overall 10\% PEG solution was attained crude supernatant obtained following centrifugation was mixed with $12.5 \% \mathrm{w}: \mathrm{v}$ PEG and subjected to rotation for 30 minutes. Following this, the enzyme/PEG mixture was centrifuged at 10,000 RPM for 30 minutes. G6PDH was precipitated in the pellet. The supernatant was discarded, and the pellet was re-suspended in $2 \mathrm{~mL}$ of buffer A and applied to a $3 \times 1 \mathrm{~cm}$ Cibacron Blue 3GA (Sigma

Chemical Co) chromatography column equilibrated in buffer A. The dye-ligand affinity column was washed with $60 \mathrm{~mL}$ of buffer $\mathrm{A}$ and a Gilson Micro-Fractionator fraction 
collector was used to collect 200-drop fractions of the eluate into fresh test tubes. The bound protein was then eluted with a gradient of $0-1 \mathrm{M} \mathrm{KCl}$ dissolved in buffer $\mathrm{A}$ followed by a $1 \mathrm{M} \mathrm{KCl}$ bump and collected in 50-drop fractions. Activity was measured in each fraction and fractions with significant activity were pooled. The pooled sample was then desalted and concentrated with an Amicon Ultra-4 centrifugal filter unit. The concentrated sample was then applied to a $48 \times 1 \mathrm{~cm}$ Sephadex G-50 size-exclusion chromatography column that was previously equilibrated in buffer A. The column was washed with $200 \mathrm{~mL}$ of buffer A and 30-drop fractions of the eluate were collected in fresh test tubes. The protein was eluted early during the wash step. The fractions with significant G6PDH activity were determined and pooled. The pooled sample was applied to a $1 \times 2.5 \mathrm{~cm}$ hydroxyapatite column equilibrated in buffer A. The bound protein was eluted with a $1.5 \mathrm{M} \mathrm{KCl}$ gradient followed by a $1.5 \mathrm{M} \mathrm{KCl}$ bump. The fractions were assayed for G6PDH activity and peak fractions were pooled. The pooled sample was then applied to an Amicon Ultra-4 centrifugal filter unit with a 10,000 kDa nominal molecular weight limit (NMWL) and centrifuged for 10 minutes at 7500 RPM in order to concentrate the enzyme prior to kinetic analysis.

\subsubsection{Protein concentration determination}

The protein concentrations of the collected G6PDH-containing pooled samples were measured as described in section 2.2.5. of Chapter 2 .

\subsubsection{Visual assessment of G6PDH purification scheme}

To ensure that $X$. laevis liver G6PDH was purified to homogeneity, the samples were analyzed via SDS-polyacrylamide gel electrophoresis (PAGE). The crude homogenate and desalted pooled samples obtained following Cibacron blue and 
hydroxyapatite fractionation were mixed 1:1, 2:1, and 4:1, respectively, with 2X SDS loading buffer supplemented with $10 \% \mathrm{v}: \mathrm{v} \beta$-mercaptoethanol. The samples were boiled for 10 minutes and then stored at $-20^{\circ} \mathrm{C}$. The control and dehydrated samples were run on separate $10 \%$ polyacrylamide gels with a GeneDirex $10.5-175 \mathrm{kDa}$ protein ladder and a purified G6PDH sample prepared in the same manner (Sigma-Aldrich, cat. \#G8404). Protein samples were run on gels for 60 minutes at $180 \mathrm{~V}$ in running buffer. Gels were subsequently stained using silver nitrate and visualized on the ChemiGenius Bioimaging System (Syngene, Frederick, MD) (Gromova and Celis, 2006).

\subsubsection{Western Blots for Post-Translational Modifications}

Relative levels of several PTMs were assessed for liver G6PDH from control versus dehydrated $X$. laevis using Western blotting techniques, as described in Chapter 2 with minor modifications. Semi-purified samples obtained after the Sephadex G-50 step of the purification scheme were mixed 2:1 v:v with SDS loading buffer and boiled for 10 minutes. The semi-pure preparations of both control and dehydrated G6PDH were confirmed to have sufficient protein band separation on an $8 \%$ polyacrylamide gel to allow accurate PTM analysis. The samples were loaded onto an $8 \%$ gel and run for 55 minutes at $180 \mathrm{~V}$. Proteins were then transferred to a PVDF membrane at $160 \mathrm{~mA}$ for 130 minutes. Following transfer, membranes were blocked with $1 \%$ w:v skim milk powder dissolved in TBST for 30 minutes to prevent non-specific antibody binding to the membrane. Analysis of G6PDH PTMs were carried out as described for GR in Chapter 2 with an additional PTM tested using rabbit polyclonal anti-malonyl lysine (PTM biolabs, cat. \#PTM-901). All primary antibodies were diluted 1:1000 v:v in TBST. Unbound primary antibody was removed with three 5 minute washes with TBST and the 
membrane was incubated with HRP-conjugated anti-rabbit or anti-mouse secondary antibody (BioShop, diluted 1:4000 v:v in TBST) for 40 minutes at room temperature. Unbound secondary antibody was removed with three 5-minute washes with TBST. Immunoreactive bands were visualized by enhanced chemiluminescence and visualized on the ChemiGenius Bioimaging System (Syngene, Frederick, MD). Quantification of the luminescent protein band intensities used GeneTools software. Luminescent protein band intensity was standardized to corresponding protein concentration of the Coomassie blue stained PVDF membrane, as described in Chapter 2 (section 2.2.7). PTM levels of G6PDH from liver of dehydrated frogs was expressed relative to the corresponding PTM levels in control frogs.

\subsubsection{Protein Expression levels via Western Blotting}

Total protein levels of G6PDH was assessed in control and dehydrated crude homogenates of $X$. laevis liver essentially as described in section 2.2.8. with minor modifications. Equal amounts of protein from control and dehydrated samples were applied to a $12 \%$ polyacrylamide gel and run at $180 \mathrm{~V}$ for 120 minutes. The gel was transferred to a PVDF membrane via electroblotting for 130 minutes at $160 \mathrm{~mA}$. Following transfer, the membrane was blocked for 30 minutes with $5 \% \mathrm{w}: \mathrm{v}$ milk in $1 \mathrm{x}$ TBST and then washed three times for 5 minutes with 1x TBST. The primary antibody for this analysis, rabbit polyclonal anti-glucose-6-phosphate dehydrogenase (Genetex, cat. \#GTX101218), was prepared as a 1:1000 dilution in TBST. Quantification of protein expression levels differed from the methodology described in section 2.2.7. in that the immunoblot band density in each lane was standardized against the summed intensity of a group of Coomassie-stained protein bands in the same lane rather than the against the 
target protein band. Protein expression of G6PDH in liver of dehydrated frogs was also analyzed relative to the corresponding expression level in control frogs.

\subsubsection{In vitro incubation to stimulate endogenous protein kinases}

In order to correlate protein phosphorylation state to changes in kinetic activity, endogenous protein kinases were stimulated in both control and dehydrated X. laevis liver homogenates and the altered kinetic parameter was revisited. The crude homogenates, previously prepared in STOP buffer (Buffer A), were filtered through a Sephadex G-25 spun column equilibrated in OPEN buffer $(20 \mathrm{mM}$ Tris $\mathrm{pH} 7.6,10 \%$ v:v glycerol, 15 $\mathrm{mM} \beta$-mercaptoethanol). Aliquots of the filtered homogenate were mixed 3:1 v:v with a concentrated stock solution of specific inhibitors and stimulators of protein kinases and phosphatases prepared in OPEN buffer, as follows:

Control "Stop" conditions: $1 \mathrm{mM}$ EGTA, $1 \mathrm{mM}$ EDTA, and $15 \mathrm{mM} \beta-$ glycerophosphate to inhibit all protein phosphatase and kinase activities.

Stimulation of endogenous protein kinase activities: $5 \mathrm{mM}$ Mg-ATP, 30 $\mathrm{mM} \beta$-glycerophosphate, and one of the following:

1) $1 \mathrm{mM}$ cAMP, to stimulate protein kinase $\mathrm{A}$ (PKA);

2) $1 \mathrm{mM}$ AMP to stimulate 5' AMP-activated protein kinase (AMPK);

3) $1 \mathrm{U}$ of calmodulin activity/incubation tube $+1.3 \mathrm{mM} \mathrm{CaCl}_{2}$ to stimulate $\mathrm{Ca}^{2+} /$ calmodulin-dependent protein kinase (CAMK).

4) All of the above in order to stimulate Total protein kinases (Total PK) 


\subsubsection{Statistical Analyses}

The statistical analysis of data was performed as described in section 2.2.11. of Chapter 2.

\subsection{Results}

\subsubsection{Purification of G6PDH from the liver of control and dehydrated frogs}

The purification of G6PDH from liver was achieved through the application of PEG precipitation followed by three distinct chromatography columns. This procedure involved precipitating highly solvated proteins through centrifugation following incubation of the crude homogenate with the hydrophilic compound PEG. This first step retained $72.0 \%$ total G6PDH activity and only $61.8 \%$ total protein from the crude resulting in an increased specific activity of $46.0 \mathrm{mg} / \mathrm{mL}$ and a 1.17 -fold purification (Table 3.1). The second step used dye-ligand affinity chromatography with a Cibacron Blue column, eluting G6PDH using a 0-1 M KCl gradient (Fig. 3.1A). G6PDH from liver of both control and dehydrated $X$. laevis was eluted from this column at approximately $450 \mathrm{mM} \mathrm{KCl}$ (Fig. 3.1A). This step lead to a 1.56 -fold purification, a specific activity $61.5 \mathrm{mU} / \mathrm{mg}$, and the retention of $67.9 \%$ total G6PDH activity. The third step of this purification scheme involved the application of pooled enzyme activity to a Sephadex G50 size-exclusion chromatography column (Fig. 3.1B). This column resulted in a 1.70fold purification, a specific activity of $66.9 \mathrm{mU} / \mathrm{mg}$, and the retention of $8.1 \%$ total G6PDH activity (Table 3.1). The final step involved the application of pooled enzyme activity to a hydroxyapatite column, eluting $\mathrm{G} 6 \mathrm{PDH}$ at $1.2 \mathrm{M} \mathrm{KCl}$ using a $0-2 \mathrm{M} \mathrm{KCl}$ gradient for both control and dehydrated sample preparations (Fig. 3.1C). Control frog liver G6PDH was purified 3.07-fold with a final specific activity of $121 \mathrm{mU} / \mathrm{mg}$ and the 
retention of $0.3 \%$ total G6PDH activity (Table 3.1). In the dehydrated liver tissue, the purification scheme gave a final fold purification of 2.99 , a specific activity of 109.0 $\mathrm{mU} / \mathrm{mg}$, and a yield of $0.2 \%$ total G6PDH activity.

\subsubsection{Quality assessment of G6PDH purification}

In order to assess the purity of G6PDH obtained from the purification scheme, a sample of each pooled elution was applied to a $10 \%$ polyacrylamide gel and stained using the silver nitrate protocol. As shown in Fig. 3.2, each chromatography column facilitated G6PDH purification by reducing the number of contaminating protein bands. Using Expasy, a bioinformatic resource portal, the expected subunit molecular weight of G6PDH in $X$. laevis was calculated to be $\sim 59.7 \mathrm{kDa}$ based on the protein sequence obtained from the NCBI database (NP_001080019.1). From this knowledge, it was confirmed that G6PDH was purified to near homogeneity as there is a large abundant protein band located at the corresponding molecular weight of $\sim 60 \mathrm{kDa}$ (Fig. 3.2). The identity of this protein band was validated through Western blot techniques using a polyclonal anti-G6PDH antibody (Fig. 3.3).

\subsubsection{Kinetic characterization of G6PDH}

A number of kinetic parameters were analysed to determine if there was a change in G6PDH properties upon dehydration stress in $X$. laevis liver (Table 3.2). A functionally purified sample of G6PDH obtained following the Sephadex G-50 chromatography column elution was used for kinetic analysis of the target enzyme. Under normal assay conditions with saturating $\mathrm{NADP}^{+}$, there was a significant change in $\mathrm{K}_{\mathrm{m}} \mathrm{G} 6 \mathrm{P}$ between $\mathrm{G} 6 \mathrm{PDH}$ from control versus dehydrated frog liver $(0.33 \pm 0.04 \mathrm{mM}$ and $0.60 \pm 0.10 \mathrm{mM}$, respectively). When exposed to $55 \mathrm{mM}$ urea, a concentration that is 
physiologically relevant to dehydrated $X$. laevis, the $\mathrm{K}_{\mathrm{m}} \mathrm{G6P}$ in the presence of urea did not change significantly compared to the enzyme without urea nor did the $\mathrm{K}_{\mathrm{m}} \mathrm{G6P}$ values differ between control and dehydrated conditions with urea present $(0.50 \pm 0.06 \mathrm{mM}$ vs $0.39 \pm 0.06 \mathrm{mM} \mathrm{G6P}$, respectively) (Table 3.2).

In the presence of saturating G6P, the $\mathrm{K}_{\mathrm{m}} \mathrm{NADP}^{+}$of $\mathrm{G} 6 \mathrm{PDH}$ was significantly reduced for the dehydrated enzyme compared with the control, values being $0.64 \pm 0.04$ $\mathrm{mM}$ in control and $0.43 \pm 0.06 \mathrm{mM}$ for the dehydrated form (Table 3.2). Exposure to 55 $\mathrm{mM}$ urea added to the assay resulted in a significant decrease in $\mathrm{K}_{\mathrm{m}} \mathrm{NADP}^{+}$of the control enzyme from $0.64 \pm 0.04 \mathrm{mM}$ to $0.36 \pm 0.07 \mathrm{mM}$ whereas the enzyme from dehydrated frogs show a significant increase in $\mathrm{K}_{\mathrm{m}} \mathrm{NADP}^{+}$from $0.43 \pm 0.06 \mathrm{mM}$ to $0.69 \pm 0.02 \mathrm{mM}$. The $\mathrm{K}_{\mathrm{m}} \mathrm{NADP}^{+}$in the presence of urea was also significantly higher (by 1.9-fold) than the control value, $p<0.05$.

These changes in kinetics upon the addition of $55 \mathrm{mM}$ urea might be attributed to molecular crowding such as could occur inside cells during dehydration or to a molecular interaction between the osmolyte and G6PDH. PEG is a hydrophilic compound that is often used to mimic the molecular crowding that occurs a dehydrating cell. G6PDH purified from control and dehydrated frog liver was exposed to $1 \%$ PEG and then $\mathrm{K}_{\mathrm{m}}$ $\mathrm{NADP}^{+}$was measured to assess whether PEG could affect a kinetic parameter. Fig. 3.4 shows the relative changes in $\mathrm{K}_{\mathrm{m}} \mathrm{NADP}^{+}$after brief exposure to $1 \% \mathrm{PEG}$ or $55 \mathrm{mM}$ urea in comparison to control values adjusted to 1.0. This incubation had no significant change in $\mathrm{K}_{\mathrm{m}} \mathrm{NADP}^{+}$in comparison to the control.

In control frog liver, ATP was found to have an activating effect on G6PDH with a $\mathrm{K}_{\mathrm{a}}$ value of $5.1 \pm 0.3 \mathrm{mM}$ and fold activation of 1.36 (Table 3.2). However, the enzyme 
from dehydrated frog liver was activated at a much lower ATP level with half-maximal activation $\left(\mathrm{K}_{\mathrm{a}}\right)$ occurring at just $0.67 \pm 0.1 \mathrm{mM}$ but with a lower overall fold activation of just 1.19. By contrast, ADP was an inhibitor of the enzyme, reducing G6PDH activity by $50 \%$ in control tissue at $19.4 \pm 0.5 \mathrm{mM}$ ADP and in dehydrated tissue at $16.3 \pm 0.9 \mathrm{mM}$ ADP.

The activity of G6PDH functionally purified from control and dehydrated frog liver was monitored following the addition of increasing salt concentrations to determine $\mathrm{I}_{50}$ values as shown in Table 3.3. A similar concentration of $\mathrm{NaCl}$ was required to deplete liver G6PDH activity by $50 \%$ in control $(1.34 \pm 0.04 \mathrm{M})$ and dehydrated $(1.35 \pm 0.01 \mathrm{M})$ frogs. Similarly, the concentration of $\mathrm{KCl}$ required to inhibit G6PDH activity by $50 \%$ in control and dehydrated liver tissue was comparable, being $1.2 \pm 0.6 \mathrm{M}$ and $1.7 \pm 0.1 \mathrm{M}$, respectively. However, a significantly greater concentration of urea was required to deplete G6PDH activity by $50 \%$ for the enzyme from dehydrated $(7.1 \pm 0.5 \mathrm{M})$ versus control $(4.46 \pm 0.09 \mathrm{M})$ frogs.

\subsubsection{Post-translational modification of G6PDH}

Western blotting was used to assess and quantify PTM variations between control and dehydrated liver G6PDH. Figure 3.5 shows relative changes in the phosphorylation of serine, threonine or tyrosine residues on the enzyme between control and dehydrated liver G6PDH. Only serine phosphorylation changed between the two states with a $21.8 \%$ decrease in PTM intensity for dehydrated G6PDH relative to control. A variety of other PTMs were also investigated (Fig. 3.6). Immunoblotting revealed a significant change in acetylation (0.57-fold), lysine-methylation (0.32-fold), arginine-methylation (0.56-fold), 
lysine-malonylation (0.37-fold), ubiquitination (1.60-fold), and sumoylation $2 / 3$ (1.60fold) for G6PDH from dehydrated liver in comparison to the control enzyme (Fig. 3.6).

\subsubsection{In vitro incubation to stimulate endogenous protein kinases}

Changes in G6PDH phosphorylation in response to dehydration (Fig. 3.5) indicated that the enzyme was modified by dephosphorylation. To determine if the change in G6PDH substrate affinity (observed in section 3.3.4) between control and dehydrated frogs was attributable to reversible phosphorylation of the protein, crude liver extracts were incubated with activators of specific endogenous protein kinases, and then the $\mathrm{K}_{\mathrm{m}} \mathrm{NADP}^{+}$in the presence of $55 \mathrm{mM}$ urea was revisited (Fig. 3.7). In vitro incubations (described in section 3.2.9) set up a series of conditions that allowed individual kinase types to be active as well as conditions that both fully inhibited (STOP condition) or fully facilitated (Total PK) all endogenous protein kinases. The $\mathrm{K}_{\mathrm{m}}$ for $\mathrm{NADP}+$ in the presence of $55 \mathrm{mM}$ urea was chosen as the kinetic parameter to assess given its large change between control and dehydrated states (Table 3.2). The results obtained provide insight regarding the correlation between the phosphorylation state of G6PDH and its substrate affinity. In extracts of dehydrated frog liver, the $\mathrm{K}_{\mathrm{m}} \mathrm{NADP}^{+}$was strongly reduced by treatment with protein kinases relative to G6PDH in STOP buffer that contained inhibitors of both protein kinases and phosphatases. Compared to values for extracts of dehydrated tissue in STOP buffer $\left(\mathrm{K}_{\mathrm{m}}=0.37 \mathrm{mM}\right)$, relative values for $\mathrm{K}_{\mathrm{m}}$ fell to $0.08 \mathrm{mM}$ when incubated under conditions that facilitated all protein kinases (Total PK), to $0.15 \mathrm{mM}$ when protein kinae A (PKA) was stimulated, to $0.17 \mathrm{mM}$ when calcium-calmodulin protein kinase (CAMK) was stimulated, and to $0.05 \mathrm{mM}$ under conditions that promoted the AMP-activated protein kinase (AMPK) (Fig. 3.7). In the 
control liver homogenate, the $\mathrm{K}_{\mathrm{m}} \mathrm{NADP}^{+}$in STOP buffer $\left(\mathrm{K}_{\mathrm{m}}=0.13 \mathrm{mM}\right)$ was increased to $0.18 \mathrm{mM}$ via stimulation of total $\mathrm{PK}$ and to $0.15 \mathrm{mM}$ via stimulation of PKA. However, stimulation of AMPK in control liver homogenate generated a significant decrease in the $\mathrm{K}_{\mathrm{m}}$ of G6PDH for $\mathrm{NADP}^{+}$from $0.13 \mathrm{mM}$ to $0.07 \mathrm{mM}$ (Fig. 3.7).

\subsubsection{Protein Expression level of G6PDH}

Immunoblotting allowed for the determination of total protein expression levels of G6PDH in liver extracts from control and dehydrated $X$. laevis. Figure 3.8 shows that G6PDH protein levels did not change significantly in response to dehydration stress.

\subsection{Discussion}

The continuous availability of NADPH is very important in the dehydrating African clawed frog, serving as a reducing equivalent for biosynthetic pathways, antioxidant defenses, and xenobiotic detoxification. Upon whole-animal dehydration, there is a novel source of ROS generated due to an indirect HIF-1-mediated compromise of the ETC that requires rapid neutralization to prevent significant oxidative damage. GPx and GST represent glutathione-based AOEs that are known to be upregulated in $X$. laevis and R. sylvatica liver, respectively, and require high cellular levels of GSH for antioxidant function. In order to regenerate GSH, GR relies on the continuous availability of NADPH. The first catalytic step of the PPP provides one of the main sources of NADPH to sustain GR activity. Results of this study reveal that the dehydrated form of G6PDH exhibits notable differences in kinetic properties compared to the control form. Western blot analysis and incubation of the crude extracts with stimulators of protein kinases revealed that reversible protein phosphorylation is a likely mechanism responsible for these observed changes in the kinetic properties of G6PDH. 


\subsubsection{Kinetic changes of G6PDH during dehydration}

The kinetic properties of $X$. laevis G6PDH were significantly different between the control and dehydrated conditions, suggesting that the enzyme is being regulated during aestivation (Table 3.2). The affinity of G6PDH for G6P substrate decreased substantially in response to dehydration, with $\mathrm{K}_{\mathrm{m}} \mathrm{G} 6 \mathrm{P}$ increasing from $0.33 \pm 0.04 \mathrm{mM}$ to $0.6 \pm 0.1 \mathrm{mM}$ G6P. The addition of molecules that are known to accumulate as a mechanistic response to adverse environmental conditions may generate a significant change in an enzyme's kinetic properties and demonstrate an influence of physiological adaptations to environmental stress on enzyme regulation. For instance, in X. laevis, physiological urea levels stimulated an increase in GR affinity for GSSG that could result in an enhanced propensity to regenerate GSH equivalents for glutathione-based antioxidant defense (see Chapter 2). Physiological urea was likewise found to stimulate an increase in LDH affinity for pyruvate that allowed for unimpeded glycolytic ATP fermentation during whole-animal dehydration by regenerating $\mathrm{NAD}^{+}$(Katzenback et al., 2014). However, in this study, substrate affinity of G6PDH for G6P following the addition of $55 \mathrm{mM}$ urea remained constant.

Accordingly, previous studies have demonstrated that G6PDH is differentially regulated in response to environmental stress. Ramnanan and Storey (2006) found increased substrate affinity for G6P in G6PDH of the aestivating 0 . lactea. This finding along with a decreased substrate affinity for F6P by the key glycolytic regulatory enzyme phosphofructokinase (PFK) during aestivation indicated that G6P may be preferentially directed to the PPP for NADPH generation at this time (Whitman and Storey, 1991). In comparison to $X$. laevis, $O$. lactea experiences a similar enhanced reliance on glycolytic 
ATP fermentation due to stimulation by hypoxic sensor HIF-1. In contrast, the snail is hypometabolic during aestivation (Barnhart and McMahon, 1988) and consequently has a lower demand for ATP. Metabolic rate depression may allow the snail to maintain an elevated NADPH:NADP ${ }^{+}$ratio through G6PDH activity without suffering adverse metabolic consequences due to inadequate ATP production. Therefore, the nonhypometabolic dehydrated frog could potentially prioritize ATP fermentation for its energy-demanding cells over the synthesis of NADPH via the PPP (possibly leading to recruiting the involvement of other NAPDH-producing enzymes to support GR). A similar increase in G6PDH substrate affinity for G6P was also found in the hepatopancreas of anoxia-tolerant $L$. littorea and $O$. virilis, both of which rely on hypometabolism for survival (Lama et al., 2013; Lant and Storey, 2011; Larade and Storey, 2002). In contrast, liver G6PDH from frozen $R$. sylvatica showed a lower substrate affinity for this glycolytic intermediate with no recovery of G6P affinity following the addition of $250 \mathrm{mM}$ glucose (Dieni and Storey, 2010). The differential regulation of G6PDH in response to freeze-stress is rational because $R$. sylvatica uses glucose derived from G6P via glucose-6-phosphatase as a cryoprotectant during freezing, explaining the preferential redirection of G6P to glucose synthesis (Dieni and Storey, 2010). The increased total activity of glucose-6-phosphatase as well as decreased $V_{\max }$ and substrate affinity of hexokinase for glucose supports the enhanced G6P flux towards generating glucose (Storey and Storey, 1984; Dieni and Storey, 2011). Therefore, the lower substrate affinity of G6PDH for G6P in the freeze-tolerant wood frog can be considered physiologically important for this model organism as it allows G6P to be preferentially directed towards cryoprotectant synthesis. 
Since the rate of oxygen consumption was found to be unchanged between control and dehydrated X. laevis, this frog is considered to be a non-hypometabolic model organism (Hillman, 1978). Without metabolic suppression, the frog is obligated to meet the normal energy requirements for basal metabolism. Due to a HIF-1-mediated dysregulation of the TCA cycle, ATP production through oxidative phosphorylation is limited and therefore, the dehydrated frog could have a significant dependency on fermentative ATP generation via anaerobic glycolysis (Kim et al., 2006). As such, it is possible that in $X$. laevis, G6P is being preferentially redirected to drive glycolysis for fermentative production of ATP in order to generate sufficient energy to meet the metabolic demands of the non-hypometabolic, dehydrated frog as opposed to redirecting G6P to PPP for NADPH regeneration. Assuming that this glycolytic G6P flux is not tissue-specific in the frog, augmented glycolytic activity is supported by the increased hexokinase maximum velocity in muscle tissue and increased affinity for pyruvate by LDH in liver tissue ultimately driving the increased generation of lactate under high urea levels associated with whole-animal dehydration (Childers and Storey, 2016; Katzenback et al., 2014).

Under standard conditions, liver G6PDH from dehydrated frogs had a significantly greater affinity for the cofactor $\mathrm{NADP}^{+}$than control G6PDH $\left(\mathrm{K}_{\mathrm{m}}=0.43 \pm 0.06 \mathrm{mM}\right.$ vs $0.64 \pm 0.04 \mathrm{mM} \mathrm{NADP}{ }^{+}$) (Table 3.2). To properly elucidate the physiological implications of the present findings, kinetic experiments were performed in the presence of physiological concentrations of urea $(55 \mathrm{mM})$ found in the liver of dehydrating $X$. laevis. Exposure to physiological urea levels, reduced the control enzyme's $\mathrm{K}_{\mathrm{m}} \mathrm{NADP}^{+}$ towards that found for the dehydrated G6PDH without the addition of urea (Table 3.2). 
Similarly, exposure to $55 \mathrm{mM}$ urea increased the $\mathrm{K}_{\mathrm{m}} \mathrm{NADP}^{+}$for dehydrated G6PDH towards that found for the control enzyme without urea. Since physiological levels of this cofactor are quite low, e.g. $\sim 0.019 \mathrm{mM} \mathrm{NADP}{ }^{+}$as measured in Caudiverbera caudiverbera (Preller et al., 1999), these changes in $\mathrm{K}_{\mathrm{m}} \mathrm{NADP}^{+}$could have significant impact on G6PDH regulation in response to dehydration.

The addition of increasing concentrations of adenylates (ATP and ADP) provides additional insight regarding the regulation of G6PDH in the dehydrating frog (Table 3.2). ATP served as an activator of enzyme activity, increasing control G6PDH activity by $50 \%$ at $5.1 \mathrm{mM}$ ATP $\left(\mathrm{K}_{\mathrm{a}}=5.1 \pm 0.3 \mathrm{mM}\right)$ and increasing dehydrated G6PDH activity by $50 \%$ with only $0.67 \mathrm{mM} \mathrm{ATP}\left(\mathrm{K}_{\mathrm{a}}=0.67 \pm 0.1 \mathrm{mM}\right)$. Liver ATP concentrations in other frog species are in the 1.3-1.9 mM range for control animals (Storey, 1987; Churchill and Storey, 1996). Hence, for the dehydrated frog, in particular, G6PDH should be substantially activated by physiological concentrations of ATP which should be significantly higher in vivo than the $\mathrm{K}_{\mathrm{a}}$ value measured in this study (Table 3.2). ADP served as an inhibitor of G6PDH, reducing the control enzyme's activity by $50 \%$ at 19.4 $\pm 0.5 \mathrm{mM}$ ADP and the dehydrated enzyme at $16.3 \pm 0.9 \mathrm{mM}$ ADP. However, in vivo concentrations of ADP in liver are 50-100-fold lower than these values, and so, ADP effects would have little or no physiological value to G6PDH control.

The data from the analysis of G6PDH kinetic properties strongly suggests that the enzyme is negatively regulated during environmental dehydration. This suggests that during whole body dehydration, the frog appears to preferentially redirect G6P towards glycolysis than the PPP to provide the cellular energy required for this nonhypometabolic amphibian. However, when ATP levels are elevated during dehydration 
stress, G6PDH activity increases which would allow for augmented NADPH biosynthesis via PPP.

\subsubsection{Sensitivity of G6PDH to salts, urea, and molecular crowding}

The half maximal inhibitor $\left(\mathrm{I}_{50}\right)$ concentration for various salts and urea were also determined for G6PDH purified from control and dehydrated frog liver to assess the relative susceptibility of the enzyme to denaturation. This enzyme was not differentially affected by physiological salts including $\mathrm{NaCl}$ and $\mathrm{KCl}$ in response to dehydration stress. That is, the $I_{50}$ for these salts remained constant (Table 3.3). However, the enzyme from dehydrated frogs was less sensitive to urea in comparison to the control enzyme ( $\mathrm{I}_{50}$ urea $=7.1 \pm 0.5 \mathrm{M}$ vs $4.46 \pm 0.09 \mathrm{M})$. This result suggests that the dehydrated form may be modified with PTMs to ensure that activity is maintained under high urea conditions which is important for dehydrating frogs. An increased stability of G6PDH during dehydration would allow $X$. laevis to continue producing energy through substrate level phosphorylation and maintain an osmotic gradient through urea biosynthesis.

To ensure that the effects of urea on G6PDH from the liver of dehydrated $X$. laevis were not simply due to a protein-crowding effect of increased osmolytes, a $1 \%$ PEG solution was employed as a control (Fig. 3.4). The addition of PEG to mimic the molecular crowding experienced by a dehydrating frog exerted no effect on G6PDH substrate affinity for $\mathrm{NADP}^{+}$. This insinuates that the effect of urea on dehydrated G6PDH function is unique and not due to protein crowding. When proteins are exposed to urea, the osmolyte displaces water molecules from the protein's solvation layer and directly binds to amide residues (Zou et al., 1998). At low urea concentrations, the protein's solvation shell will be reduced forcing the proteins to aggregate which 
simulates molecular crowding of a dehydrated cell. At elevated urea concentrations, the osmolyte is found to reduce the protein's hydrophobic effect and result in protein denaturation (Zou et al., 1998). It may be likely that urea is displacing water molecules from the solvation shell around G6PDH and inducing a direct conformational change in the $\mathrm{NADP}^{+}$binding site of G6PDH.

\subsubsection{Reversible protein phosphorylation of G6PDH}

The kinetic differences observed in this study indicated that there may be distinct structural differences between the control and dehydrated forms of G6PDH which may be regulated through differential enzyme modification, including post-translational modifications, including phosphorylation. Western blot analysis identified a $21.8 \%$ decrease in serine-phosphorylation of G6PDH in response to dehydration (Fig. 3.5) which corresponded with a decrease in substrate affinity for $\mathrm{NADP}^{+}$(in the presence of physiological urea) (Table 3.2). Incubation of crude extracts from liver of dehydrated frogs with stimulators of several types of protein kinases resulted in a significant increase in $\mathrm{NADP}^{+}$substrate affinity from the no-kinase control, as shown by decreased $\mathrm{K}_{\mathrm{m}}$ values. The $\mathrm{K}_{\mathrm{m}}$ decreased from $0.37 \mathrm{mM} \mathrm{NADP}{ }^{+}$for controls to $0.08 \mathrm{mM}, 0.15 \mathrm{mM}$, $0.17 \mathrm{mM}$, or $0.05 \mathrm{mM}$ following stimulation of total protein kinases, PKA, CAMK, or AMPK, respectively (Fig. 3.7). However, incubation of control crude extracts with stimulators of CAMK and AMPK had no significant effect on $\mathrm{NADP}^{+}$substrate affinity compared with the no-kinase control $\left(\mathrm{K}_{\mathrm{m}}=0.13 \mathrm{mM}\right)$, whereas the stimulation of Total PK and PKA resulted in a significant increase in $\mathrm{K}_{\mathrm{m}}(0.18 \mathrm{mM}$ and $0.15 \mathrm{mM}$, respectively). The results show a strong correlation between G6PDH phosphorylation state and its substrate affinity for $\mathrm{NADP}^{+}$: as protein phosphorylation is increased, there 
is an increase in affinity (in the presence of $55 \mathrm{mM}$ urea) in response to dehydration stress.

\subsubsection{Other post-translational modifications of G6PDH}

Although reversible protein phosphorylation serves as a convenient and energyefficient mechanism for protein regulation, there are many other PTMs that could be involved in modifying kinetic properties, subcellular localization, and stability of enzymes. Several other PTMs were investigated for their potential effects on G6PDH. Western blot analysis indicated a significant reduction in pan-acetylation, lysinemethylation, arginine-methylation and lysine-malonylation to $57,32,56$, and $37 \%$ of the control value, respectively, whereas ubiquitination and sumoylation-2/3 content each increased by 1.60 -fold in response to dehydration stress (Figure 3.6). This study represents the first time in which the majority of the aforementioned PTMs have been examined for G6PDH and so, the exact consequences of these PTMs for G6PDH activity and/or stability has yet to be investigated.

The decrease in acetylation of G6PDH in response to dehydration is rather interesting. HEK293 cell cultures studies identified Lys403 of human G6PDH to be the key amino acid that allows dimerization of the polypeptide structure to form an active dehydrogenase enzyme. Acetylation at this site inhibits dimer formation, leaving the polypeptide as inactive, monomeric subunits (Wang et al., 2004). Deacetylation at this lysine-residue is mediated by Sirt2 deacetylase in both human cells and X. laevis. In X. laevis liver tissue, sirt $2 \mathrm{mRNA}$ levels were unchanged during dehydration, but global Sirt activity, which includes sirtuin protein homologs 1-7, increased in response to dehydration (Luu, B.E., personal communication). Further experimentation is required to 
specifically investigate sirt2 activity levels in response to dehydration in the liver of $X$. laevis.

This study is the first time that lysine-methylation, arginine-methylation, ubiquitination, and sumoylation- $2 / 3$ has been investigated for G6PDH. Therefore, the regulatory consequences of these PTMs are purely inferences from current literature and require further experimentation to elucidate their mechanism of control for this $X$. laevis G6PDH. Most studies regarding lysine-methylation investigate the regulatory role of this PTM for histone-mediated control of gene expression. However, recent literature found evidence of methylation-phosphorylation crosstalk for non-histone targets where protein methylation sites may regulate further post-translational modifications including phosphorylation (Biggar and $\mathrm{Li}, 2015$ ). The unanimous decrease in phosphorylation state and methylation state of $X$. laevis G6PDH in response to dehydration suggests that crosstalk may be involved in coordinating this PTM-mediated enzymatic regulation. However, Lys-methylation crosstalk is not limited to the regulation of protein phosphorylation but can also be seen to promote or repress arginine-methylation and ubiquitination as well. Although the physiological value of a reduced methyl-arginine protein content is currently unknown for this rate-limiting PPP enzyme, arginine-demethylation is a common activation feature for transcription factors including forkhead box O1 (FoxO1) and CREB regulated transcription coactivators 2 (CRTC2) (Han et al., 2016). Proteinubiquitination is commonly linked to protein degradation signal cascades but also serves a role in subcellular localization and regulating enzyme kinetics. Further experimentation is required to establish the exact function of ubiquitination for G6PDH regulation. Protein modification via sumoylation often generates enhanced protein stability and changes in 
subcellular localization (Klenk et al., 2005; Yang et al., 2012). During periods of torpor in hibernating 13-lined ground squirrels (I. tridecemlineatus), both sumo-1 and sumo-2/3 protein conjugates are known to increase reflecting the importance of sumoylated proteins in response to environmental stress (Lee et al., 2007). There is ubiquitous expression of free, unconjugated sumo-2/3 in the cell. However, when cells were exposed to heat stress, oxidative stress, chemical stress (ethanol), or osmotic stress, there is a reduction in free sumo- $2 / 3$ and corresponding increase in conjugated sumo- $2 / 3$ proteins (Saitoh and Hinchey, 2000). The increased conjugation of sumo-2/3 to G6PDH from dehydrated frogs may provide enhanced protein stability during dehydration stress.

\subsubsection{HIF-1 and G6PDH protein expression}

HIF-1 is selectively overexpressed during dehydration stress and is expected to activate the expression of G6PDH, since one of the targets for this transcription factor is g6pd (Kim et al., 2006; Kiani et al., 2007). However, in this investigation, X. laevis at $35 \%$ dehydration does not appear to have a change in G6PDH protein expression. As a result, the protein does not appear to be regulated at the transcriptional level.

\subsubsection{Conclusion}

In this study, dehydrated G6PDH was found to have a decreased affinity for the major G6P substrate and a significant increase in affinity for $\mathrm{NADP}^{+}$co-substrate. Exposure to physiological urea levels had opposite effects on control versus dehydrated G6PDH, with a decrease in the dehydrated enzyme's affinity for NADP ${ }^{+}$and an increase in control enzyme's $\mathrm{NADP}^{+}$affinity. The results from this study suggest a reversible protein phosphorylation-mediated regulation of G6PDH, promoting enhanced substrate affinity for $\mathrm{NADP}^{+}$in the presence of physiological urea concentrations in the hydrated 
frog. Phosphorylation control may similarly be a regulatory feature for diminishing the enzyme's affinity for G6P in response to dehydration. The lower substrate affinity of G6PDH for the major substrate G6P during whole-animal dehydration would suggest that the enzyme would require high supplementation of G6P to sustain elevated levels of NADPH generation for the maintenance of the glutathione-based antioxidant system via GR activity, as studied in Chapter 2. However, the demand for cellular energy in this non-hypometabolic amphibian may retain G6P within the glycolytic pathway for ATP production, activating G6PDH and PPP only when cellular ATP levels are elevated. 
Table 3.1. Representative purification and yield of G6PDH from liver of control African clawed frogs. The optimized purification scheme includes: (a) 10\% PEG precipitation, (b) dye-ligand affinity chromatography on a Cibacron Blue column pre-cleared with an elution using a 0-1 $\mathrm{M} \mathrm{KCl}$ gradient, (c) sizeexclusion chromatography on a Sephadex G-50 column, (d) hydroxyapatite chromatography column with an elution using a 0-2 $\mathrm{M} \mathrm{KCl}$ gradient.

\begin{tabular}{ccccccc}
\hline Step & $\begin{array}{c}\text { Total } \\
\text { Protein } \\
(\mathrm{mg})\end{array}$ & \%Yield & $\begin{array}{c}\text { Total } \\
\text { Activity } \\
(\mathrm{mU})\end{array}$ & \%Yield & $\begin{array}{c}\text { Specific } \\
\text { Activity } \\
(\mathrm{mU} / \mathrm{mg})\end{array}$ & $\begin{array}{c}\text { Fold } \\
\text { purification }\end{array}$ \\
\hline Crude extract & 88.2 & --- & 3478 & --- & 39.4 & --- \\
10\% PEG & 54.5 & 61.8 & 2505 & 72.0 & 46.0 & 1.17 \\
Cibacron Blue & 38.4 & 43.5 & 2360 & 67.9 & 61.5 & 1.56 \\
Sephadex G-50 & 4.2 & 4.8 & 281 & 8.1 & 66.9 & 1.70 \\
Hydroxyapatite & 0.10 & 0.11 & 12.1 & 0.3 & 121 & 3.07 \\
\hline
\end{tabular}


A.
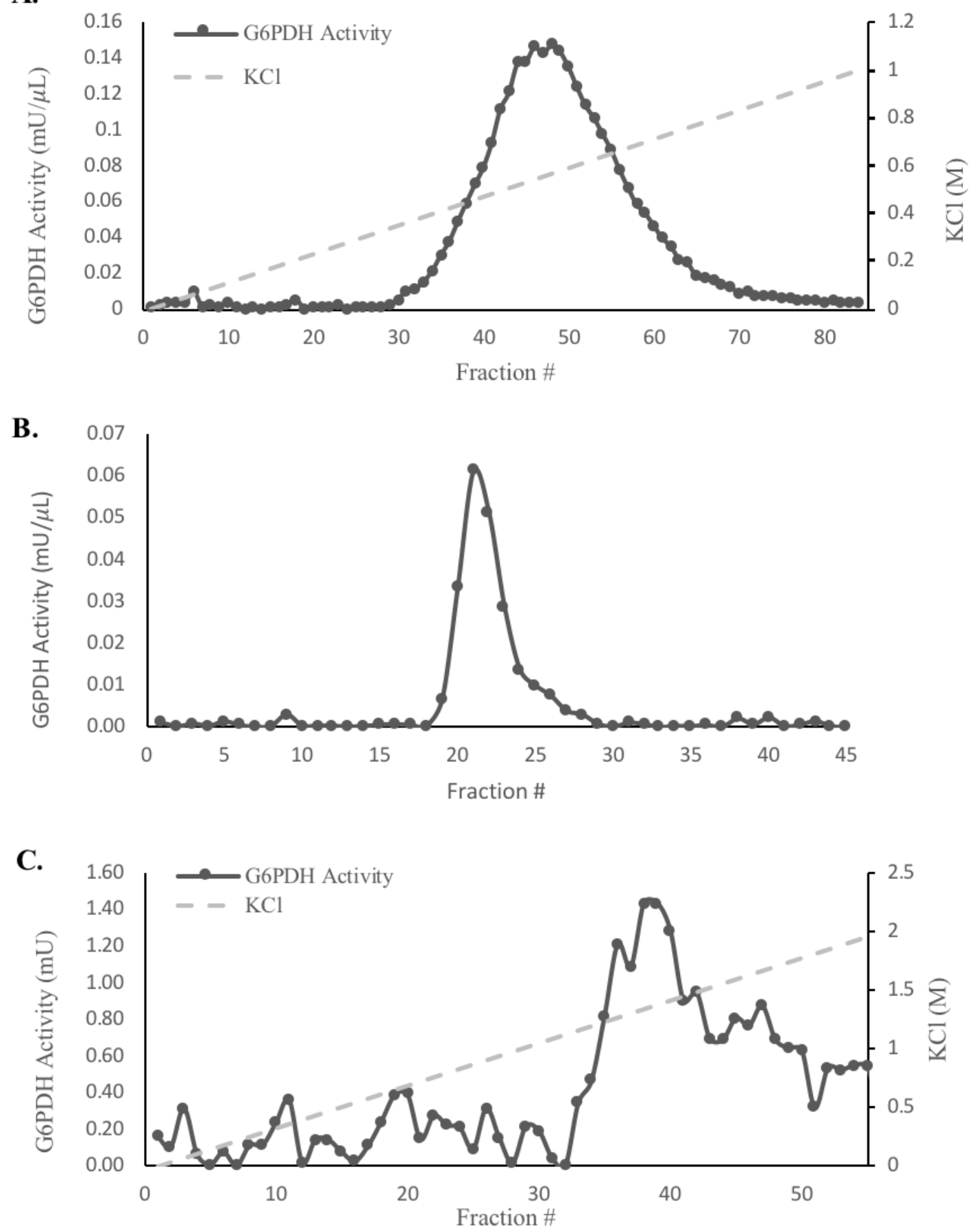

Figure 3.1. (A) Representative Cibacron Blue elution profile for G6PDH activity from liver of control X. laevis. (B) Representative Sephadex G-50 elution profile for G6PDH activity from liver of control $X$. laevis. (C) Representative hydroxyapatite elution profile for G6PDH activity from liver of control $X$. laevis. 


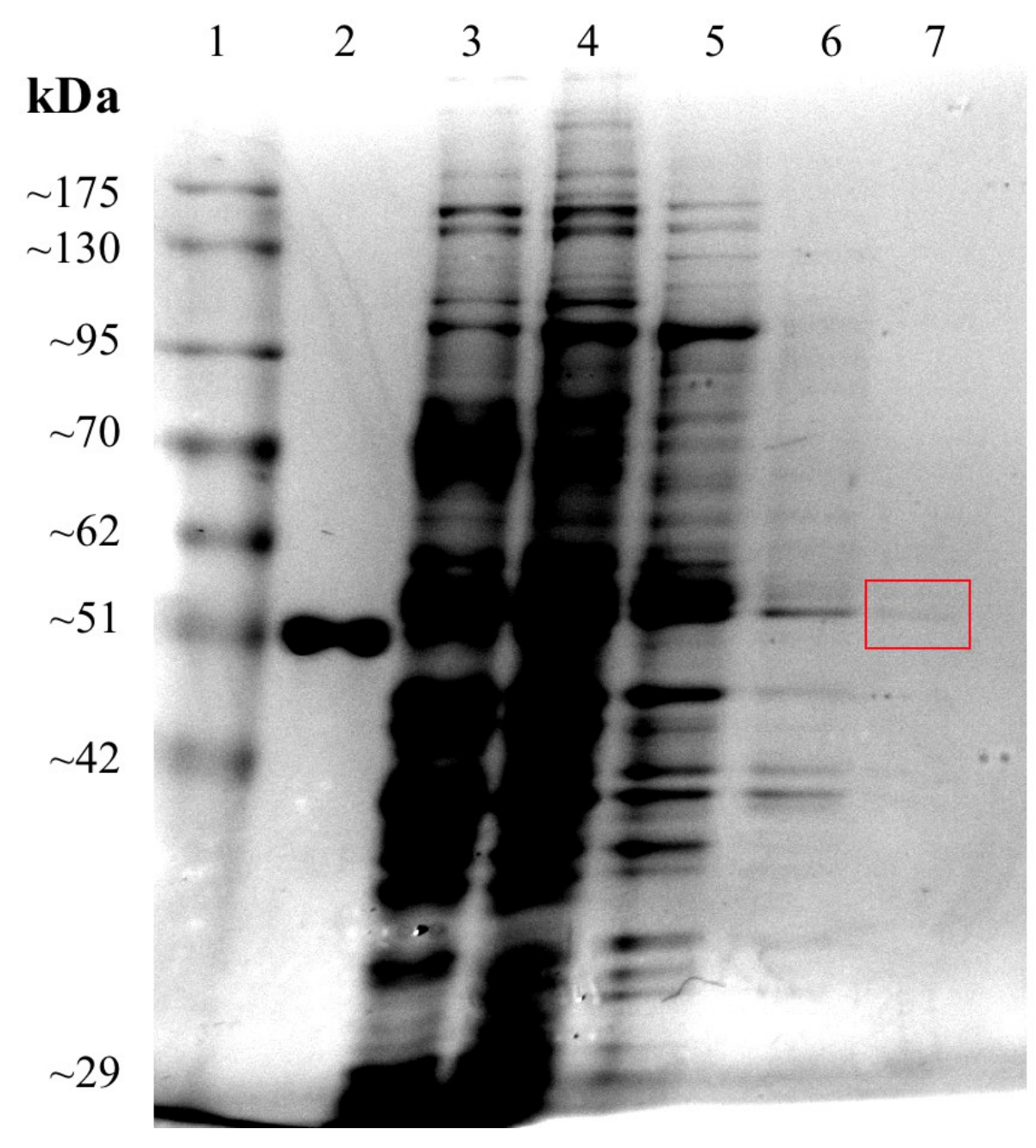

Figure 3.2. Silver stained $10 \%$ SDS-PAGE gel representing the four-step purification of G6PDH from liver of control X. laevis. Gel image depicts GeneDirex protein ladder (10.5-175kDa, lane 1), commercial standard G6PDH (Sigma-Aldrich cat. \#G8404, lane 2), crude extract (lane 3), resuspension from 10\% PEG precipitation (lane 4), pooled fraction from Cibacron Blue column (lane 5), pooled fraction from Sephadex G-50 column (lane 6), and the pooled fraction from the final hydroxyapatite column (lane 7, highlighted with a red box). 


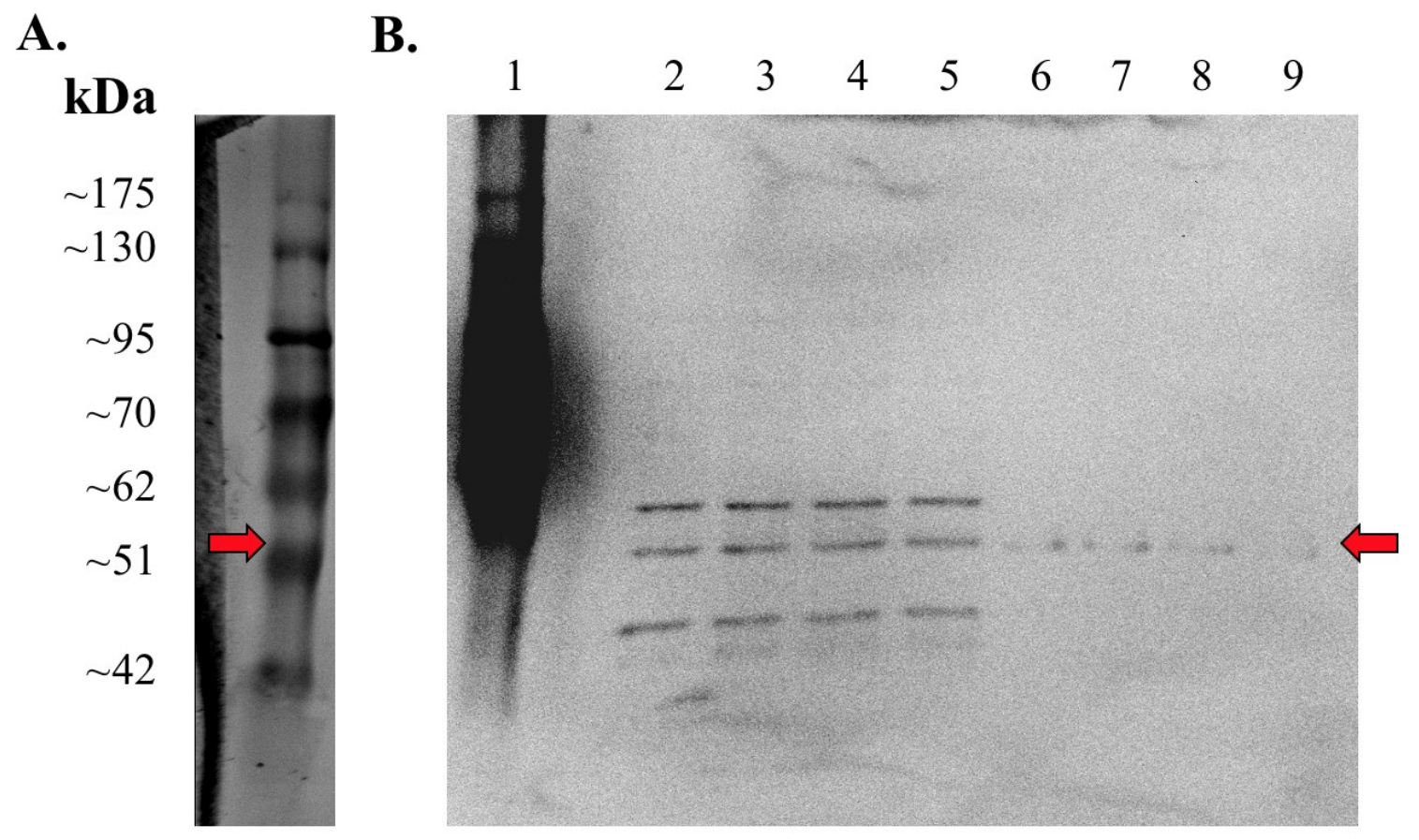

Figure 3.3. Confirmation of G6PDH protein band identity using a polyclonal antiG6PDH antibody. The membrane includes a GeneDirex protein ladder (10.5-175kDa, lane 1), four technical replicates of the dehydrated liver elution from the Sephadex G-50 column (lanes 2-6), and four technical replicates of the control liver elution from hydroxyapatite (lanes 7-11). The target protein band is expected to be $\sim 59.7 \mathrm{kDa}$ according to the Expasy bioinformatic resource portal. Molecular weight was calculated using the protein sequence of G6PDH in $X$. laevis acquired from the NCBI database (NP_001080019.1). 
Table 3.2. Kinetic parameters of functionally purified $X$. laevis G6PDH taken from control and $35 \%$ dehydrated African clawed frogs. $K_{m}$ values were determined using saturating conditions of co-substrate(s). Data are presented as means SEM, $\mathrm{n}=4$ determinations on separated preparations of enzyme. Statistical significance was determined from the Student's t-test, two-tailed, $p$ $<0.05$. All assays were performed at $\mathrm{pH} 7.5,22^{\circ} \mathrm{C}$.

\begin{tabular}{lcc}
\hline \multicolumn{1}{c}{ Enzyme Parameter } & Control $(\mathrm{mM})$ & Dehydrated $(\mathrm{mM})$ \\
\hline $\mathrm{K}_{\mathrm{m}} \mathrm{G} 6 \mathrm{P}$ & $0.33 \pm 0.04$ & $0.6 \pm 0.1^{\mathrm{a}}$ \\
$\mathrm{K}_{\mathrm{m}} \mathrm{G} 6 \mathrm{P}+55 \mathrm{mM}$ urea & $0.50 \pm 0.06$ & $0.39 \pm 0.06$ \\
$\mathrm{~K}_{\mathrm{m}} \mathrm{NADP}^{+}$ & $0.64 \pm 0.04$ & $0.43 \pm 0.06^{\mathrm{a}}$ \\
$\mathrm{K}_{\mathrm{m}} \mathrm{NADP}^{+}+55 \mathrm{mM}$ urea & $0.36 \pm 0.07$ & $0.69 \pm 0.02^{\mathrm{a}, \mathrm{b}}$ \\
& & \\
$\mathrm{K}_{\mathrm{a}}$ ATP & $5.1 \pm 0.3$ & $0.67 \pm 0.1$ \\
Fold activation & 1.36 & 1.19 \\
$\mathrm{I}_{50}$ ADP & $19.4 \pm 0.5$ & $16.3 \pm 0.9^{\mathrm{a}}$ \\
\hline
\end{tabular}

a - indicates a significant difference from the corresponding control tissue

b- indicates a significant difference from the corresponding condition parameter without urea 
Table 3.3. Inhibition concentrations of functionally purified $X$. laevis G6PDH taken from control and 35\% dehydrated African clawed frogs. Data are presented as means SEM, $\mathrm{n}=4$ determinations on separated preparations of enzyme. Statistical significance was determined from the Student's t-test, two-tailed, $p$ $<0.05$. All assays were performed at $\mathrm{pH} 7.5,22^{\circ} \mathrm{C}$.

\begin{tabular}{ccc}
\hline Enzyme Parameter & Control (M) & Dehydrated (M) \\
\hline $\mathrm{I}_{50} \mathrm{NaCl}(\mathrm{M})$ & $1.34 \pm 0.04$ & $1.35 \pm 0.01$ \\
$\mathrm{I}_{50} \mathrm{KCl}(\mathrm{M})$ & $1.2 \pm 0.6$ & $1.7 \pm 0.1$ \\
$\mathrm{I}_{50}$ Urea $(\mathrm{M})$ & $4.46 \pm 0.09$ & $7.1 \pm 0.5^{\mathrm{a}}$ \\
\hline
\end{tabular}

a - indicates a significant difference from the corresponding control tissue 


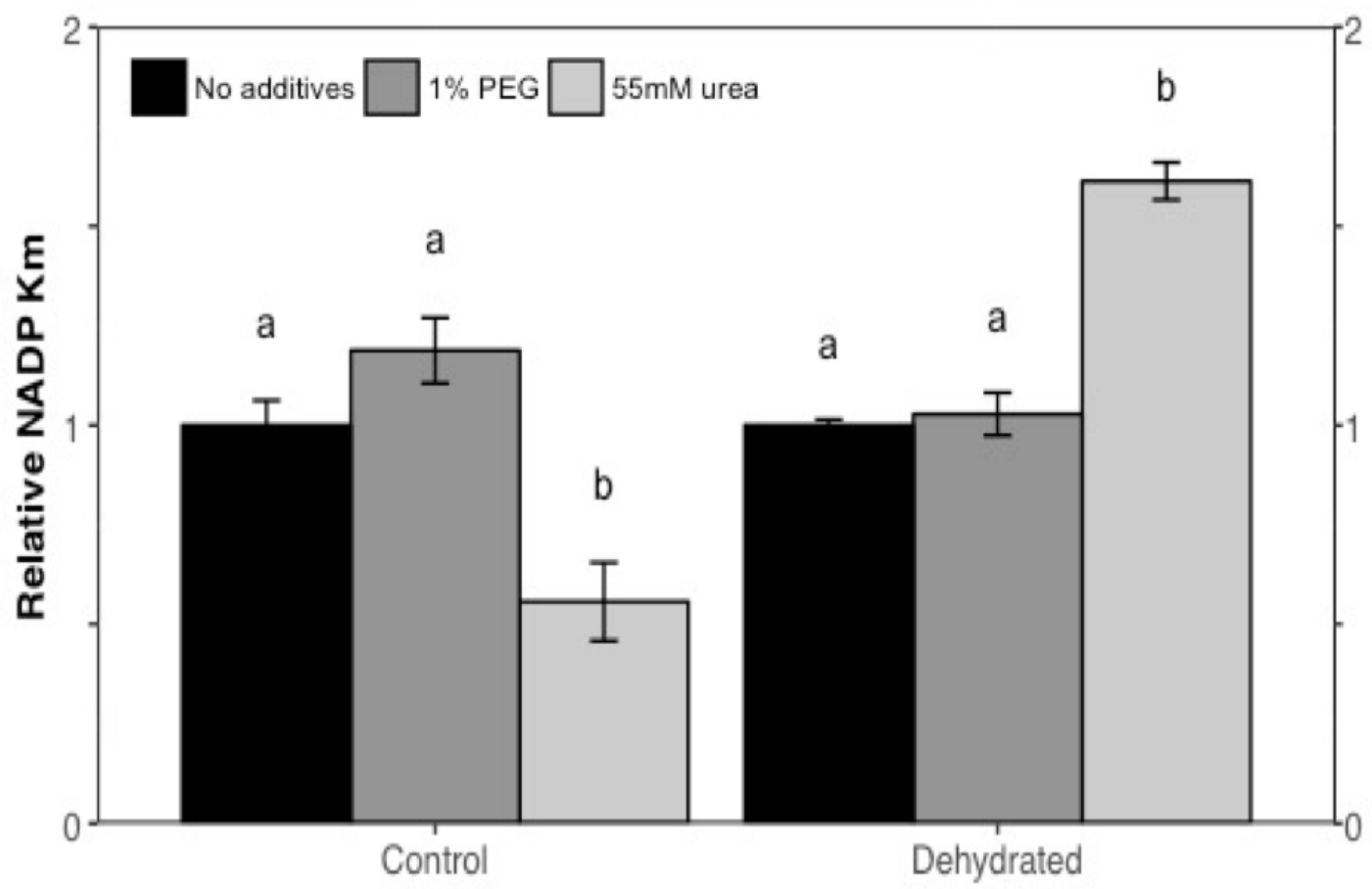

Figure 3.4. Effect of $1 \%$ polyethylene glycol (PEG) or $55 \mathrm{mM}$ urea on the relative $\mathrm{K}_{\mathrm{m}}$ $\mathrm{NADP}^{+}(\mathrm{mM})$ for liver G6PDH from control and dehydrated frogs. Data presented in the figure are mean \pm SEM, normalized to the "No additives" control, $n=3-4$ determinations of enzyme. Statistical analysis use ANOVA followed by a Tukey post-hoc test $(p<0.05)$ assessed using the RBioplot statistics and graphing R package (Zhang and Storey, 2016).

a- insignificant difference from corresponding "No additives" control value, b- significantly different from corresponding "No additives" control value. 


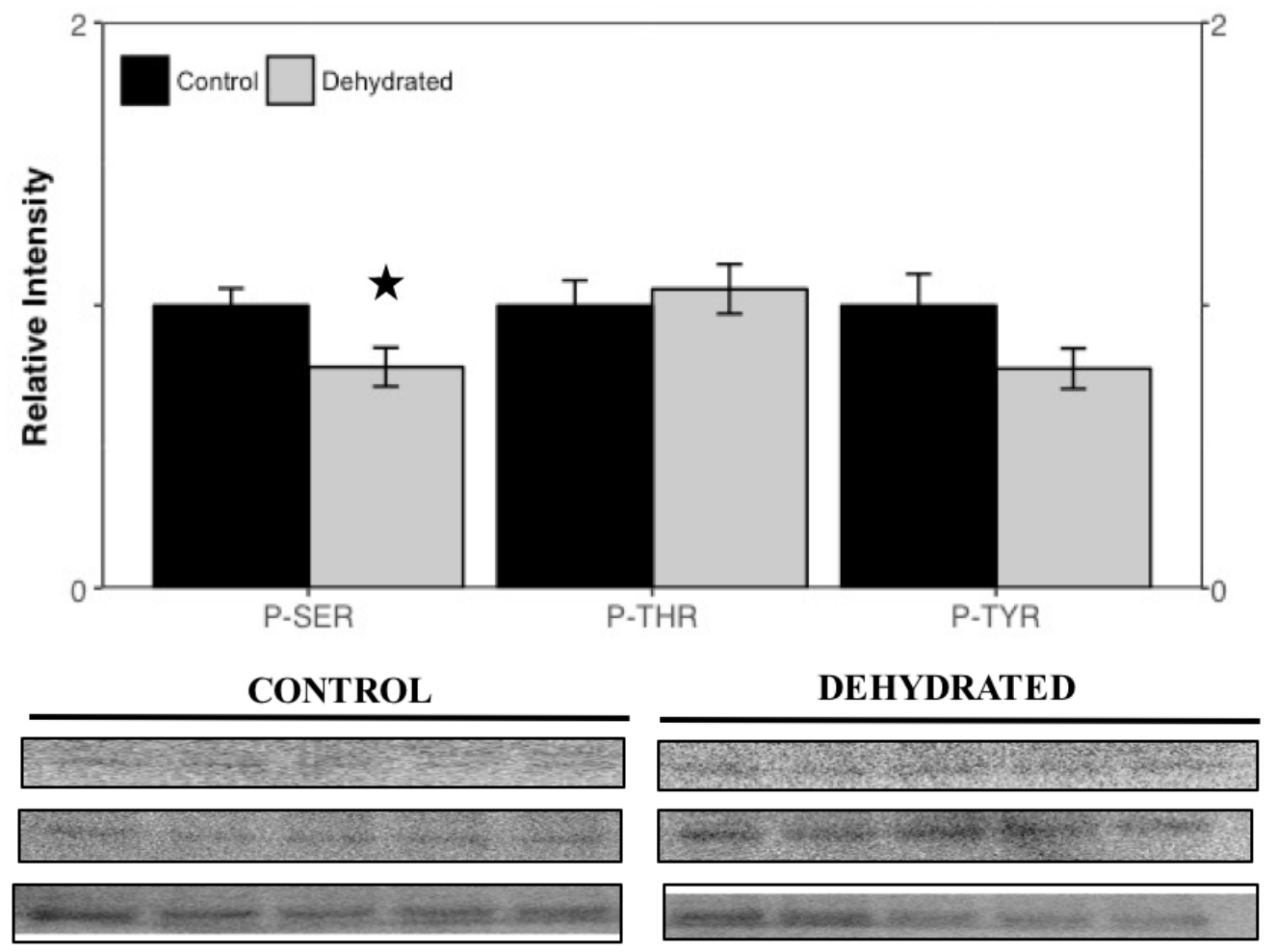

Figure 3.5. Relative post-translational modifications of semi-pure liver G6PDH from control and dehydrated $X$. laevis: phosphoserine, phosphothreonine, and phosphotyrosine. Data presented in the figure are normalized relative band intensities, mean \pm SEM, $\mathrm{n}=5$ determinations. Statistical analysis use ANOVA followed by a Tukey post-hoc test $(p<0.05)$ assessed using the RBioplot statistics and graphing R package (Zhang and Storey, 2016). Statistical significance from the corresponding control PTM level is indicated by a $(\star)$. 

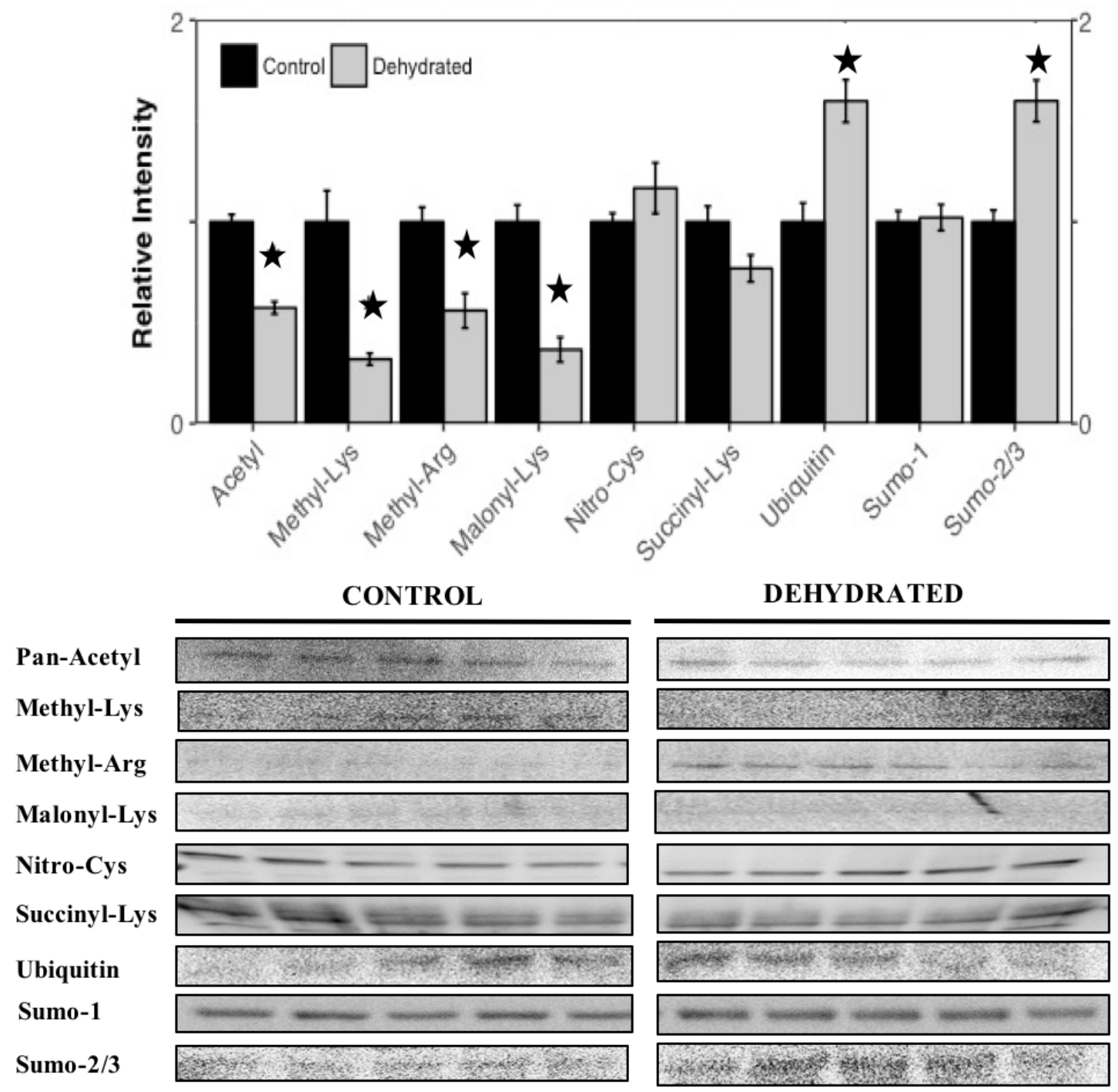

Figure 3.6. Summary of the western blots performed to ascertain the differences in post-translational modifications of semi-pure G6PDH from control and dehydrated $X$. laevis liver. Data presented in the figure are normalized relative band intensities, mean \pm SEM, $\mathrm{n}=5$ determinations. Statistical analysis use ANOVA followed by a Tukey post-hoc test $(p<0.05)$ assessed using the RBioplot statistics and graphing R package (Zhang and Storey, 2016). Statistical significance of the data from the corresponding control PTM level is denoted by ( $\star$ ). 


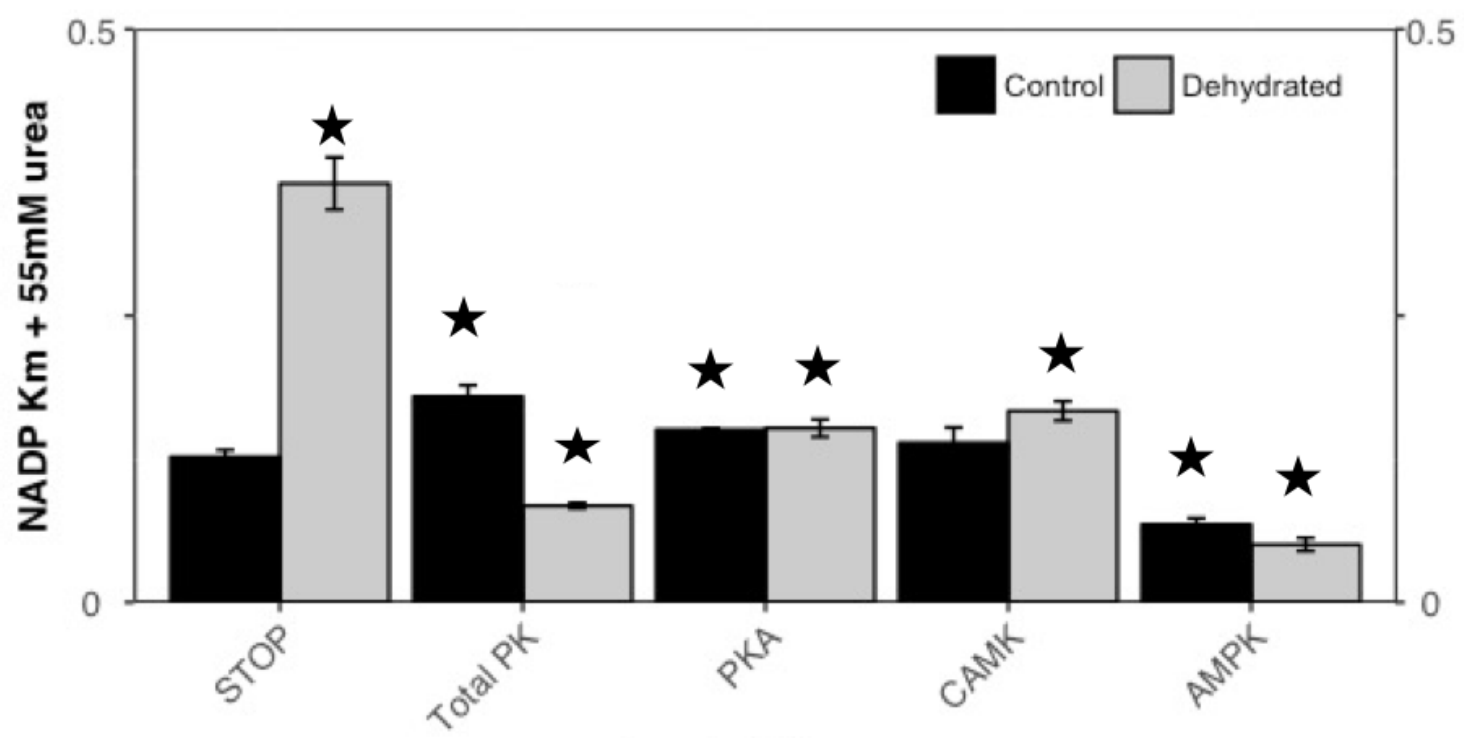

Protein Kinases

Figure 3.7. Effects of in vitro incubations to stimulate the activities of endogenous protein kinases on the relative $\mathrm{K}_{\mathrm{m}} \mathrm{NADP}^{+}$in the presence of $55 \mathrm{mM}$ urea for G6PDH purified from control and dehydrated frogs. Data are means \pm SEM, with at least $n=3-4$ determinations. Conditions are defined in the Materials and Methods. Statistical significance of the data from the "STOP" condition is denoted by $(\star)$ and determined from the Student's ttest, two-tailed, $p<0.05$. 


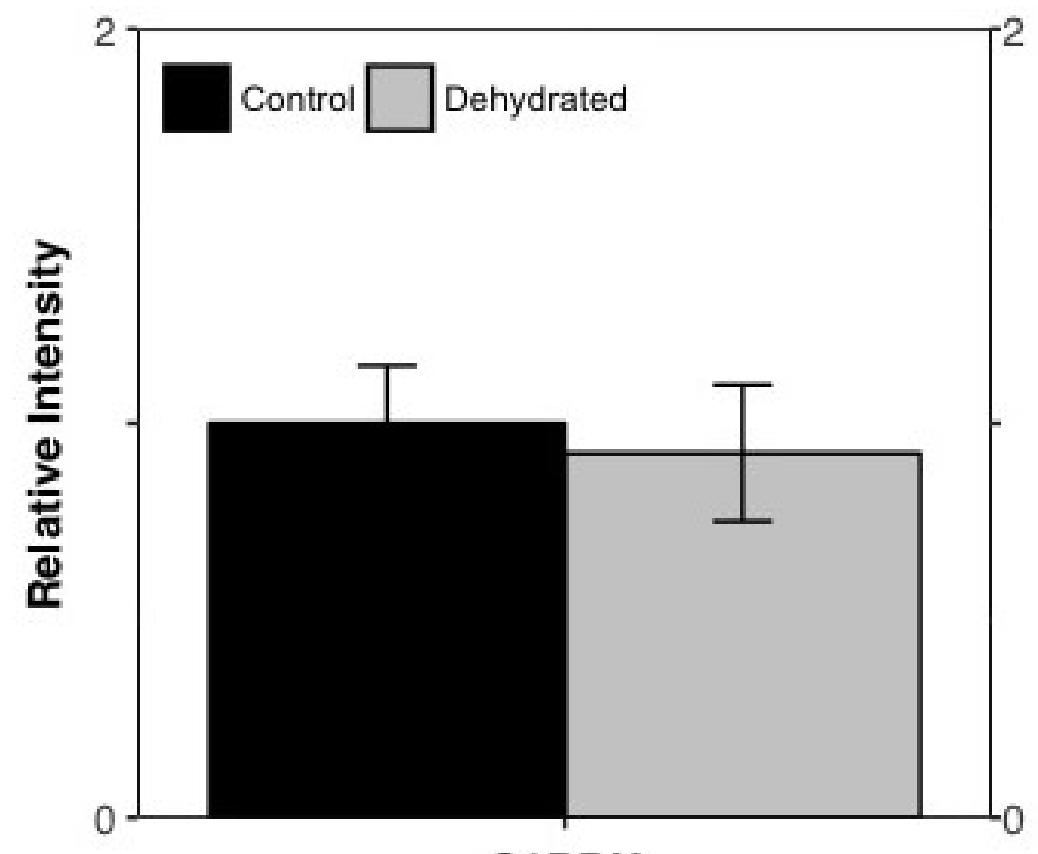

G6PDH

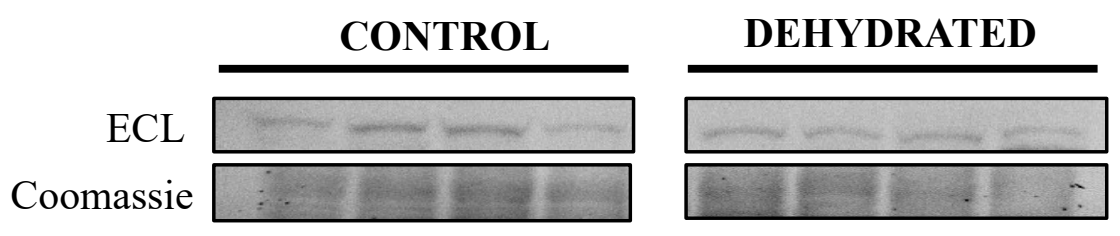

Figure 3.8. Relative protein expression levels of G6PDH in liver extracts of control and dehydrated $X$. laevis. Data are mean \pm SEM, $\mathrm{n}=4$ determinations on separate preparations of enzyme. A two-tailed Student's t-test found the protein expression levels of G6PDH to be statistically insignificant between control and dehydrated frog liver samples $(p>0.05)$. 
Chapter 4

General Discussion 


\subsection{Physiological consequences of dehydration stress}

When challenged with dehydration stress, dehydration-tolerant animals can employ a number of physiological mechanisms in order to delay the loss of tissue water and survive extended periods of water deprivation. Entering a state of summer dormancy, known as aestivation, is a common behavioural response to seasonally arid environments and dehydration stress for many animals. During this dormant period, the organism has reduced activity and, in some species, suppresses its basal metabolic rate in order to conserve the limited internal fuel reserves (Guppy and Withers, 1999). Whole-animal dehydration is highly regulated to limit significant transcutaneous water loss. Some animals create a physical barrier, such as a cocoon, to impede water efflux. For example, the semi-aquatic African lungfish genus Protopterus create a cocoon made of mucous secretions to reduce water loss (Carvalho et al., 2010), whereas burrowing frogs like $H$. viridiflavus generate a cocoon with successive layers of molted skin (Geise and Linsenmair, 1986). Other animals have an enlarged bladder that provides them with a substantial water reservoir and allows tissue hydration to be maintained, while also ensuring the internal system is hyperosmotic to the surrounding environment (Shoemaker and Nagy, 1977). For instance, the tolerance of the desert-inhabiting toad, Bufo cognatus, to dehydration stress is provided by an enlarged bladder representing $\sim 45 \%$ total body mass (Rubail, 1962). For semi-aquatic amphibians, adaptation to dehydration stress includes the conversion of nitrogenous end products to more stable and less toxic constructs of urea in order to minimize metabolic damage and generate an appreciable osmotic gradient to reduce water efflux (Storey and Storey, 2012). While the terrestrial spadefoot toad (S. couchii) is naturally ureotelic and can generate an appreciable osmotic 
gradient through the accumulation over time of $\sim 300 \mathrm{mM}$ urea (Pinder et al., 1992), the semi-aquatic African clawed frog (X. laevis) adapts to dehydration stress by becoming ureotelic and accumulates lower urea levels of at least $55 \mathrm{mM}$ urea (Malik and Storey, 2009b). A final strategy implemented by some aestivators is a suppression of their metabolic rate. This characteristic is beneficial during dormancy as the animal will have low energy demands resulting in the slow depletion of internal fuels and allowing prolonged survival in the dormant state (Storey and Storey, 1990). For instance, some species from the Protopterus genus can conserve their internal fuels through a 95\% metabolic rate depression and remain dormant for as long as 6 years (Carvalho et al., 2010), whereas S. couchii demonstrate metabolic suppression of $80 \%$ allowing 9-10 months of annual dormancy (Cowan and Storey, 2002).

Regardless of the many strategies implemented to delay whole-animal dehydration, an increase in hematocrit and hypovolemia leads to hypoxic conditions in these animals. DIH stimulates HIF-1 which triggers the accumulation of TCA cycle intermediates by activating the inhibiting kinase of pyruvate dehydrogenase (Kim et al., 2006). This inhibition compromises the ETC causing a buildup of electrons at complex I and complex III, creating a prominent source of ROS during dehydration stress due to enhanced mitochondrial electron leakage (Basaga, 1990; Donnelly et al., 2012; Jastroch et al., 2011). Animals that suppress their metabolic rate have a lower oxygen consumption and experience a reduced amount of oxidative stress in comparison to other species that are intolerant to the inflicted environmental stress (Storey and Storey, 1990). Upon arousal, there is a sudden increase in oxygen consumption and consequent surge of ROS production. In preparation for this rapid formation of ROS, dormant animals will 
demonstrate differential regulation of their AOEs either through protein modifications that alter kinetic properties, or by up-regulating $\mathrm{AOE}$ gene expression in response to environmental stress.

\subsection{Sustaining the glutathione-based antioxidant defense in X. laevis}

The African clawed frog is a dehydration-tolerant amphibian that survives for 2-3 months on internal fuel reserves without suppressing their basal metabolic rate (Balinsky et al., 1967). This is supported by a study by Hillman (1978) which found that dehydrated $X$. laevis exhibited no reduction in oxygen consumption and a greater percentage of arterial oxygen delivered to tissues as compared to control frogs. Therefore, electron leakage from the compromised ETC could generate a prominent source of ROS that will require prompt neutralization via an efficient antioxidant system to mitigate oxidative damage. GSH is an important tripeptide used by glutathione-based antioxidant enzymes to neutralize ROS, detoxify xenobiotics, and repair oxidatively damaged proteins (Meyer et al., 2009; Grant, 2001). Although GPx has yet to be studied in this dehydrated frog, the upregulation of GST expression in response to dehydration stress implied an increased oxidation of GSH in X. laevis liver under water-stressed conditions (Malik and Storey, 2009a). Maintenance of a high GSH:GSSG ratio in order to support heightened glutathione-based AOEs in dehydrating X. laevis, initially investigated by Malik and Storey (2009a, 2011), requires the active participation of GR. This thesis investigated the potential differential regulation of GR, including the importance of PTMs, in maintaining the glutathione system (GSH:GSSG ratio) in response to dehydration. Linked to GR, this thesis also characterized the differential regulation of G6PDH which is known to be an important source of the NADPH needed to support GR activity. 


\subsubsection{Glutathione Reductase}

The hypothesis for Chapter 2 proposed that GR is modified to increase the ability of $X$. laevis liver to recycle GSSG back to GSH that is a needed substrate for selected enzymes that detoxify reactive oxygen species. $X$. laevis liver GR demonstrated differential regulation in response to dehydration with increased affinity for its main substrate GSSG under physiological conditions of urea (Table 2.2). Dehydrated GR was also found to have enhanced stability as shown by the relatively low reduction in $\mathrm{V}_{\max }$ of $40 \%$ following 2-hour exposure to $2 \mathrm{M}$ urea in comparison to the $90 \%$ reduction seen for control GR. This suggests that there is a heightened response to recycle GSSG and maintain a high GSH:GSSG ratio in liver of dehydrated frogs. However, once urea levels are depleted upon rehydration, substrate affinity would decrease. This suggests that the animal is adapted to responding promptly to ROS generated from the DIH events. This glutathione-based AOE has been similarly studied in the freeze-tolerant wood frog $(R$. sylvatica) but this species did not show evidence of differential regulation during freezing (Dawson and Storey, 2017). The rate of generation of free radicals is directly proportional to the rate of oxygen consumption and should be lower in frozen frogs since respiration is halted. However, arousal from dormancy results in rapid tissue reoxygenation and increased metabolic rate which could overwhelm the ETC and stimulate rapid ROS production. Therefore, $R$. sylvatica may rely on enhanced protein expression or regulate GR activity immediately upon arousal in order to respond. Other animals that are subjected to water-restriction include the spadefoot toad (S. couchii) where GR activity in the liver was significantly lower during aestivation (Grundy and Storey, 1998), and the marine periwinkle (L. littorea) where GR activity decreased in the 
hepatopancreas during anoxia exposure as well as foot muscle upon exit from anoxia (Pannunzio and Storey, 1998). Similar to R. sylvatica, both S. couchii and L. littorea experience rapid reoxygenation and increased metabolism leading to increased oxidative stress upon arousal. Since the rate of ROS formation is proportion to the rate of metabolism, the absence of hypometabolism in the dehydrated frog and the presence of a compromised ETC would suggest that the amphibian must have a heightened glutathione-based antioxidant response to mitigate ROS-induced damage. In X. laevis, increased GR affinity for GSSG would ensure a continuous reduction of the substrate to reform GSH, facilitating the neutralization of ROS by GPx, detoxification of xenobiotics by GSTs, and repair of oxidatively damaged proteins by reducing glutaredoxin.

\subsubsection{Glucose-6-phosphate dehydrogenase}

The hypothesis for Chapter 3 proposed that G6PDH is modified in order to increase the ability of $X$. laevis liver to replenish the NADPH supply needed by GR in order to generate a strong enzymatic response by GST-dependent enzymes to ROS generated under dehydration stress. In this study, G6PDH from liver of dehydrated frogs was found to have a decreased affinity for the major G6P substrate and a significantly decreased affinity for the $\mathrm{NADP}^{+}$co-substrate in the presence of physiological urea conditions. The lower substrate affinity of G6PDH for G6P during whole-animal dehydration suggests that the enzyme would require high supplementation of G6P to sustain NADPH generation. However, the demand for cellular energy in this nonhypometabolic amphibian may retain G6P within the glycolytic pathway for ATP production, activating G6PDH and PPP only when cellular ATP levels are elevated. A similar finding was observed in frozen $R$. sylvatica which relies on the synthesis of 
glucose from G6P as a cryoprotectant. In contrast, when studied in hypometabolic animals, such as O. lactea, G6PDH is found to have increased substrate affinity showing a preferential redirection of G6P towards NADPH biosynthesis than ATP fermentation via glycolysis (Ramnanan and Storey, 2005). In conclusion, the data suggest that in $X$. laevis, G6P is driven through glycolysis for ATP needed by energy-demanding cells (non-hypometabolic frog) and may have increased flux through the PPP for NADPH biosynthesis when cellular ATP levels are high.

\subsection{Enzymatic regulation through post-translational modification}

Reversible post-translational modifications allow enzymes to be quickly modified in response to an environmental stimulus and are readily removed when optimal conditions return. In these studies of GR and G6PDH, the kinetic alterations of the enzymes all occurred along with covalent modifications to enzyme structure. Both enzymes from liver of dehydrated frogs showed significant dephosphorylation; GR exhibited decreased threonine-phosphorylation and G6PDH had a reduced serinephosphorylation content in response to dehydration. Whereas GR purified from skeletal muscle of control and frozen $R$. sylvatica demonstrated an absence in total protein phosphorylation, $X$. laevis liver GR was found to be regulated via reversible phosphorylation in the dehydrated frog. This thesis showed a strong correlation between a decreased phospho-threonine content and increased substrate affinity for GSSG in the presence of physiological urea. Studies investigating G6PDH regulation in animals experiencing environmental stress also found substrate affinity to be mediated through reversible phosphorylation. Whether the phosphorylation state of G6PDH increased or decreased in response to stress, the enzyme displayed enhanced affinity for its substrate 
as seen in the aestivating milk snail $(O$. lactea $)$, anoxia-tolerant crayfish (O. virilis), anoxia-tolerant marine periwinkle snail ( $L$. littorea), and freeze-tolerant wood frog $(R$. sylvatica) (Ramnanan and Storey, 2005; Lant and Storey, 2011; Lama et al., 2013; Dieni and Storey, 2010). However, reversible phosphorylation is no longer the sole PTM considered to be involved in metabolic regulation. This thesis showed that other PTMs including cys-nitrosylation, acetylation, and sumoylation may also play a pertinent role in regulating kinetic activity and/or protein stability of GR and G6PDH in response to dehydration and these PTMs deserve further investigation.

\subsection{Conclusion}

This thesis investigated the regulation of enzymes supporting the glutathionebased antioxidant defense system during dehydration stress of the African clawed frog. GR was found to be positively regulated in response to dehydration, with greater propensity to recycle GSSG to produce GSH equivalents that are pertinent to the frog's antioxidant defense. G6PDH was also differentially regulated in response to dehydration with dehydrated G6PDH having a significantly decreased affinity for G6P in comparison to the control enzyme. This finding may suggest that the dehydrated frog is prioritizing ATP fermentation for its energy-demanding cells over the synthesis of NADPH via the PPP, however this statement is speculative and requires further research for validity. This study also found that when ATP levels were high, the activity of this pentose phosphate pathway enzyme was enhanced by $20 \%$ which could allow for an increased flux of G6P towards NADPH synthesis. Whereas both GR and G6PDH appeared to be regulated via reversible protein phosphorylation, changes in kinetic properties and protein stability might also be attributable to other PTMs including sumoylation, cys- 
nitrosylation, and acetylation and the influence of these other protein modifications should be investigated further. Taken together, these results provide novel insights into the importance of the glutathione-based antioxidant response in the survival of environmental stress.

\subsection{Future directions}

The research presented in this thesis primarily characterized the kinetic properties and PTM states of GR and G6PDH from liver tissue of control and dehydrated X. laevis. This investigation revealed that these enzymes may be common targets for regulation in response to environmental stress and that protein phosphorylation is pertinent to this regulation. However, these results suggest that the regulatory effects of additional PTMs investigated in this project should be further characterized.

\subsubsection{Furthering investigation of GR and G6PDH PTM-mediated regulation}

The data presented in this thesis could be expanded by experiments that attempt to determine a causal link between the observed kinetic differences or protein stability and PTM changes to the enzymes studied in control and dehydrated $X$. laevis liver. As previously mentioned, dehydrated GR demonstrated an enhanced affinity for GSSG in the presence of physiological urea and was structurally more stability than the control (Table 2.2; Fig. 2.8). Although this thesis demonstrated the role of phosphorylation regulation on GR substrate affinity, stimulation of total protein kinases and phosphatases in crude extracts (as described in sections 3.2.9 and 2.2.9, respectively) followed by stability analysis of the purified protein (as described in section 2.2.10) will be needed to assess a firm correlation between GR phosphorylation and protein stability. Further experimentation could also investigate the consequences of other PTMs that changed in 
response to dehydration for both GR and G6PDH (e.g. effects on enzyme kinetic constants, activity, and stability, etc.).

GR activity is initiated through the nucleophilic attack on GSSG by the cys-cys disulfide bond at the active site (Berkholz et al., 2008). Therefore, the significant 0.82fold change in cys-nitrosylation content and increased affinity for GSSG in the presence of urea for dehydrated GR serves as a very important finding that deserves further investigation. Cell culture studies have shown increases in cys-nitrosylated proteins upon exposure to exogenous $\cdot \mathrm{NO}$ (by adding $10 \mu \mathrm{M}$ N-4-1-3-aminopropyl-2-hydroxy-2nitrosohydrazinobutyl-1,3-propane-diamine) (Bosworth et al., 2009). Therefore, incubating crude liver extracts with this chemical may increase GR cys-nitrosylation allowing the effect of nitrosylation on GR substrate affinity to be evaluated. This method will only nitrosylate reduced cysteine residues in the protein and has no effect on the important Cys-Cys bond of the active site. In order to make the disulfide at the active site susceptible to nitrosylation, the crude extract could be reduced with DTT prior to nitrosylation and substrate affinity can be revisited.

It would be quite interesting to further investigate the 0.57 -fold change in acetylation of G6PDH in response to dehydration due to the connection between lysine acetylation and protein dimerization. In HEK293T cells, acetylation of Lys403 was found to inhibit G6PDH activity by interrupting dimer formation and preventing proper protein folding (Wang et al., 2004). Deacetylation at this site is mediated by sirt2 in human and $X$. laevis cells. Recent research detected no change in sirt 2 mRNA in liver of dehydrated $X$. laevis but there is enhanced global sirt activity which may suggest enhanced deacetylation activity in response to dehydration (Luu, B.E., personal communication). 
However, the sirt protein family has a wide range of cellular functions, so further study is required to measure exact sirt2 activity in this tissue. In this thesis, G6PDH protein expression remained constant in response to dehydration but it may be important to note that the measured protein expression levels were analyzed from a denaturing SDS-PAGE western blot and, consequently, measured the relative number of G6PDH subunits present in the tissue under control versus dehydrated conditions. If the increased protein acetylation described in section 3.4.4 for control G6PDH includes increased lysineacetylation, specifically at the intersection between the two dimers, this could imply a differential distribution of dimerized (active) vs monomeric (inactive) G6PDH in the tissue from control versus dehydrated frogs. This could suggest another level of reversible metabolic regulation that might be available to alter enzyme functionality in response to environmental stress - a mechanism that does not rely on a need to change overall enzyme protein content by altering transcription, translation or proteolysis. In order to further investigate this finding, two experiments can be proposed: (1) assess the amount of dimeric vs monomeric G6PDH in liver extracts by measuring protein expression via native PAGE; or, (2) stimulate endogenous histone deacetylases (HDACs) and sirtuin proteins to correlate the acetylation state with substrate affinity (as described with protein kinase incubations in section 3.2.9). In the latter experiment, total HDACs can be stimulated with crotonyl-coA and NADPH while sirtuin proteins (sirt1, 2, and 5) can be stimulated with resveratrol and $\mathrm{NAD}^{+}$(Vogelauer et al., 2012; Villalba and Alcaín, 2012; Pan et al., 2017; Gertz et al., 2012).

Both GR and G6PDH also appear to be differentially regulated via protein sumoylation, a PTM that has been implicated as a response to oxidative stress. While 
oxidative stress triggers the upregulation of sumo-1 and consequently increases its protein conjugation, sumo-2/3 is ubiquitously expressed in cells as a free, non-conjugate and is only found to modify proteins when exposed to oxidative stress (Saitoh and Hinchey, 2000). Such oxidative stress-mediated protein modification of GR and G6PDH is an interesting response that deserves further investigation. It would be interesting to study the effect of sumoylation on protein stability or activity, by assessing changes in enzyme $V_{\max }$ following urea incubation experiments (as described in section 2.3.7) or measuring the enzyme's substrate affinity, respectively. It is possible to do this assessment in a cell culture-based experiment. Desumoylating isopeptidase 1 (DeSI-1) is a protease that removes sumo-1, sumo-2, and sumo-3 conjugation to proteins (Hickey et al., 2013). If this protease is overexpressed or knocked down in HEK293 cells, there will be a global decrease or increase in protein sumoylation, respectively. The purified enzymes from control and mutant HEK293 cells can be analyzed via western blots to detect the change in sumoylation (sumo-1 vs sumo-2/3) and the enzyme's activity and protein stability can be assessed as described previously.

\subsubsection{Investigation of other enzymes that help sustain the glutathione system}

Aside from additional studies on the two enzymes studied in this thesis, other future directions could also be pursued that are related to the present research. As stated previously, there are several enzymes that are involved in glutathione-based antioxidant defenses, all of which are believed to be differentially regulated in response to dehydration stress experienced by $X$. laevis. Previous work has shown an upregulation of GSTs, a family of glutathione-based AOEs that are involved in xenobiotic detoxification, in the liver of the dehydrating frog and it would be quite interesting to further investigate 
the kinetic properties GSTs in X. laevis (Malik and Storey, 2009a). This enzyme has been purified and characterized in the anoxia-tolerant turtle (T.s. elegans), providing a functional purification scheme that could be modified to purify GSTs from X. laevis liver (Willmore and Storey, 2005). The kinetic assay to measure GST activity relies on the thiolation of 1-chloro-2,4-dinitrobenzene (CDNB) by GSH that can be detected spectrophotometrically at $340 \mathrm{~nm}$. Similarly, characterization of GPx from this frog would provide additional insight into whether dehydration stress promotes the neutralization of peroxides in order to combat ROS. Purification of this enzyme is facilitated by detecting GPx activity through the consumption of $\mathrm{H}_{2} \mathrm{O}_{2}$ at $240 \mathrm{~nm}$. Another very important defense against oxidative stress is the repair of the oxidativelydamaged proteins. This is mediated primarily through the action of glutaredoxin that reduces disulfides formed in ROS-damaged proteins (Grant, 2001). Enzyme activity can be detected through the commonly used HEDs assay which involves preincubation of hydroxyethyl disulfide (HED) with GSH to produce a mixed disulfide (GSSEtOH). Glutaredoxin from the crude or the chromatography column elution fraction will reduce this mixed disulfide, consuming GSH and generating GSSG for reduction by GR with cofactor NADPH. The activity of glutaredoxin is monitored by the consumption of NADPH at $340 \mathrm{~nm}$. This mechanism for detecting glutaredoxin activity is illustrated in Figure 4.1 (obtained from Begas et al., 2015). 


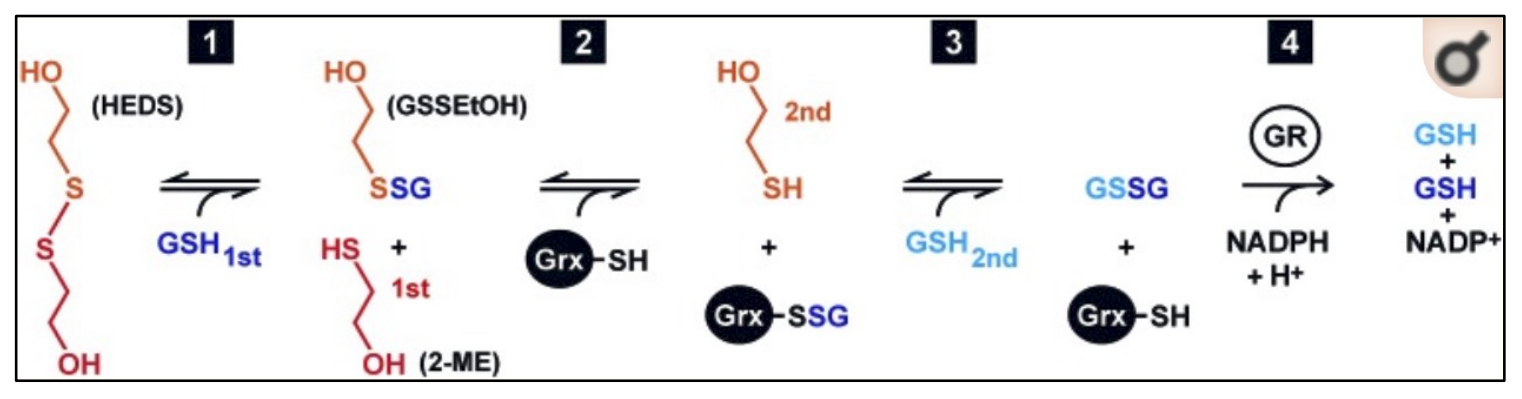

Figure 4.1. A mechanistic model for the HEDs assay which could be used to detect glutaredoxin activity and purify the enzyme (Begas et al., 2015). 


\section{$\underline{\text { References }}$}


Balinsky, J.B., Cragg, M.M., and Baldwin, E. 1961. The adaptation of amphibian waste nitrogen excretion to dehydration. Comp. Biochem. Physiol. 3(4), 236-244.

Barnhart, M.C. and McMahon, B.R. 1988. Depression of aerobic metabolism and intracellular $\mathrm{pH}$ by hypercapnia in land snails, Otala lactea. J. Exp. Biol. 138(1), 289-299.

Basaga, H.S. 1990. Biochemical aspects of free radicals. Biochem. Cell Biol. 68:989-998.

Bentley, P.J., 1969. Neurohypophysial function in Amphibia: hormone activity in the plasma. J. Endocrinol. 43(3), 359-369.

Berkholz, D.S., Faber, H.R., Savvides, S.N. and Karplus, P.A. 2008. Catalytic cycle of human glutathione reductase near 1 Å resolution. J. Mol. Biol. 382(2), 371-384.

Biggar, K.K. and Li, S.S.C. 2015. Non-histone protein methylation as a regulator of cellular signalling and function. Nat. Rev. Mol. Cell Biol. 16(1), 5.

Boutilier, R.G., Stiffler, D.F. and Toews, D.P. 1992. Exchange of respiratory gases, ions, and water in amphibious and aquatic amphibians. In: Environmental Physiology of the Amphibia. (Feder, M.E. and Burggren, W., eds.). University of Chicago Press, Chicago. pp.81-124.

Bosworth, C.A., Toledo, J.C., Zmijewski, J.W., Li, Q. and Lancaster, J.R. 2009. Dinitrosyliron complexes and the mechanism (s) of cellular protein nitrosothiol formation from nitric oxide. P. Natl. A. Sci. 106(12), 4671-4676.

Brooks, S.P.J., 1992. A simple computer program for the analysis of enzyme kinetics. BioTechniques 13, 906-911.

Brooks, S.P.J., and Storey, K.B. 1992. Mechanisms of glycolytic control during hibernation in the ground squirrel Spermophilus lateralis. J. Comp. Physiol. B. 162(1), 23-28.

Cartledge, V.A., Withers, P.C., and Bradshaw, S.D. 2007. Water balance and arginine vasotocin in the cocooning frog Cyclorana platycephala (Hylidae), Physiol. Biochem. Zool. 81(1), 43- 53.

Carvalho, J.E., Navas, C.A. and Pereira, I.C. 2010. Energy and water in aestivating amphibians. In: Aestivation (Arturo Navas C., and Carvalho J., eds.) Springer, Berlin, Heidelberg. pp. 141-169

Childers, C.L. and Storey, K.B. 2016. Post-translational regulation of hexokinase function and protein stability in the aestivating frog Xenopus laevis. Protein J. 35(1), 61-71.

Chinopoulos, C. 2013. Which way does the citric acid cycle turn during hypoxia? The critical role of $\alpha$-ketoglutarate dehydrogenase complex. J. Neurosci. Res. 91(8), 1030-1043. 
Churchill, T.A. and Storey, K.B. 1994. Effects of dehydration on organ metabolism in the frog Pseudacris crucifer: hyperglycemic responses to dehydration mimic freezinginduced cryoprotectant production. J. Comp. Physiol. B. 164(6), 492-498.

Churchill, T.A. and Storey, K.B. 1995. Metabolic effects of dehydration on an aquatic frog, Rana pipiens. J. Exp. Biol. 198(1), 147-154.

Circu, M.L. and Aw, T.Y. 2008. Glutathione and apoptosis. Free Radic. Res. 42, 689706.

Cowan, K.J. and Storey, K.B. 2002. Urea and KCl have differential effects on enzyme activities in liver and muscle of aestivating versus non-estivating species. Biochem. Cell Biol. 80, 745-755.

Dawson, N.J. and Storey, K.B. 2017. Passive regeneration of glutathione: Glutathione reductase regulation from the freeze-tolerant North American wood frog, Rana sylvatica. J. Exp. Biol. 220 (17), 3162-3171.

Desterro, J.M., Rodriguez, M.S. and Hay, R.T. 1998. SUMO-1 modification of IאB $\alpha$ inhibits NF-אB activation. Mol. Cell 2(2), 233-239.

Dieni, C.A. and Storey, K.B. 2010. Regulation of glucose-6-phosphate dehydrogenase by reversible phosphorylation in liver of a freeze tolerant frog. J. Comp. Physiol. B. $180(8), 1133-1142$.

Dieni, C.A. and Storey, K.B. 2011. Regulation of hexokinase by reversible phosphorylation in skeletal muscle of a freeze-tolerant frog. Comp. Biochem. Phys. B. 159(4), 236-243.

Donnelly, P.S., Liddell, J.R., Lim, S., Paterson, B.M., Cater, M.A., Savva, M.S., Mot, A.I., James, J.L., Trounce, I.A., White, A.R. and Crouch, P.J. 2012. An impaired mitochondrial electron transport chain increases retention of the hypoxia imaging agent diacetylbis (4-methylthiosemicarbazonato) copper II. P. Natl. A. Sci. 109(1), 47-52.

Eggleston, L.V. and Krebs, H.A. 1974. Regulation of the pentose phosphate cycle. Biochem. J. 138(3), 425-435.

Forman, H.J., Zhang, H., Rinna, A. 2008. Glutathione: overview of its protective roles, measurement, and biosynthesis. Mol Aspects Med. 30, 1-12.

França, M. B., Panek, A. D., and Eleutherio, E. C. A. 2007. Oxidative stress and its effects during dehydration. Comp. Biochem. Physiol. A. 146(4), 621-631.

Galluzzi, L., Maiuri, M.C., Vitale, I., Zischka, H., Castedo, M., Zitvogel, L., and Kroemer, G. 2007. Cell death modalities: classification and pathophysiological implications. Cell Death Differ. 14, 1237-1243. 
Gao, L., Mejías, R., Echevarría, M. and López-Barneo, J. 2004. Induction of the glucose6-phosphate dehydrogenase gene expression by chronic hypoxia in $\mathrm{PC} 12$ cells. FEBS let. 569(1-3), 256-260.

Geise, W. and Linsenmair, K.E. 1986. Adaptations of the reed frog Hyperolius viridiflavus (Amphibia, anura, Hyperoliidae) to its arid environment. Oecologia, 68(4), 542-548.

Grant, C.M. 2001. Role of the glutathione/glutaredoxin and thioredoxin systems in yeast growth and response to stress conditions. Mol. Microbiol. 39(3), 533-541.

Gray, L.R., Tompkins, S.C. and Taylor, E.B. 2014. Regulation of pyruvate metabolism and human disease. Cell. Mol. Life Sci. 71(14), 2577-2604.

Gromova, I. and Celis, J. E. 2006. Protein detection in gels by silver staining: a procedure compatible with mass spectrometry. In: Cell Biology, A Laboratory Handbook (Celis, J.E., ed.) Elsevier Science, Amsterdam. pp. 219-223.

Grundy, J.E. and Storey, K.B. 1998. Antioxidant defenses and lipid peroxidation damage in estivating toads, Scaphiopus couchii. J. Comp. Physiol. B. 168(2), 132-142.

Guppy, M. and Withers, P. 1999. Metabolic depression in animals: physiological perspectives and biochemical generalizations. Biol. Rev. 74(1), 1-40.

Han, H.S., Kang, G., Kim, J.S., Choi, B.H. and Koo, S.H. 2016. Regulation of glucose metabolism from a liver-centric perspective. Exp. Mol. Med. 48(3), e218.

Hayyan, M., Hashim, M.A. and Al-Nashef, I.M. 2016. Superoxide ion: generation and chemical implications. Chem. Rev. 116(5), 3029-3085.

Hermes-Lima, M. and Storey, K.B. 1995. Antioxidant defenses and metabolic depression in a pulmonate land snail. Am. J. Physiol. -Reg. I. 268(6), R1386-R1393.

Hermes-Lima, M. and Storey, K.B. 1998. Role of antioxidant defenses in the tolerance of severe dehydration by anurans. The case of the leopard frog Rana pipiens. Mol. Cell. Biochem. 189(1-2), 79-89.

Hermes-Lima, M., and Zenteno-Savin, T. 2002. Animal response to drastic changes in oxygen availability and physiological oxidative stress. Comp. Biochem. Phys. C. 133(4), 537-556.

Hermes-Lima, M., Storey, J.M. and Storey, K.B. 1998. Antioxidant defenses and metabolic depression. The hypothesis of preparation for oxidative stress in land snails. Comp. Biochem. Phys. B. 120(3), 437-448.

Hillman, S.S. 1978. The roles of oxygen delivery and electrolyte levels in the dehydrational death of Xenopus laevis. J. Comp. Physiol. 128(2), 169-175. 
Hillman, S.S. and Sommerfeldt, R.W. 1981. Microsphere studies of amphibian systemic blood flow redistribution during dehydration, hypovolemia, and salt load. J. Exp. Zoo., 218(2), 305-308.

Ireland, M.P. 1973. Studies on the adaptation of Xenopus laevis to hyperosmotic media. Comp. Biochem. Phys. A. 46(3), 469-476.

Janssens, P.A., 1972. The influence of ammonia on the transition to ureotelism in Xenopus laevis. J. Exp. Zoo. 182(3), 357-366.

Jastroch, M., Divakaruni, A.S., Mookerjee, S., Treberg, J.R. and Brand, M.D. 2010. Mitochondrial proton and electron leaks. Essays Biochem. 47, 53-67.

Joanisse, D.R. and Storey, K.B. 1996. Oxidative damage and antioxidants in Rana sylvatica, the freeze-tolerant wood frog. Am. J. Physiol.-Reg. I. 271(3), R545-R553.

Jokumsen, A. and Weber, R.E. 1980. Haemoglobin-oxygen binding properties in the blood of Xenopus laevis, with special reference to the influences of aestivation and of temperature and salinity acclimation. J. Exp. Biol. 86(1), 19-37.

Jorgensen, C.B. 1997. 200 years of amphibian water economy: from Robert Townson to the present. Biol. Rev. 72, 153-237.

Katzenback, B.A., Dawson, N.J. and Storey, K.B. 2014. Purification and characterization of a urea sensitive lactate dehydrogenase from the liver of the African clawed frog, Xenopus laevis. J. Comp. Phys. B. 184(5), 601-611.

Kiani, F., Schwarzl, S., Fischer, S. and Efferth, T. 2007. Three-dimensional modeling of glucose-6-phosphate dehydrogenase-deficient variants from German ancestry. PloS One. 2(7), e625.

Kim, J. W., Tchernyshyov, I., Semenza, G. L., and Dang, C. V. 2006. HIF-1-mediated expression of pyruvate dehydrogenase kinase: a metabolic switch required for cellular adaptation to hypoxia. Cell Metab. 3(3), 177-185.

Klenk, C., Humrich, J., Quitterer, U. and Lohse, M.J. 2006. SUMO-1 controls the protein stability and the biological function of phosducin. J. Biol. Chem. 281(13), 83578364.

Kobelt, F., and Linsenmair, K.E. 1995. Adaptations of the reed frog Hyperolius viridiflavus (Amphibia, Anura, Hyperoliidae) to its arid environment. VII. The heat budget of Hyperolius viridiflavus nitidulus and the evolution of an optimized body shape. J. Comp. Phys. B. 165(2), 110-124.

Krauth-Siegel, R.L., Arscott, L.D., Schönleben-Janas, A., Schirmer, R.H. and Williams, C.H. 1998. Role of active site tyrosine residues in catalysis by human glutathione reductase. Biochemistry. 37(40), 13968-13977. 
Lama, J.L., Bell, R.A. and Storey, K.B. 2013. Glucose-6-phosphate dehydrogenase regulation in the hepatopancreas of the anoxia-tolerant marine mollusc, Littorina littorea. PeerJ, 1, e21.

Lant, B. and Storey, K.B. 2011. Glucose-6-phosphate dehydrogenase regulation in anoxia tolerance of the freshwater crayfish Orconectes virilis. Enzyme research, 2011.

Larade, K. and Storey, K.B. 2002. A profile of the metabolic responses to anoxia in marine. In: Sensing, signaling and cell adaptation (Storey, K.B. and Storey, J.M., eds.). Elsevier Science, Amsterdam. pp. 27-46.

Lee, A.R., Silove, M., Katz, U. and Balinsky, J.B., 1982. Urea cycle enzymes and glutamate dehydrogenase in Xenopus laevis and Bufo viridis adapted to high salinity. Journal of Experimental Zoology, 221(2), pp.169-172.

Lee, Y.J., Miyake, S.I., Wakita, H., McMullen, D.C., Azuma, Y., Auh, S. and Hallenbeck, J.M. 2007. Protein SUMOylation is massively increased in hibernation torpor and is critical for the cytoprotection provided by ischemic preconditioning and hypothermia in SHSY5Y cells. J. Cerebr. Blood F. Met. 27(5), 950-962.

Lobos, G., and Jaksic, F.M. 2005. The ongoing invasion of African clawed frogs (Xenopus laevis) in Chile: causes of concern. Biodivers. Conserv. 14(2), 429-439.

Loveridge, J.P. 1976. Strategies of water conservation in southern African frogs. Zool. Afr. 11(2), 319-333.

Malik, A.I. and Storey, K.B. 2009a. Activation of antioxidant defense during dehydration stress in the African clawed frog. Gene, 442(1), 99-107.

Malik, A.I. and Storey, K.B. 2009b. Activation of extracellular signal-regulated kinases during dehydration in the African clawed frog, Xenopus laevis. J. Exp. Biol. 212(16), 2595-2603.

Malik, A.I., and Storey, K.B. 2011. Transcriptional regulation of antioxidant enzymes by FoxO1 under dehydration stress. Gene, 485, 114-119.

McBean, R.L. and Goldstein, L. 1970. Accelerated synthesis of urea in Xenopus laevis during osmotic stress. Am. J. Physiol. 219(4), 1124-1130.

Meyer, Y., Buchanan, B.B., Vignols, F. and Reichheld, J.P. 2009. Thioredoxins and glutaredoxins: unifying elements in redox biology. Аnпи. Rev. Genet. 43, 335-367.

Nishida, Y., Rardin, M.J., Carrico, C., He, W., Sahu, A.K., Gut, P., Najjar, R., Fitch, M., Hellerstein, M., Gibson, B.W. and Verdin, E. 2015. SIRT5 regulates both cytosolic and mitochondrial protein malonylation with glycolysis as a major target. Mol. Cell. 59(2), 321-332. 
Pinder, A.W., Storey, K.B. and Ultsch, G.R. 1992. Estivation and Hibernation. In: Environmental Physiology of Amphibians (Feder, M.E. and Burggren, W., eds). The University of Chicago press, Ltd., Chicago. pp. 250-274.

Preller, A., Guixé, V. and Ureta, T. 1999. In vivo operation of the pentose phosphate pathway in frog oocytes is limited by $\mathrm{NADP}^{+}$availability. FEBS Lett. 446(1), 149152.

Radivojac, P., Vacic, V., Haynes, C., Cocklin, R.R., Mohan, A., Heyen, J.W., Goebl, M.G. and Iakoucheva, L.M. 2010. Identification, analysis, and prediction of protein ubiquitination sites. Proteins. 78(2), 365-380.

Ramnanan, C.J. and Storey, K.B. 2006. Glucose-6-phosphate dehydrogenase regulation during hypometabolism. Biochem. Bioph. Res. Co. 339(1), 7-16.

Ruibal, R. 1962. The adaptive value of bladder water in the toad, Bufo cognatus. Physiol. Zool. 35(3), 218-223.

Saitoh, H. and Hinchey, J. 2000. Functional heterogeneity of small ubiquitin-related protein modifiers SUMO-1 versus SUMO-2/3. J. Biol. Chem. 275(9), 6252-6258.

Schnell, J.D. and Hicke, L. 2003. Non-traditional functions of ubiquitin and ubiquitinbinding proteins. J. Biol. Chem. 278, 35857-35860.

Shao, R., Zhang, F.P., Tian, F., Anders Friberg, P., Wang, X., Sjöland, H. and Billig, H. 2004. Increase of SUMO-1 expression in response to hypoxia: direct interaction with HIF-1 $\alpha$ in adult mouse brain and heart in vivo. FEBS Lett. 569(1-3), 293-300.

Shoemaker, V., and Nagy, K.A. 1977. Osmoregulation in amphibians and reptiles. Annu. Rev. Phys. 39(1), 449-471.

Storey, J.M. and Storey, K.B. 2004. Cold hardiness and freeze tolerance. In: Functional Metabolism: Regulation and Adaptation. (Storey, K.B., ed.) Wiley-Liss, Hoboken. pp. 473-503.

Storey, J.M., and Storey, K.B. 1990. Metabolic rate depression and biochemical adaptation in anaerobiosis, hibernation and estivation. Q. Rev. Biol. 65(2), 145-174.

Storey, K.B. and Storey, J.M. 1984. Biochemical adaption for freezing tolerance in the wood frog, Rana sylvatica. J. Comp. Phys. B. 155(1), 29-36.

Storey, K.B. and Storey, J.M. 2004. Metabolic rate depression in animals: transcriptional and translational controls. Biol. Rev. 79(1), 207-233.

Storey, K.B. 1990. Life in a frozen state: adaptive strategies for natural freeze tolerance in amphibians and reptiles. Am J Physiol. 258, R559-R568.

Storey, K.B. 1996. Oxidative stress: animal adaptations in nature. Braz. J. Med. Biol. Res. 29, 1715-1733. 
Storey, K.B., and Storey, J.M. 2012. Aestivation: signaling and hypometabolism. J. Exp. Biol. 215(9), 1425-1433.

Tian, W.N., Braunstein, L.D., Apse, K., Pang, J., Rose, M., Tian, X. and Stanton, R.C. 1999. Importance of glucose-6-phosphate dehydrogenase activity in cell death. Am. J. Physiol.-Cell Ph. 276(5), C1121-C1131.

Ursini, M.V., Parrella, A., Graziella, R., Salzano, S. and Martini, G. 1997. Enhanced expression of glucose-6-phosphate dehydrogenase in human cells sustaining oxidative stress. Biochem. J. 323(3), 801-806.

Wang, Y.P., Zhou, L.S., Zhao, Y.Z., Wang, S.W., Chen, L.L., Liu, L.X., Ling, Z.Q., Hu, F.J., Sun, Y.P., Zhang, J.Y. and Yang, C. 2014. Regulation of G6PD acetylation by SIRT2 and KAT9 modulates NADPH homeostasis and cell survival during oxidative stress. EMBO J. 33, 1304-1320

Weigl, K. and Sies, H. 1977. Drug Oxidations Dependent on Cytochrome P-450 in Isolated Hepatocytes: The Role of the Tricarboxylates and the Aminotransferases in NADPH Supply. Eur. J. Biochem. 77(2), 401-408.

Whitwam, R.E. and Storey, K.B. 1991. Regulation of phosphofructokinase during estivation and anoxia in the land snail, Otala lactea. Physiol. Zool. 64(2), 595-610.

Willmore, W.G. and Storey, K.B. 1997. Glutathione systems and anoxia tolerance in turtles. Am. J. Physiol.-Reg. I. 273(1), R219-R225.

Willmore, W.G. and Storey, K.B. 2007. Purification and properties of glutathione reductase from liver of the anoxia-tolerant turtle, Trachemys scripta elegans. Mol. Cell. Biochem. 297(1-2), 139-149.

Yang, F., Yao, Y., Jiang, Y., Lu, L., Ma, Y. and Dai, W. 2012. Sumoylation is important for stability, subcellular localization and transcriptional activity of Sall4, an essential stem cell transcription factor. J. Biol. Chem. 287(46), 38600-38608.

Zhang, J. and Storey, K.B., 2016. RBioplot: an easy-to-use R pipeline for automated statistical analysis and data visualization in molecular biology and biochemistry. PeerJ, 4, e2436.

Zou, Q., Habermann-Rottinghaus, S.M. and Murphy, K.P. 1998. Urea effects on protein stability: hydrogen bonding and the hydrophobic effect. Proteins. 31(2), 107-115. 


\section{Appendix I}

Communications at Scientific Meetings 
Publications

Smolinski MB, Mattice JJ, and Storey KB. 2017. Regulation of pyruvate kinase in skeletal muscle of the freeze tolerant wood frog, Rana sylvatica. Cryobiology $77,25-33$.

\section{List of Conference Presentations}

Mattice JL, and Storey, KB. Regulation of liver glutamate dehydrogenase in response to dehydration in the African clawed frog, Xenopus laevis. Poster presentation. Presented at the $13^{\text {th }}$ Annual Ottawa-Carleton Institute of Biology symposium, Ottawa, Canada, May 2016.

Mattice JJL, Smolinski MB, and Storey KB. Regulation of Pyruvate Kinase in Muscle of the freeze-tolerant wood frog, Rana sylvatica. (Poster presentation). Presented at the $53^{\text {rd }}$ Annual Meeting of the Society for Cryobiology, Ottawa, Canada, July 2016.

Mattice JL, Ruberto AA, and Storey KB. Examining the mechanism of glutamate dehydrogenase regulation in the dehydrating African clawed frog, Xenopus laevis. Poster presentation. Presented at the $14^{\text {th }}$ Annual Ottawa-Carleton Institute of Biology symposium, Ottawa, Canada, April 2017.

Mattice JL, Ruberto AA, and Storey KB. Examining the mechanism of glutamate dehydrogenase regulation in the dehydrating African clawed frog, Xenopus laevis. Poster presentation. Presented at the $60^{\text {th }}$ Annual Canadian Society for Molecular Biosciences conference, Ottawa, Canada, May 2017.

Mattice JL and Storey KB. Examining the regulation of glutathione reductase in response to ischemic stress in the dehydration-tolerant African clawed frog, Xenopus laevis. Poster presentation. Presented at the $20^{\text {th }}$ Annual Chemistry and Biochemistry Graduate Research Conference, Ottawa, Canada, November 2017. 